\title{
Status of Initial Assessment of Physical and Mechanical Properties of Graphite Grades for NGNP Applications
}

J.P. Strizak and T. D. Burchell

Oak Ridge National Laboratory

And

W. E. Windes

Idaho National Laboratory

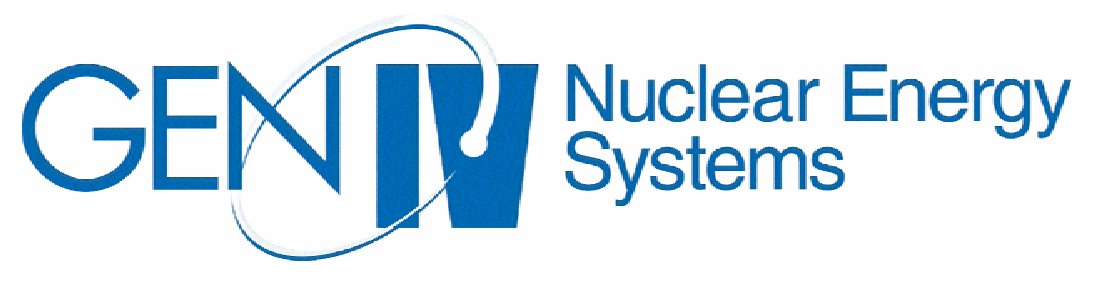

September 5, 2006 
This report was prepared as an account of work sponsored by an agency of the United States Government. Neither the United States government nor any agency

thereof, nor any of their employees, makes any warranty, express or implied, or assumes any legal liability or responsibility for the accuracy, completeness, or

usefulness of any information, apparatus, product, or process disclosed, or represents that its use would not infringe privately owned rights. Reference herein to any specific commercial product, process, or service by trade name, trademark, manufacturer, or otherwise, does not necessarily constitute or imply its endorsement, recommendation, or favoring by the United States Government or any agency thereof. The views and opinions of authors expressed herein do not necessarily state or reflect those of the United States Government or any agency thereof. 


\title{
Status of Initial Assessment of Physical and Mechanical Properties of Graphite Grades for NGNP Applications
}

\author{
J. P. Strizak and T. D. Burchell \\ Oak Ridge National Laboratory \\ And \\ W. E. Windes \\ Idaho National Laboratory
}

September 5, 2006

Prepared for

Office of Nuclear Energy Science and Technology

Prepared by

OAK RIDGE NATIONAL LABORATORY

Oak Ridge, Tennessee 37831

managed by

UT-BATTELLE, LLC

for the

U.S. DEPARTMENT OF ENERGY

Under DOE Contract No. DE-AC05-00OR22725 
This page intentionally left blank 


\section{TABLE OF CONTENTS}

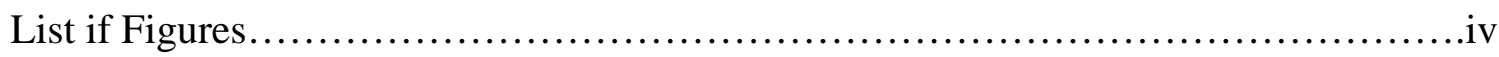

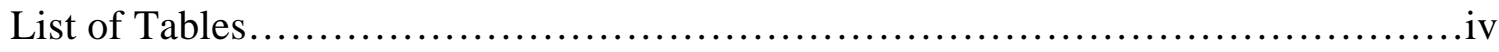

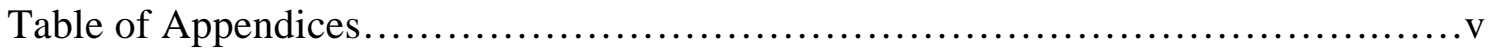

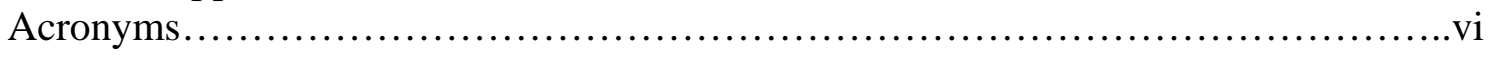

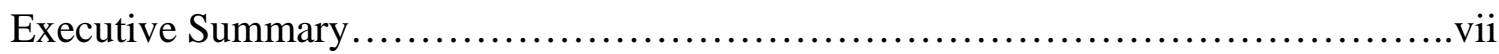

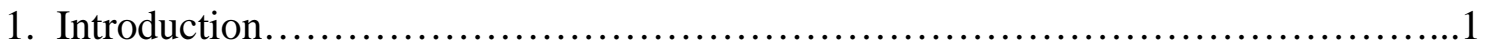

2. Graphite Procurement and Distribution........................................

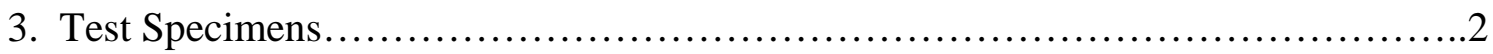

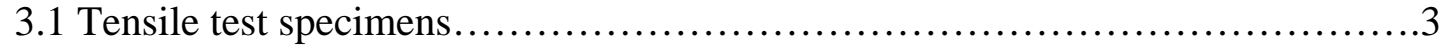

3.2 Compression test specimens...............................................

3.3 Flexure test specimens.......................................................

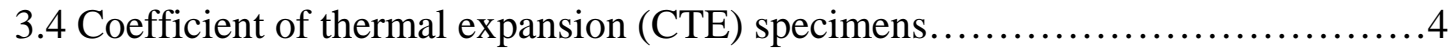

3.5 Thermal conductivity specimens..........................................

4. Billet cutting - methodology and assumptions................................. 5

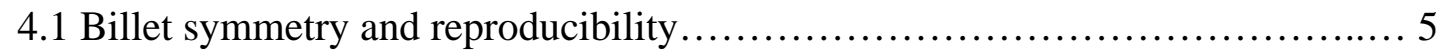

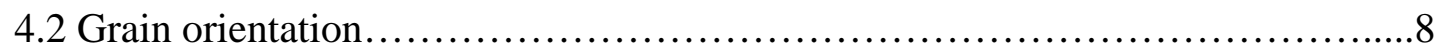

4.3 General cutting plan (billets, slabs, sub-slabs, specimens)......................8

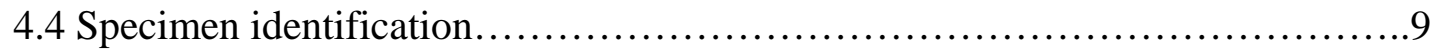

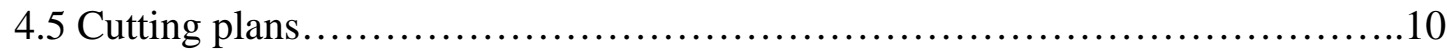

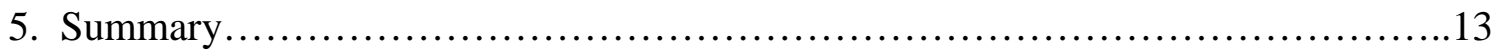

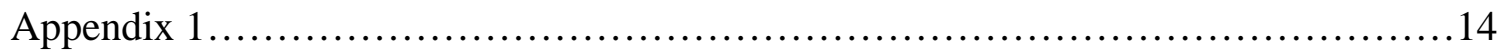

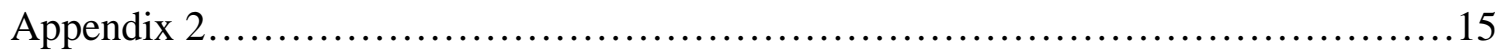

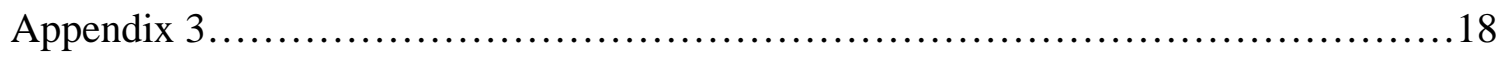

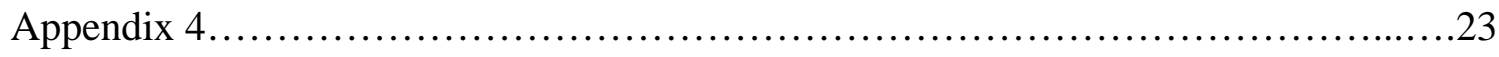

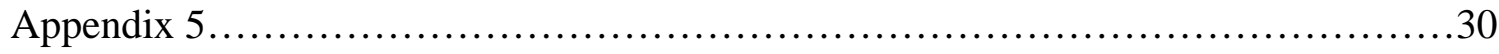

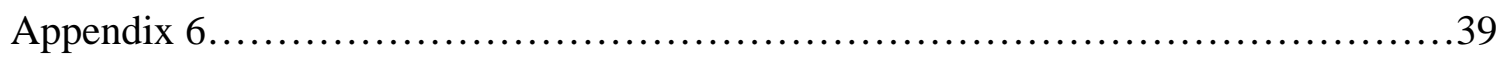

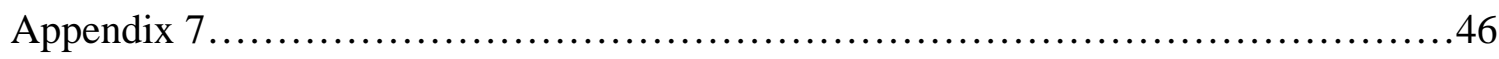

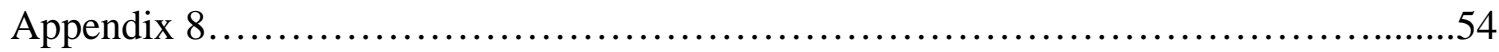




\section{List of Figures}

$\underline{\text { Page }}$

Figure 3.1. Illustration of the specimens to be used for billet

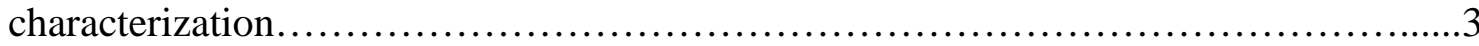

Figure 4.1. Example of symmetrical quadrant sections within a

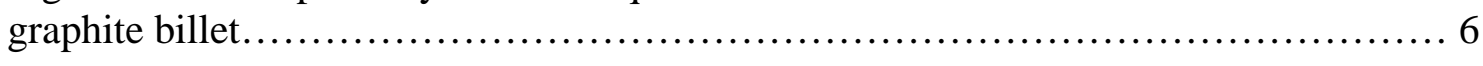

Figure 4.2. Illustration of the radial symmetry of the PCEA graphite billet..........................................................

Figure 4.3. Schematic of general cutting plan..................................

Figure 4.4. Specimen layout for IG-43........................................10

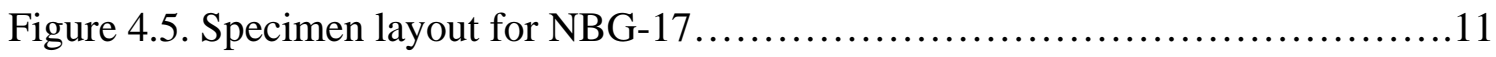

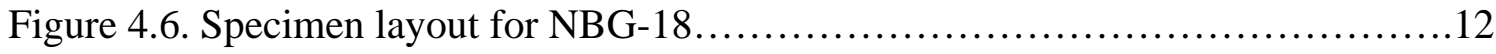

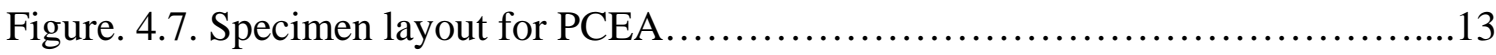

\section{List of Tables}

$\underline{\text { Page }}$

Table 4.1. Specimen identification legend....................................9 


\section{Table of Appendices}

Appendix 1. Graphite Procurement.............................................14

Appendix 2. Shiva Chemical Analysis.............................................16

Appendix 3. Billet Sizes and Distribution....................................19

Appendix 4. Specimen Detail Drawings.....................................23

Appendix 5. NBG-17 Billet Cutting Plans.......................................30

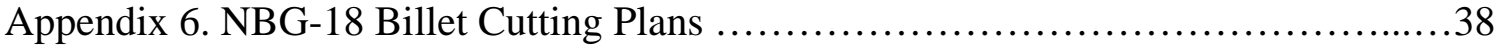

Appendix 7. PCEA Billet Cutting Plans.........................................46

Appendix 8. IG-43 Billet Cutting Plans..........................................57 


\section{Acronyms}

\begin{tabular}{ll} 
AG & against-grain \\
ASTM & American Society for Testing and Materials \\
Ca & Calcium \\
Co & Cobalt \\
Cs & Cesium \\
Fe & Iron (Ferrum) \\
FY 07 & Fiscal Year 2007 \\
GTHTR & Gas Turbine High Temperature Reactor \\
HTGR & high temperature gas-cooled reactor \\
INL & Idaho National Laboratory \\
Li & Lithium \\
NBG & Nuclear Block Graphite \\
NGNP & Next Generation Nuclear Plant \\
ORNL & Oak Ridge National Laboratory \\
Sc & Scandium \\
Ta & Tantalum \\
Ti & Titanium \\
V & Vanadium \\
WG & with-grain \\
\hline
\end{tabular}




\section{Executive Summary}

Current candidate graphite grades for the core structures of NGNP include grades NBG17, NBG-18, PCEA and IG-430. Both NBG-17 and NBG-18 are manufactured using pitch coke, and are vibrationally molded. These medium grain products are produced by SGL Carbon SAS (France). Tayo Tanso (Japan) produces IG-430 which is a petroleum coke, isostatically molded, nuclear grade graphite. And PCEA is a medium grain, extruded graphite produced by UCAR Carbon Co. (USA) from petroleum coke.

An experimental program has been initiated to develop physical and mechanical properties data for these current candidate graphites. The results will be judged against the requirements for nuclear grade graphites set forth in ASTM standard D 7219-05 "Standard Specification for Isotropic and Near-isotropic Nuclear Graphites".

Physical properties data including thermal conductivity and coefficient of thermal expansion, and mechanical properties data including tensile, compressive and flexural strengths will be obtained using the established test methods covered in D-7219 and ASTM C 781-02 "Standard Practice for Testing Graphite and Boronated Graphite Components for High-Temperature Gas-Cooled Nuclear Reactors”. Various factors known to effect the properties of graphites will be investigated. These include specimen size, spatial location within a graphite billet, specimen orientation (ag and wg) within a billet, and billet-to-billet variations.

The current status of the materials characterization program is reported herein. To date billets of the four graphite grades have been procured, and detailed cut up plans for obtaining the various specimens have been prepared. Particular attention has been given to the traceability of each specimen to its spatial location and orientation within a billet. 


\section{Introduction}

Current candidate graphite grades for the core structures of NGNP include grades NBG17, NBG-18, PCEA and IG-430. Both NBG-17 and NBG-18 are manufactured using pitch coke, and are vibrationally molded. These medium grain products (.8 mm for NBG17 and $1.5 \mathrm{~mm}$ for NBG-18) are produced by SGL Carbon SAS (France). Tayo Tanso (Japan) produces IG-430 which is a petroleum coke, isostatically molded, fine grain (0.01 $\mathrm{mm})$ nuclear grade graphite. And PCEA is a medium grain $(0.8 \mathrm{~mm})$, extruded graphite produced by UCAR Carbon Co. (USA) from petroleum coke.

An experimental program has been initiated to develop physical and mechanical properties data for the current candidate graphites. The results will be judged against the requirements for nuclear grade graphites set forth in ASTM standard D 7219-05 “Standard Specification for Isotropic and Near-isotropic Nuclear Graphites”.

Physical properties data including thermal conductivity and coefficient of thermal expansion, and mechanical properties data including tensile, compressive and flexural strengths will be obtained using the established test methods covered in D-7219 and ASTM C 781-02 "Standard Practice for Testing Graphite and Boronated Graphite Components for High-Temperature Gas-Cooled Nuclear Reactors”. Various factors known to effect the properties of graphites will be investigated. These include specimen size, spatial location within a graphite billet, specimen orientation within a billet, and billet-to-billet variations.

The current status of the materials characterization program is presented herein.

\section{Graphite procurement and distribution}

The four graphite grades were purchased by ORNL and shared with INL for the subject joint materials characterization program. References to ORNL purchase orders are given in Appendix 1. Note that at the time of purchase the availability of the NBG graphites was limited to no more than one billet. Consequently, the single billets of NBG-17 and NBG-18 were shared by ORNL and INL. On the other hand, each laboratory received a billet of IG-43 and PCEA.

ASTM standard D 7219 [1] sets requirements for the chemical purity of nuclear grade graphites. Limits are imposed on specific elements including $\mathrm{Ca}, \mathrm{Co}, \mathrm{Fe}, \mathrm{CS}, \mathrm{V}, \mathrm{Ti}, \mathrm{Li}$, Sc, and Ta. Grades NBG-17 and NBG-18 are produced as nuclear grade graphites so chemical impurity levels are strictly controlled during processing. On the other hand, 
IG-43 must be purified to become IG-430, nuclear grade. And PCEA as well has to be purified to meet the D 7219 specifications. Independent chemical analysis of each graphite grade was performed by Shiva Technologies, Inc. in Syracuse, New York under ORNL purchase order 4000052349. Chemical analyses for nuclear grade NBG-17 and NBG-18, IG-430, and PCEA (purified) are given in Appendix 2. Note that samples were taken from the same billets of NBG-17 and NBG-18 that will be employed in the subject characterization program. Likewise the PCEA sample was taken from a purified section of the ORNL billet. The chemical analysis for IG-430 was performed with a sample from a billet recently purchased for irradiation experiments. Purification of graphite to reduce impurity levels acceptable for NGNP applications provides control over oxidation, and neutron absorption and activity. Chemical impurity is not a necessary consideration in this initial physical and mechanical properties characterization program.

A billet of NBG-17 is rather large, $520 \times 470 \times 1620 \mathrm{~mm}$. A major portion of a NBG-17 billet (520 x 470 x $1250 \mathrm{~mm}$ ) was available for purchase. At ORNL's request, SGL sawed the billet into three reasonably sized blocks prior to shipment. Blocks designated for irradiation experiments and the joint materials properties characterization program at ORNL and INL are identified in Appendix 3. Similarly, the distribution of a whole billet (520 x $560 \times 1620 \mathrm{~mm}$ ) of NBG-18 which was vendor cut into four blocks is also shown in Appendix 3. INL was provided a whole billet (450 mm diameter x $920 \mathrm{~mm}$ long) of PCEA (unpurified). On the other hand, the ORNL billet was sectioned by the vendor and two (2) of the sections were purified for use in irradiation experiments, while the remaining sections will be consumed for the characterization program (See Appendix 3). Finally, both ORNL and INL have whole billets (300 x 540 x 850 mm) of IG-43 (unpurified) which will be consumed entirely for mechanical property characterization.

\section{Test specimens}

An illustration of the various specimen types and sizes which will be used for mechanical properties characterization of the NGNP candidate graphites is shown in Fig. 3.1. The specimens for tensile, compressive, and flexure testing conform to the requirements of appropriate ASTM standards (test methods). There are four tensile specimen sizes, one cylindrical compressive specimen, and one rectangular flexure test bar. Detail drawings for each specimen have been prepared are given in Appendix 4. Note that specimen dimensions are given in inches. The specific ASTM standards which will be employed use this convention, and area machinists are more at ease with this convention as well. Test-specific requirements are discussed below. 


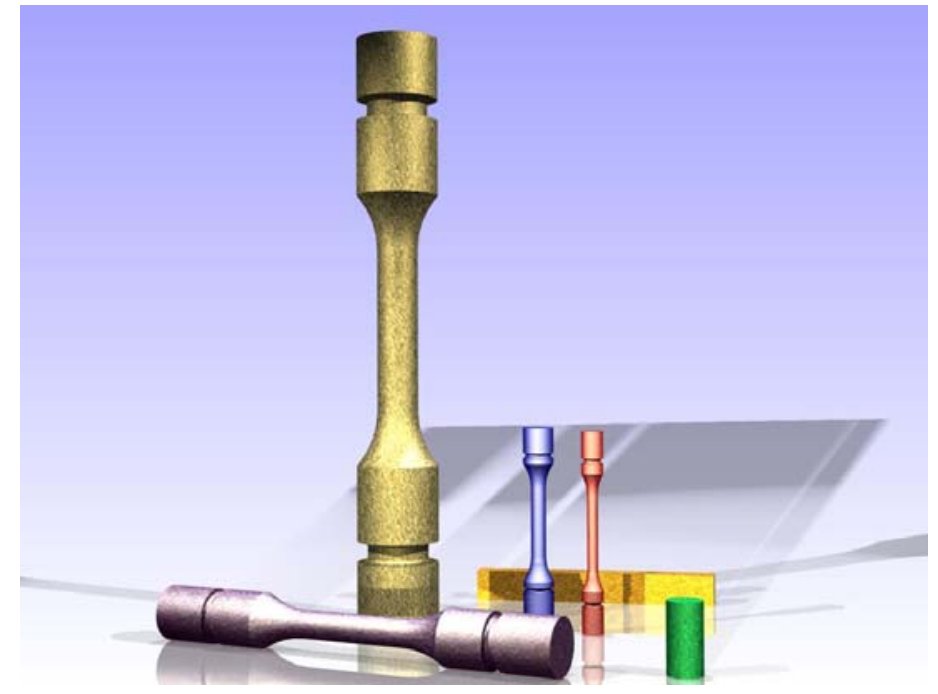

Fig. 3.1 Illustration of the specimens to be used for billet characterization

\subsection{Tensile test specimens}

ASTM test standard C 749 -02 "Standard Test Method for Tensile Stress-Strain of Carbon and Graphite" will be used for room temperature tensile strength testing. The standard provides four specimen sizes with gage diameters of 0.250 ”, 0.375 ”, 0.625 ”, and 1.000" (6.35, 9.53, 15.88, and $25.4 \mathrm{~mm}$, respectively) (See Attachment 4). The grain sizes for NBG-17, NBG-18 and PCEA $(0.8,1.5$ and $0.8 \mathrm{~mm}$, respectively) are relatively large compared with the diameter of the smallest tensile specimen $(6.35 \mathrm{~mm})$. Further, within billet and billet-to-billet spatial and orientation variations for the vibrationally molded and extruded materials may be significant. So, in order to reveal the degree of anisotropy within these grapithes, only the three larger specimens will be used. On the other hand, isostatically molded, fine grain graphites like IG-43 (0.01 mm grain size) are typically very isotropic. So, all four specimen sizes will be used to better refine the effect of specimen size on tensile strength.

\subsection{Compression test specimens}

ASTM test standard C 695 - 91 (Reapproved 2005), "Standard Test Method for Compressive Strength of Carbon and Graphite" will be used for all compression specimen testing at room temperature. The standard requires that the diameter of the test 
specimen be greater than ten times the maximum particle size of the graphite. Further, the ratio of specimen height to diameter should be 1.9 to 2.1, and the recommended minimum specimen diameter is $9.5 \mathrm{~mm}$. A specimen $15 \mathrm{~mm}$ diameter $\mathrm{x} 30 \mathrm{~mm}$ high would be required for testing the larger grain NBG-18 graphite, and would exceed the minimum requirements for other graphites having smaller grain sizes. Conveniently, this one specimen size will be used for the characterization program.

\subsection{Flexure test specimens}

ASTM test standard C 651 - 91 (Reapproved 2005) "Standard Test Method for Flexural Strength of Manufactured Carbon and Graphite Articles Using Four-Point Loading at Room Temperature" will be used for all flexural specimen testing. The standard requires that the minimum dimension of the specimen be greater than 5 times the particle size of the graphite. Further, the width to thickness ratio should not be greater than 2, and the ratio of length to thickness should be at least 8. Again, based on NBG-18, the single specimen selected for the characterization program is a rectangular bar 16 x $20 \times 160$ $\mathrm{mm}$. The ratio of the specimen thickness to the particle size of NBG-18 is slightly over 10 while the ratio of the width to thickness is 1.25 , and the length to thickness ratio is 8 .

\subsection{Coefficient of thermal expansion (CTE) specimens}

ASTM test standard E 228 - 95, "Standard Test Method for Linear Thermal Expansion of Solid Materials with a Vitreous Silica Dilatometer” will be used for determining the CTE of the graphites. Typically, CTE specimens are long thin rods. Cylindrical specimens with dimensions of 3-4 mm diameter $x$ 30-40 mm long are being considered for the subject characterization program. Some adjustment to specimen dimensions may be required to ensure the reliability of measurements on the coarser NBG-18 graphite. The CTE specimens will be conveniently machined from the ends of the tensile specimens after they have been tested. Traceability to spatial location and orientation for each of the CTE specimens will be straight forward, and tensile, compressive and flexure specimen yields for spatial and orientation characterization can be maximized.

\subsection{Thermal conductivity specimens}

ASTM test standards C 781 - 02, “Standard Practice for Testing Graphite and Boronated Graphite Components for High-Temperature Gas-Cooled Nuclear Reactors” and E 1461 01 , "Standard Test Method for Thermal Diffusivity by the Flash Method" will be used for all thermal conductivity specimen testing. (E 1461 - 01 is a more detailed form of C 714, "Standard Test Method for Thermal Diffusivity by the Flash Method", and has applicability to a much wider range of materials and temperatures.) Standard specimen sizes are thin circular discs 6 to $18 \mathrm{~mm}$ diameter $\mathrm{x} 2$ to $3 \mathrm{~mm}$ thick. So these specimens can be machined from the ends of the previously tested tensile specimens similar to the CTE specimens above. 


\section{Billet cutting - methodology and assumptions}

The primary objective was to maximize the number of test specimens that could be obtained from each billet. This would promote a more complete or finer resolution material property "mapping" for each of the billets. However, in order to provide statistically significant results from the various test methods a minimum of four samples are needed from each location/orientation within the same billet (per ASTM methodologies). Since this is physically impossible it was assumed that the billets had some level of symmetry in material properties throughout the entire structure which allows samples from different sections of the billet to effectively be "similar" with respect to material properties. Using samples from similar locations within each billet section would yield enough samples to provide for statistical validity.

To facilitate machining the billets will be cut into smaller sections designated as "slabs". Each slab is sized to accommodate the proper grain orientation within the test samples. All test specimen blanks machined for a given slab will have the same grain orientation (ag or wg) as the slab. The slabs will be further sectioned into sub-slabs to allow the rectangular test specimen blanks to be machined to the correct size.

Slabs govern specimen grain orientation

Sub-slabs dictate specimen size and geometry

Finally, a tracking methodology has been devised to account for every specimen machined from a graphite billet. A unique identification number will be assigned to each test specimen providing the exact location and orientation of the sample within the graphite billet. This identification system is based upon the cutting methodology to provide an easy and concise method for identifying the different samples.

Details of the billet symmetry, cutting methodology, and sample identification are provided below.

\subsection{Billet symmetry and reproducibility}

To provide statistically significant results for the various mechanical property test methods a minimum of four samples would be needed from each location/orientation within the same billet. Since this is physically impossible it was assumed that the billets had some level of symmetry in material properties throughout the entire structure. In other words, it was assumed that the material properties on the "top" of a billet were the same as the material properties on the "bottom". This was also assumed to apply from "front" and "back" of the billets. Test samples machined from symmetrical regions within the billet are considered to be similar and could be used to meet the four sample minimum required for statistical accuracy (see Fig. 4.1). 


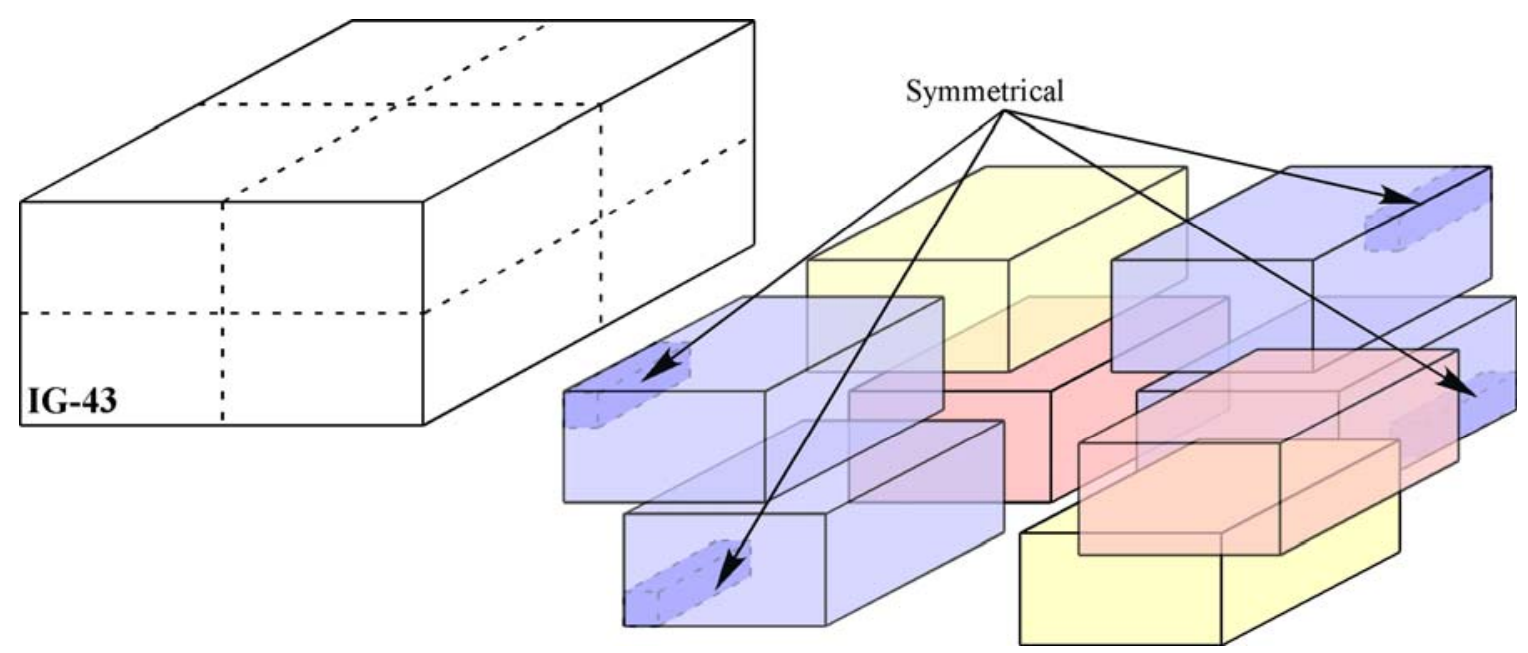

Fig. 4.1. Example of symmetrical quadrant sections within a graphite billet

Using these symmetry assumptions the billets were divided into quadrants where the material properties were assumed to be the same at similar locations. At least four test samples of a given geometry and size (e.g.. 0.625” diameter tensile specimens) will be taken from the same locations in separate quadrants in order to provide a statistically accurate number of samples.

These symmetrical quadrants are easily seen in the rectangular block billets (i.e. the NBG \& IG-43 billets) but pose a problem with the extruded PCEA cylinder. The PCEA is expected to possess radial symmetry as illustrated in Fig. 4.2. Since the billet is extruded as a right cylinder the material properties and grain structure are assumed to change in a uniform manner from the center out to the outer radius of the billet. In addition, it is assumed that the "front" and "back" of the cylinder are also symmetrical allowing specimen blanks to be cut from either end to be similar. 


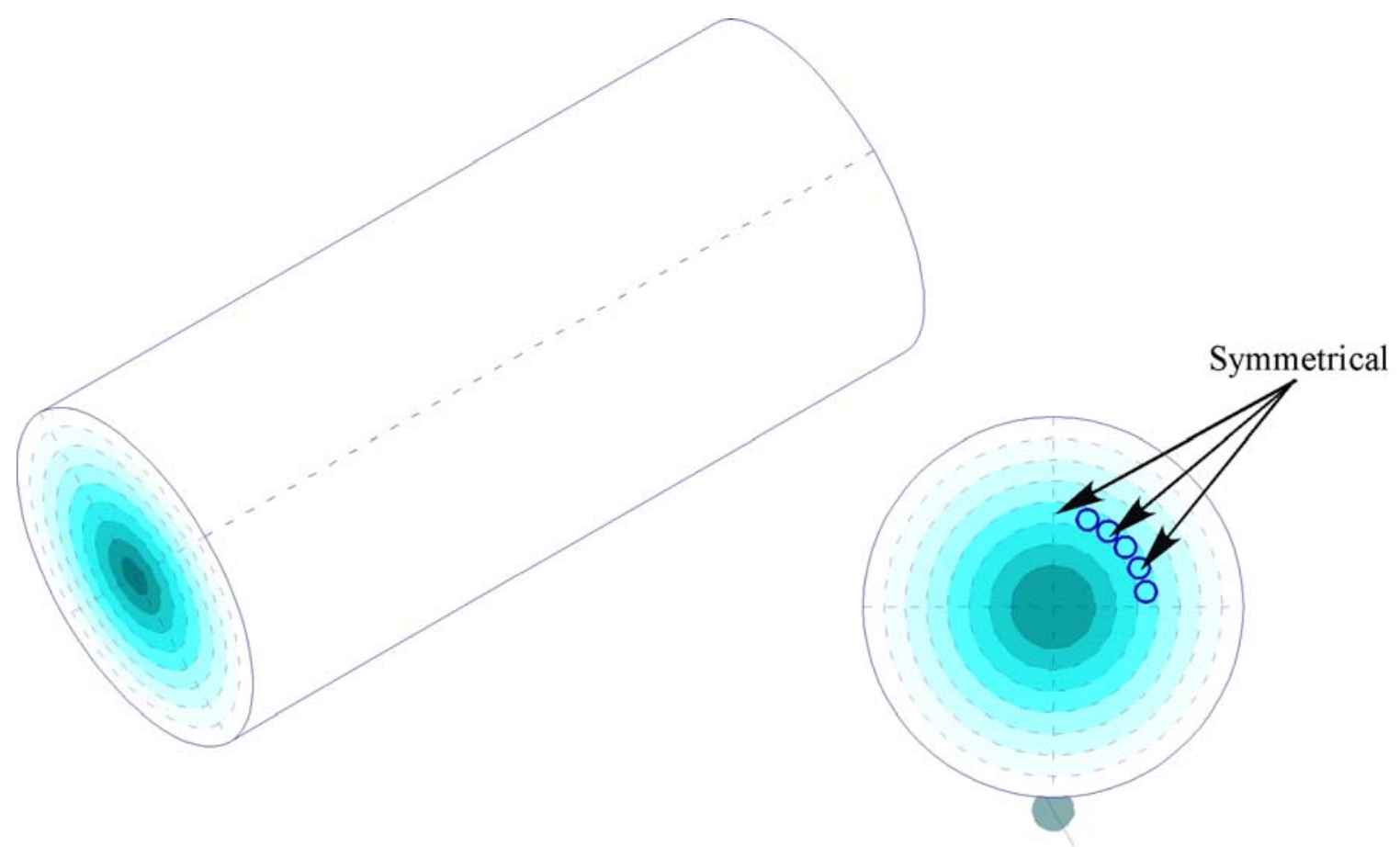

Fig. 4.2. Illustration of the radial symmetry of the PCEA graphite billet

It was difficult to accommodate all the tensile test specimen sizes within the billets cutting plans. Test specimen sizes were eliminated if the 10X grain size guideline exceeded the diameter of the tensile specimen. Thus, for those graphites with larger grain sizes (NBG-18, NBG-18 and PCEA) the small tensile test specimens (0.250” diameter) were eliminated. On the other hand, the small tensile specimen is appropriate for the fine grain IG-43 graphite, so the 1.000" diameter tensile specimens were eliminated in order to improve the resolution of the characterization.

All billets will have a distribution of the singular compression, and flexure test specimen sizes.

Finally, it was decided that specimens for the physical property tests (CTE and thermal diffusivity) could be machined from the ends of the tensile specimens after mechanical testing. This approach maximizes the specimen yield for mechanical property characterization. 


\subsection{Grain orientation}

It is known that the grain structure within graphite billets can affect the mechanical and thermal properties of the test samples. To capture this difference test specimens oriented "with" grain and "against" grain will be machined from each billet. Therefore, the effects of both the spatial position and orientation on material properties are considered in the cutting plans. The known wg and ag directions for the NBG and PCEA billets are given in Attachment 2. Since the IG-43 graphite is expected to be very isotropic, and because the vendor (Toyo Tanso) does not distinguish between ag and wg directions, these will be arbitrarily assigned in the cutting plans.

The rectangular billets are considered to have a Cartesian coordinate orientation while the extruded PCEA billet presents a cylindrical orientation. Therefore, the test samples in the rectangular block billets will be cut from the blocks in $90^{\circ}$ orientations (with respect to each other), whereas the cut up plans for the PCEA will be based on a radial orientation, with specimens being positioned at specified radii within the billet.

\subsection{General cutting plan (billets, slabs, sub-slabs, specimens)}

Billets are cut into successively smaller slabs of graphite until individual specimen blanks are machined from the smallest slab. In general, the billets are cut into slabs to maintain a specific grain orientation for all specimens in the slab. Each slab is cut into a number of sub-slabs providing material for a given size and orientation. The sub-slabs are relatively thin, rectangular plates. Rectangular test specimen blanks with square cross-sections are then cut from each sub-slab with the actual number blanks taken from the sub-slab dictated by the size and geometry of the final test specimen type. A unique identification number is attached to each specimen blank indicating the location and orientation within the specific billet. A test specimen will machined from each specimen blank in conformance with the appropriate detail drawing (See Attachment 4). The identification number will be transcribed to the test specimen after final machining. The slabbing process is depicted graphically in Fig. 4.3. 


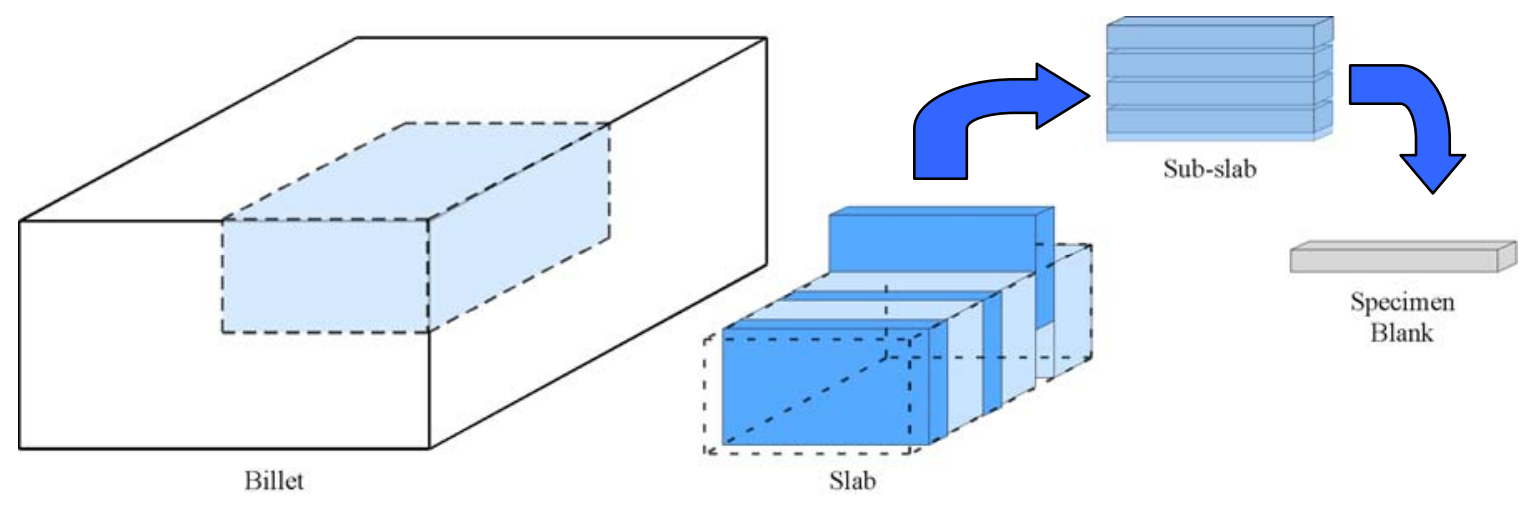

Fig. 4.3. Schematic of general cutting plan

\subsection{Specimen identification}

Identification of each test specimen is linked to the graphite grade, billet, slab and subslabs and the specimen blank from which it is machined from.. Thus, each specimen number has a specific graphite billet designatior, a specific slab number as cut from the billet, a specific sub-slab number as cut from the slab, and a specimen number indicating where the specimen was cut from the sub-slab.

The four graphite billet types were given alphabetic designators of A (PCEA), B (NBG17), D (NBG-18), and F (IG-43). Slabs and Sub-slabs were identified by numerical order within the billet or slab, respectively. The specimens were identified both by an alphabetical and a numeric designator. The alphabetic letter represents the type of test specimen to be produced while the number represents the numerical order of the test specimen in the sub-slab. These alphanumeric designators are summarized in Table 4.1 below.

\begin{tabular}{|l|c|l|l|l|l|}
\hline \multicolumn{2}{|c|}{ Billet type } & \multicolumn{1}{c|}{ Slab } & \multicolumn{1}{c|}{ Sub-slab } & Specimen type & \\
\hline PCEA & A & $1,2,3,4, \ldots$ & $1,2,3,4, \ldots$ & Tensile & T \\
NBG-17 & B & & & Compression & C \\
NBG-18 & D & & & Flexure & F \\
IG-43 & F & & & CTE & E \\
& & & & Thermal Diffusivity & D \\
\hline
\end{tabular}

Table 4.1. Specimen identification legend 
An example of the identification number system would be:

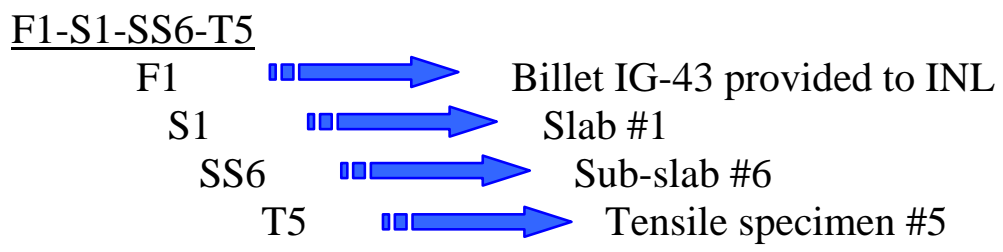

\subsection{Cutting plans}

Illustrations of the layout of tensile, compression, and flexure specimens within the graphite billets resulting from the spatial location and orientation considerations discussed above are given in Figs. 4.4 -4.7. Detailed billet cutting plans for NBG-17, NBG-18, PCEA and IG-43 are given in Appendices 5 -8, respectively.

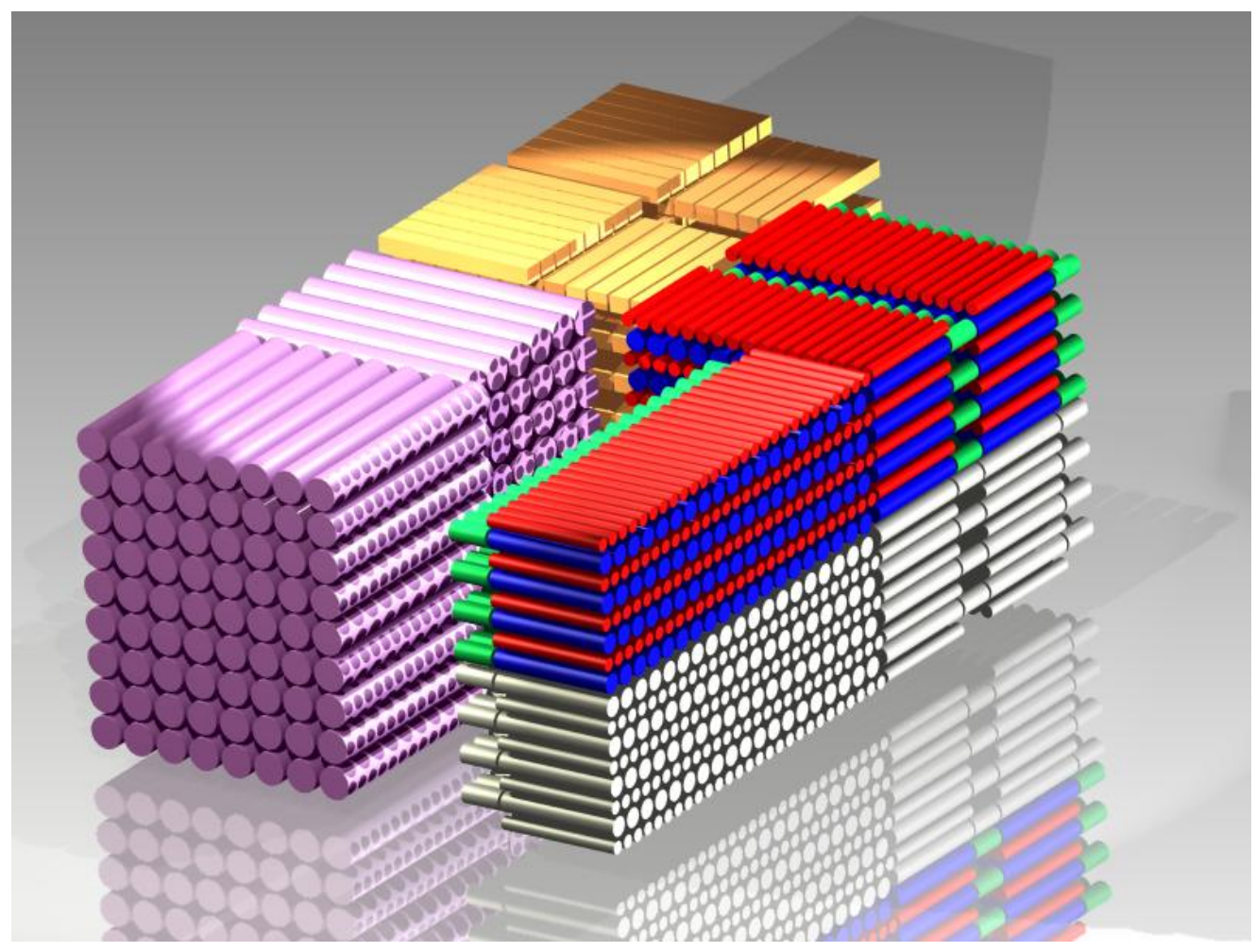

Fig. 4.4. Specimen layout for IG-43 


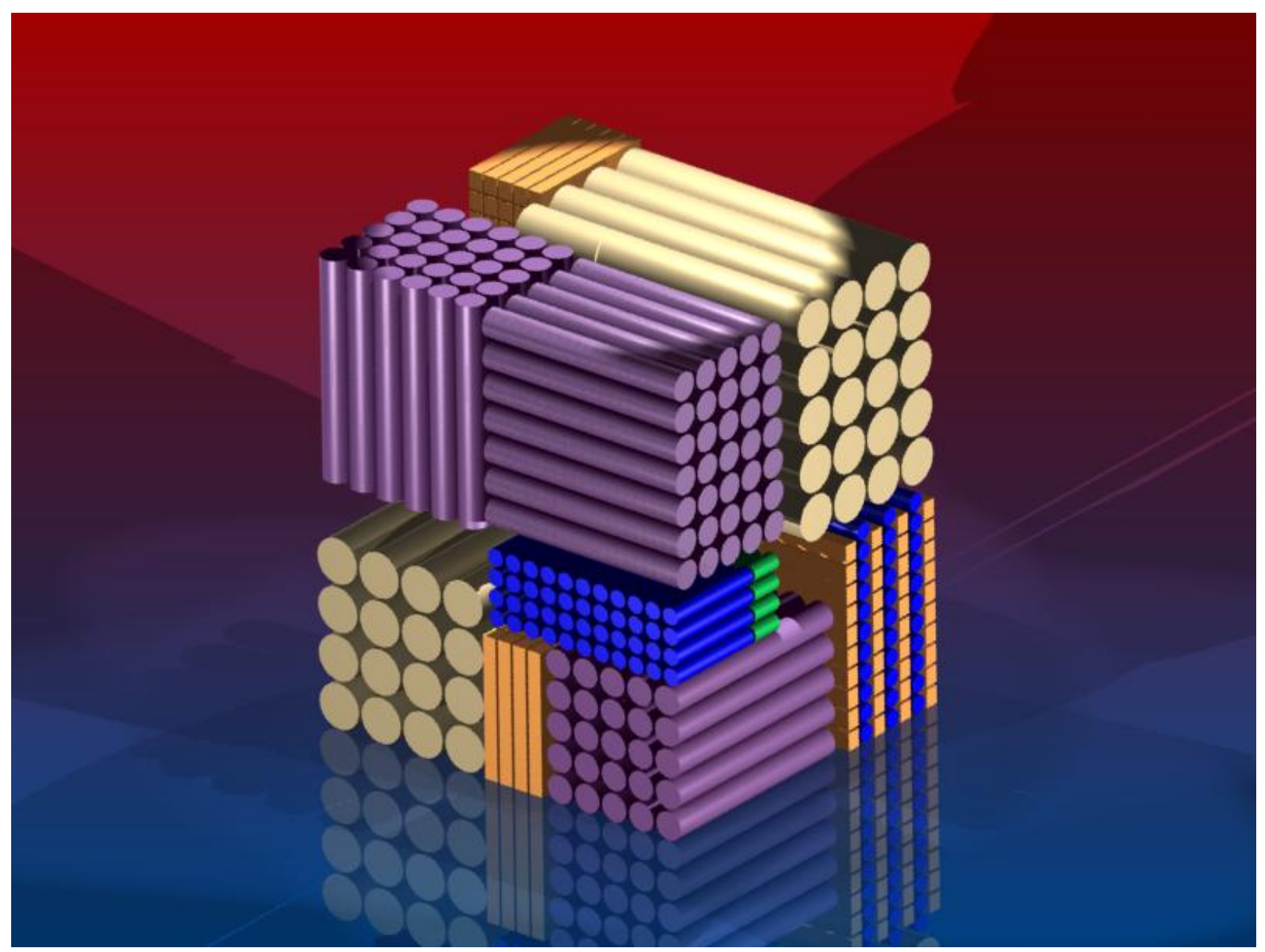

Fig. 4.5. Specimen layout for NBG-17 


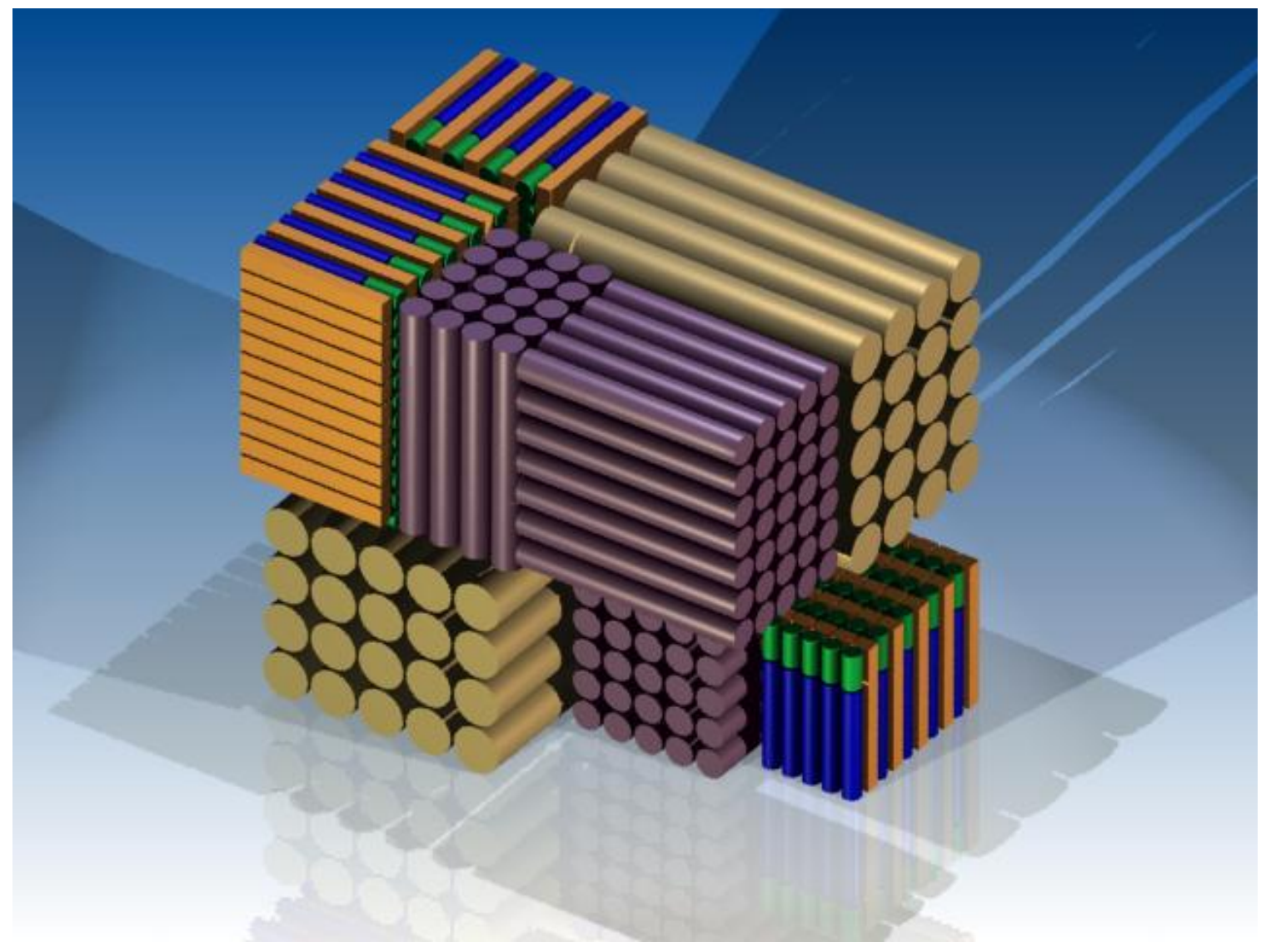

Fig. 4.6. Specimen layout for NBG-18 


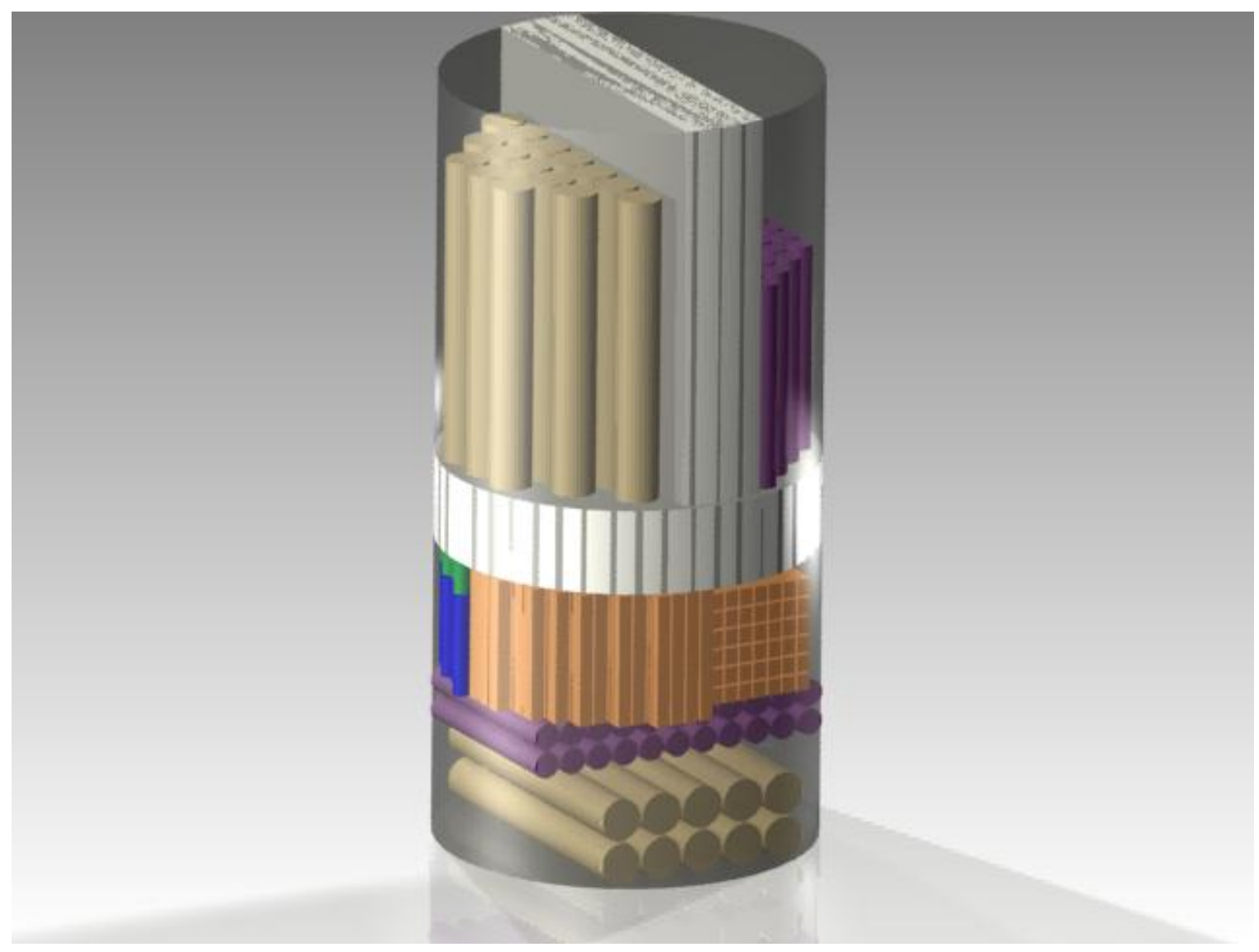

Fig. 4.7. Specimen layout for PCEA

\section{Summary}

A joint ORNL and INL program has been initiated to characterize the physical and mechanical properties of candidate NGNP graphites including NBG-17, NBG-18, PCEA and IG-43. Graphite billets have been purchased. Detail drawings for machining tensile, compression and flexure specimens have been prepared in conformance with applicable ASTM standard test methods. Billet slabbing plans and a specimen identification legend have been conceived . And detailed billet cutting plans have been prepared. It is anticipated that specimen machining, and subsequent testing will be undertaken in FY 07 as funding permits. 
Appendix 1. Graphite Procurement 
Graphite Purchases

\begin{tabular}{|l|l|l|l|}
\hline Grade & Source & $\begin{array}{l}\text { ORNL } \\
\text { Purchase Order }\end{array}$ & Comments \\
\hline NBG-17 & SGL Carbon S.A.S. (France) & 4000048662 & Shared with INL \\
\hline NBG-18 & SGL Carbon S.A.S. (France) & 4000049662 & Shared with INL \\
\hline PCEA & $\begin{array}{l}\text { UCAR Carbon Co. } \\
\text { Parma, OH }\end{array}$ & 4000047677 & Billet sent to INL \\
\cline { 2 - 4 } IG-430 & $\begin{array}{l}\text { Toyo Tanso USA Inc. } \\
\text { Troutsdale, OR }\end{array}$ & 4000049350 & ORNL billet \\
\hline
\end{tabular}


Appendix 2. Shiva Chemical Analysis 


\section{Customer UT-Battelle Oak Ridge \\ Date 07-Aug-06 07-Aug-06 08-Aug-06 08-Aug-06}

\begin{tabular}{|c|c|c|c|c|}
\hline Customer ID & Graphite & Graphite & Graphite & Graphite \\
& NBG-17 & NBG-18 & PCEA & IG-430 \\
Shiva ID & U060802015 & U060802016 & U060802018 & U060802020 \\
\hline
\end{tabular}

P.O. \# 3400075184

Job \# UP4897

\begin{tabular}{|c|c|c|c|c|}
\hline Element & $\begin{array}{c}\text { Concentration } \\
{[\mathrm{ppm} w \mathrm{wt}]}\end{array}$ & $\begin{array}{c}\text { Concentration } \\
\text { [ppm wt ] }\end{array}$ & $\begin{array}{c}\text { Concentration } \\
\text { [ppm wt ] }\end{array}$ & \begin{tabular}{|c|} 
Concentration \\
[ppm wt ]
\end{tabular} \\
\hline $\mathrm{Li}$ & 0.21 & 0.05 & $<0.01$ & $<0.01$ \\
\hline $\mathrm{Be}$ & $<0.01$ & $<0.01$ & $<0.01$ & $<0.01$ \\
\hline$B$ & 0.61 & 0.57 & 0.71 & 0.08 \\
\hline $\mathrm{C}$ & Matrix & Matrix & Matrix & Matrix \\
\hline $\mathrm{N}$ & - & - & - & - \\
\hline $\mathrm{O}$ & - & - & - & - \\
\hline$F$ & $<1$ & $<1$ & $<1$ & $<1$ \\
\hline $\mathrm{Na}$ & 0.28 & 0.17 & 0.08 & $<0.05$ \\
\hline $\mathrm{Mg}$ & $<0.5$ & $<0.5$ & $<0.5$ & $<0.5$ \\
\hline $\mathrm{Al}$ & 0.09 & 0.24 & 0.06 & $<0.05$ \\
\hline $\mathrm{Si}$ & 100 * & 38 & 1.5 & 1.9 \\
\hline$P$ & 0.35 & $<0.1$ & 0.22 & $<0.1$ \\
\hline $\mathrm{S}$ & 12 & 4.8 & 4.6 & 0.25 \\
\hline $\mathrm{Cl}$ & 0.21 & 0.14 & 0.19 & 0.22 \\
\hline $\mathrm{K}$ & 0.35 & $<0.1$ & $<0.1$ & $<0.1$ \\
\hline $\mathrm{Ca}$ & 2.2 & 5.9 & 0.19 & $<0.05$ \\
\hline $\mathrm{Sc}$ & $<0.05$ & $<0.05$ & $<0.05$ & $<0.05$ \\
\hline $\mathrm{Ti}$ & 5.5 & 0.23 & 0.04 & $<0.01$ \\
\hline V & 0.73 & 0.04 & 0.28 & $<0.01$ \\
\hline $\mathrm{Cr}$ & $<0.5$ & $<0.5$ & $<0.5$ & $<0.5$ \\
\hline $\mathrm{Mn}$ & $<0.05$ & $<0.05$ & $<0.05$ & $<0.05$ \\
\hline $\mathrm{Fe}$ & 26 & 4.8 & 0.06 & $<0.01$ \\
\hline Co & 0.11 & $<0.05$ & $<0.05$ & $<0.05$ \\
\hline $\mathrm{Ni}$ & 1.2 & $<0.1$ & $<0.1$ & $<0.1$ \\
\hline $\mathrm{Cu}$ & $<0.1$ & $<0.1$ & $<0.1$ & $<0.1$ \\
\hline $\mathrm{Zn}$ & $<0.1$ & $<0.1$ & $<0.1$ & $<0.1$ \\
\hline $\mathrm{Ga}$ & $<0.1$ & $<0.1$ & $<0.1$ & $<0.1$ \\
\hline $\mathrm{Ge}$ & $<0.1$ & $<0.1$ & $<0.1$ & $<0.1$ \\
\hline As & $<0.1$ & $<0.1$ & $<0.1$ & $<0.1$ \\
\hline $\mathrm{Se}$ & $<0.1$ & $<0.1$ & $<0.1$ & $<0.1$ \\
\hline $\mathrm{Br}$ & $<0.1$ & $<0.1$ & $<0.1$ & $<0.1$ \\
\hline $\mathrm{Rb}$ & $<0.05$ & $<0.05$ & $<0.05$ & $<0.05$ \\
\hline $\mathrm{Sr}$ & $<0.05$ & 0.06 & $<0.05$ & $<0.05$ \\
\hline $\bar{Y}$ & $<0.05$ & $<0.05$ & $<0.05$ & $<0.05$ \\
\hline $\mathrm{Zr}$ & 0.49 & 0.22 & $<0.05$ & $<0.05$ \\
\hline $\mathrm{Nb}$ & $<0.1$ & $<0.1$ & $<0.1$ & $<0.1$ \\
\hline $\mathrm{Mo}$ & 0.08 & $<0.05$ & 0.35 & $<0.05$ \\
\hline $\mathrm{Ru}$ & $<0.1$ & $<0.1$ & $<0.1$ & $<0.1$ \\
\hline $\mathrm{Rh}$ & $<0.1$ & $<0.1$ & $<0.1$ & $<0.1$ \\
\hline $\mathrm{Pd}$ & $\begin{array}{c}<0.1 \\
\end{array}$ & $<0.1$ & $<0.1$ & $<0.1$ \\
\hline
\end{tabular}




\begin{tabular}{|c|c|c|c|c|}
\hline Customer ID & Graphite & Graphite & Graphite & Graphite \\
& NBG-17 & NBG-18 & PCEA & IG-430 \\
Shiva ID & U060802015 & U060802016 & U060802018 & U060802020 \\
\hline
\end{tabular}

\begin{tabular}{|c|c|c|c|c|}
\hline Element & $\begin{array}{c}\text { Concentration } \\
\text { [ppm wt ] }\end{array}$ & $\begin{array}{c}\text { Concentration } \\
\text { [ppm wt ] }\end{array}$ & $\begin{array}{c}\text { Concentration } \\
\text { [ppm wt ] }\end{array}$ & \begin{tabular}{|c|} 
Concentration \\
{$[\mathrm{ppm} w \mathrm{wt}]$}
\end{tabular} \\
\hline $\mathrm{Ag}$ & $<0.1$ & $<0.1$ & $<0.1$ & $<0.1$ \\
\hline $\mathrm{Cd}$ & $<0.1$ & $<0.1$ & $<0.1$ & $<0.1$ \\
\hline In & $<0.1$ & $<0.1$ & $<0.1$ & $<0.1$ \\
\hline Sn & $<0.5$ & $<0.5$ & $<0.5$ & $<0.5$ \\
\hline $\mathrm{Sb}$ & $<0.5$ & $<0.5$ & $<0.5$ & $<0.5$ \\
\hline $\mathrm{Te}$ & $<0.1$ & $<0.1$ & $<0.1$ & $<0.1$ \\
\hline I & $<0.1$ & $<0.1$ & $<0.1$ & $<0.1$ \\
\hline Cs & $\begin{array}{c}<0.1 \\
\end{array}$ & $<0.1$ & $\begin{array}{c}<0.1 \\
\end{array}$ & $<0.1$ \\
\hline $\mathrm{Ba}$ & $<0.1$ & $<0.1$ & $<0.1$ & $<0.1$ \\
\hline $\mathrm{La}$ & $<0.5$ & $<0.5$ & $<0.5$ & $<0.5$ \\
\hline $\mathrm{Ce}$ & $<0.05$ & $<0.05$ & $<0.05$ & $<0.05$ \\
\hline $\mathrm{Pr}$ & $<0.05$ & $<0.05$ & $<0.05$ & $<0.05$ \\
\hline $\mathrm{Nd}$ & $<0.05$ & $<0.05$ & $<0.05$ & $<0.05$ \\
\hline $\mathrm{Sm}$ & $<0.05$ & $<0.05$ & $<0.05$ & $<0.05$ \\
\hline $\mathrm{Eu}$ & $<0.05$ & $<0.05$ & $<0.05$ & $<0.05$ \\
\hline $\mathrm{Gd}$ & $<0.05$ & $<0.05$ & $<0.05$ & $<0.05$ \\
\hline $\mathrm{Tb}$ & $<0.05$ & $<0.05$ & $<0.05$ & $<0.05$ \\
\hline Dy & $<0.05$ & $<0.05$ & $<0.05$ & $<0.05$ \\
\hline $\mathrm{Ho}$ & $<0.05$ & $<0.05$ & $<0.05$ & $<0.05$ \\
\hline $\mathrm{Er}$ & $<0.05$ & $<0.05$ & $<0.05$ & $<0.05$ \\
\hline $\mathrm{Tm}$ & $<0.05$ & $<0.05$ & $<0.05$ & $<0.05$ \\
\hline $\mathrm{Yb}$ & $<0.05$ & $<0.05$ & $<0.05$ & $<0.05$ \\
\hline $\mathrm{Lu}$ & $<0.05$ & $<0.05$ & $<0.05$ & $<0.05$ \\
\hline $\mathrm{Hf}$ & $<0.05$ & $<0.05$ & $<0.05$ & $<0.05$ \\
\hline $\mathrm{Ta}$ & $<5$ & $<5$ & $<5$ & $<5$ \\
\hline $\mathrm{W}$ & $<0.05$ & $<0.05$ & $<0.05$ & 0.35 \\
\hline $\mathrm{Re}$ & $<0.05$ & $<0.05$ & $<0.05$ & $<0.05$ \\
\hline Os & $<0.05$ & $<0.05$ & $<0.05$ & $<0.05$ \\
\hline $\mathrm{Ir}$ & $<0.05$ & $<0.05$ & $<0.05$ & $<0.05$ \\
\hline $\mathrm{Pt}$ & $<0.05$ & $<0.05$ & $<0.05$ & $<0.05$ \\
\hline $\mathrm{Au}$ & $<0.1$ & $<0.1$ & $<0.1$ & $<0.1$ \\
\hline $\mathrm{Hg}$ & $<0.5$ & $<0.5$ & $<0.5$ & $<0.5$ \\
\hline $\mathrm{TI}$ & $<0.1$ & $<0.1$ & $<0.1$ & $<0.1$ \\
\hline $\mathrm{Pb}$ & $<0.5$ & $<0.5$ & $<0.5$ & $<0.5$ \\
\hline $\mathrm{Bi}$ & $<0.1$ & $<0.1$ & $<0.1$ & $<0.1$ \\
\hline Th & $<0.05$ & $<0.05$ & $<0.05$ & $<0.05$ \\
\hline $\bar{U}$ & $<0.05$ & $<0.05$ & $<0.05$ & $<0.05$ \\
\hline
\end{tabular}

Note: analyzed by GDMS exept as noted by "*"

* analyzed by ICP-OES 
Appendix 3. Billet Sizes and Distribution 


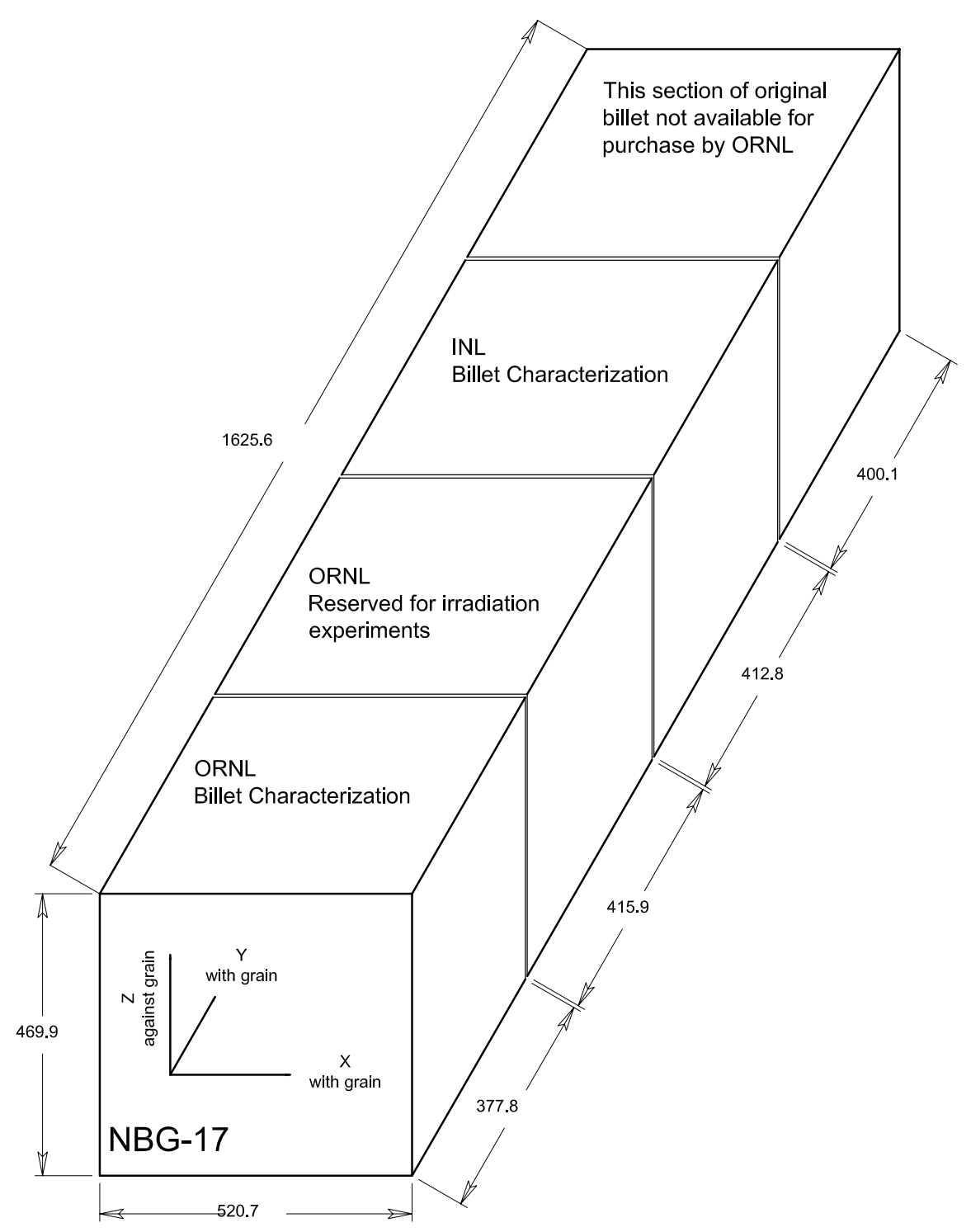

Dimensions in millimeters. 


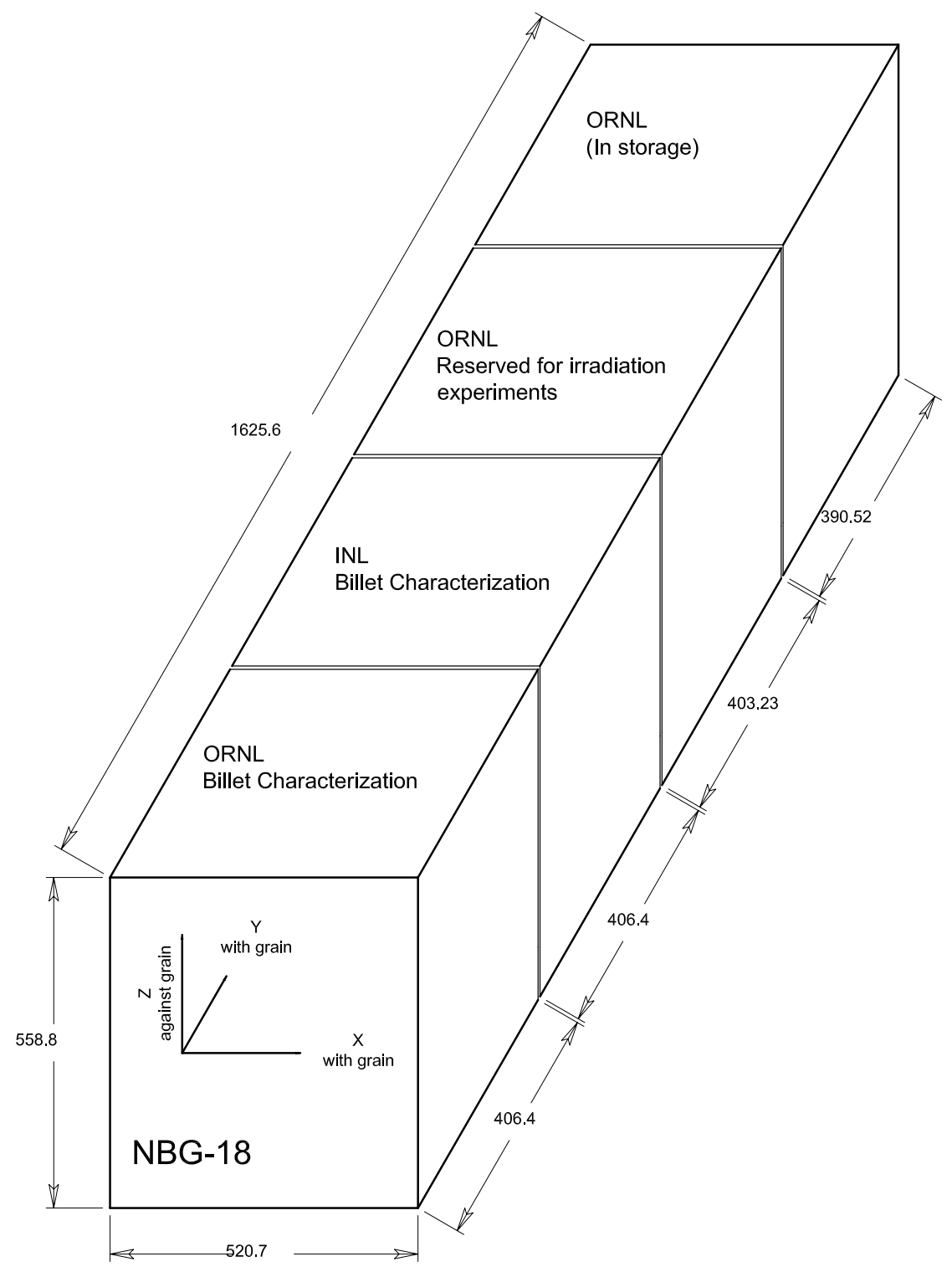

Dimension in millimeters. 


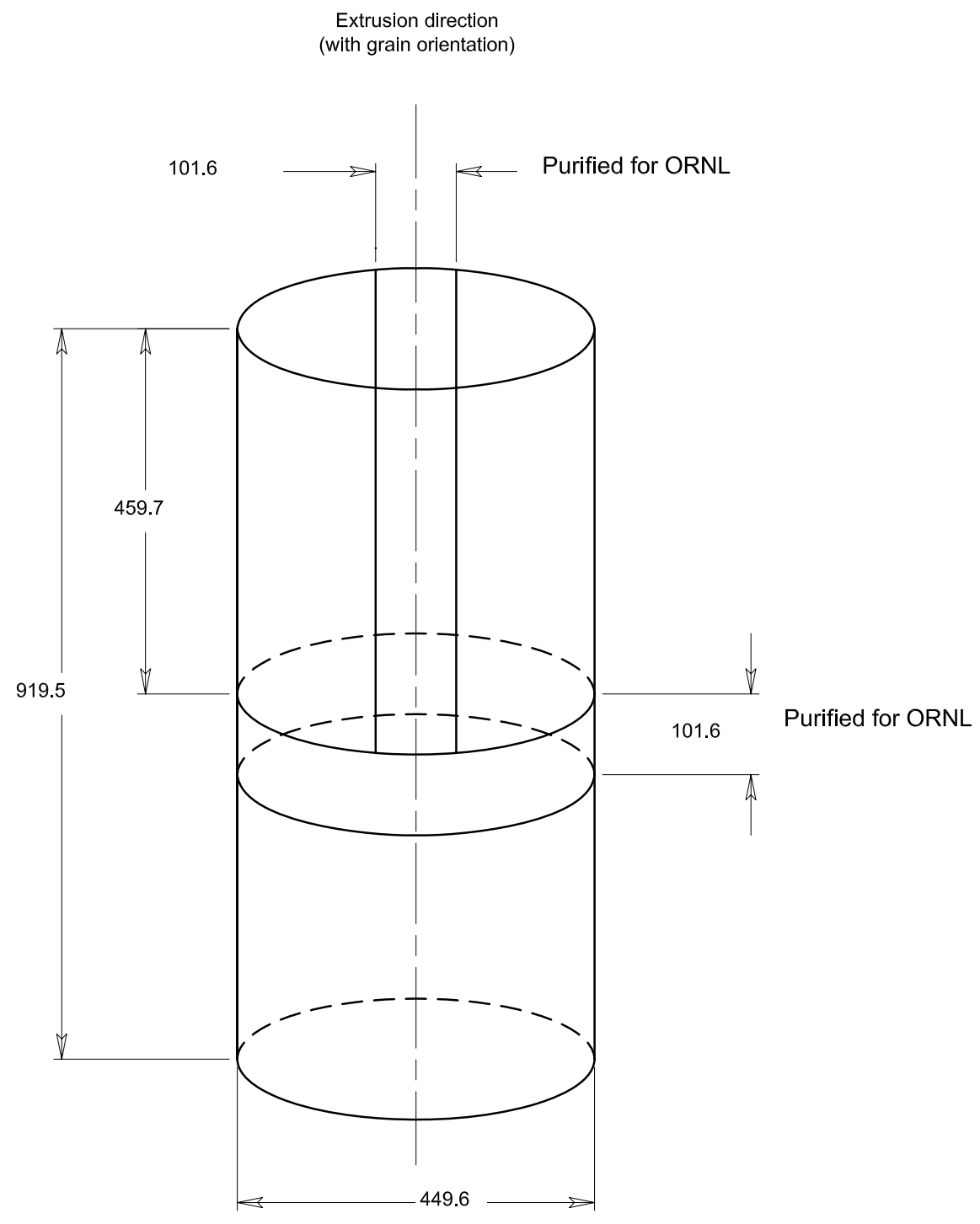

Dimensions in millimeters 
Appendix 4. Specimen Detail Drawings 
Notes. 1. Grahite grade to be machined shall be specified on the accompanying purchase order.

2. Dimensional inspection shall be performed at ORNL upon receipt.

3. Reference ASTM Standard C 749 - 92 (Reapproved 2002), Fig. 9, Item109.

4. ORNL Deviation form to be completed prior to deviation from the drawing.

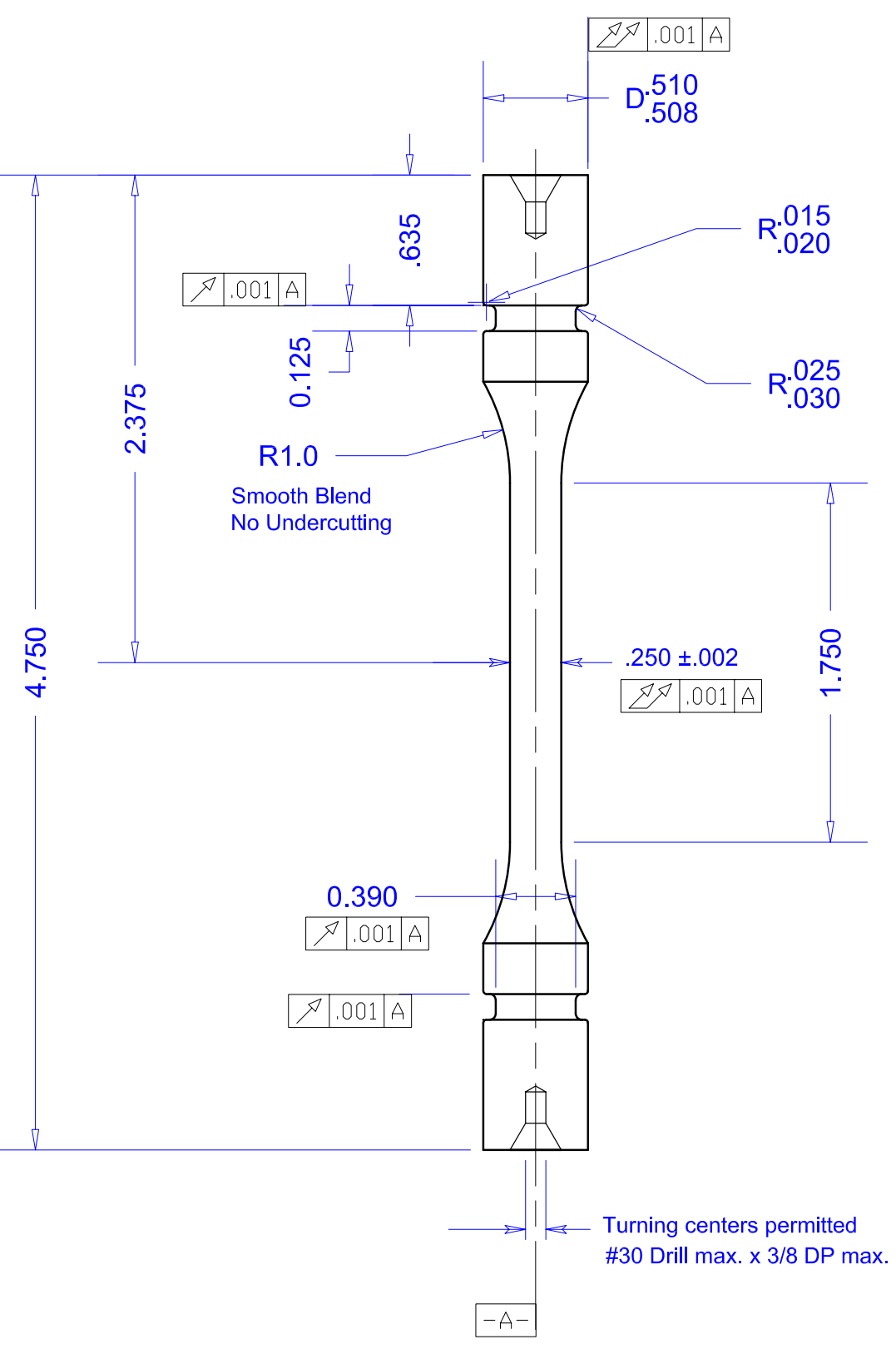

General surface finish 32-microinch or better

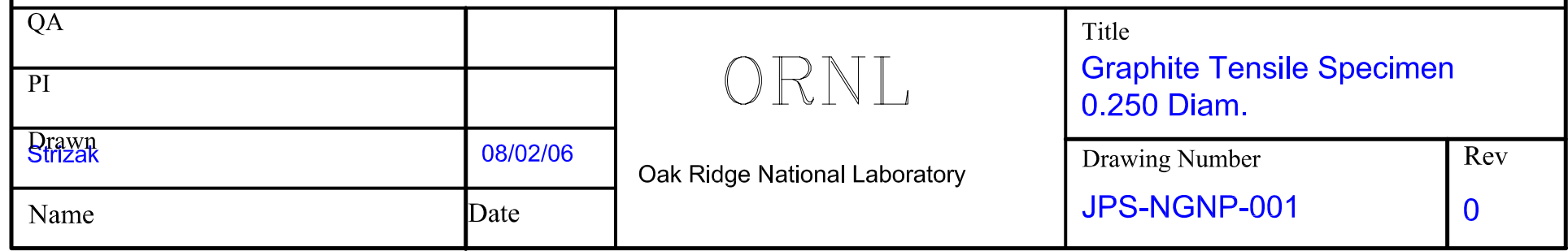


Notes. 1. Grahite grade to be machined shall be specified on the accompanying purchase order.

2. Dimensional inspection shall be performed at ORNL upon receipt.

3. Reference ASTM Standard C 749 - 92 (Reapproved 2002), Fig. 9, Item113.

4. ORNL Deviation form to be completed prior to deviation from the drawing.

General surface finish 32-microinch or better

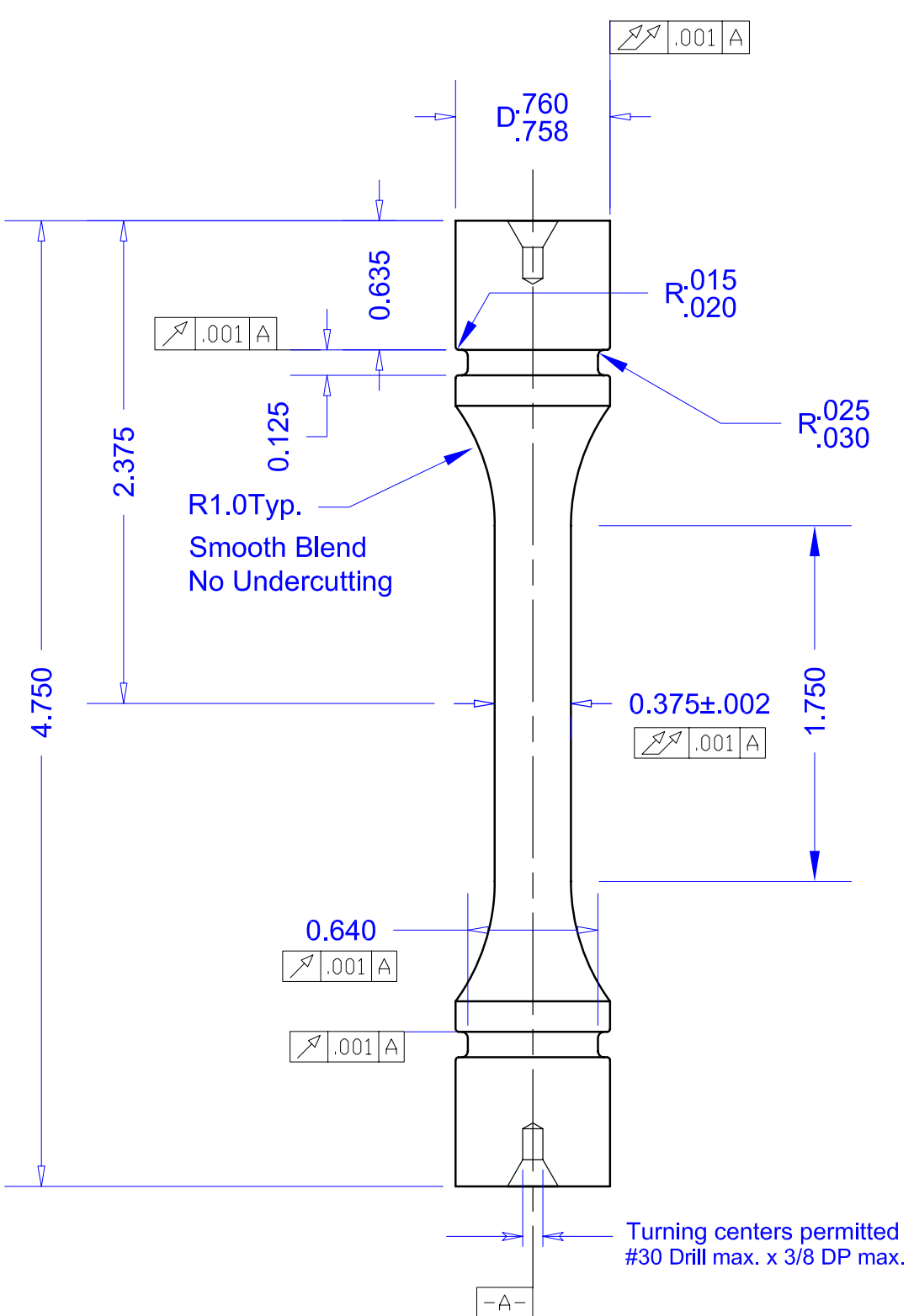

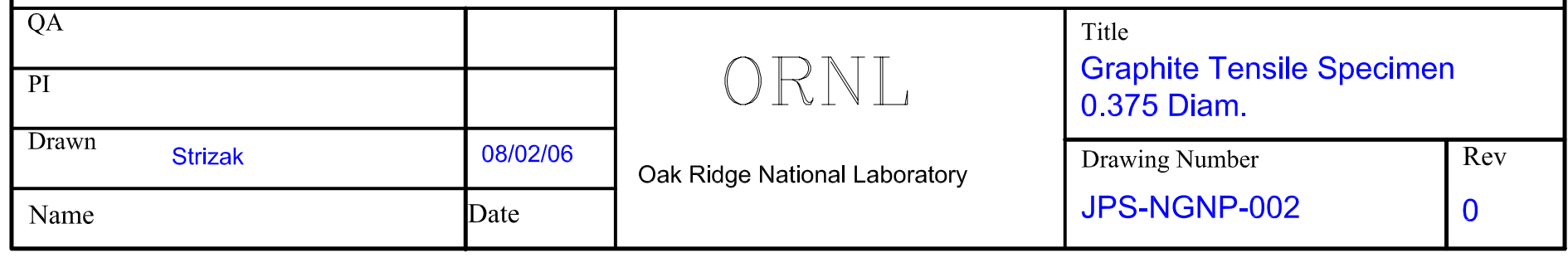


Notes. 1. Grahite grade to be machined shall be specified on the accompanying purchase order.

2. Dimensional inspection shall be performed at ORNL upon receipt.

3. Reference ASTM Standard C 749 - 92 (Reapproved 2002), Fig. 9, Item123.

4. ORNL Deviation form to be completed prior to deviation from the drawing.

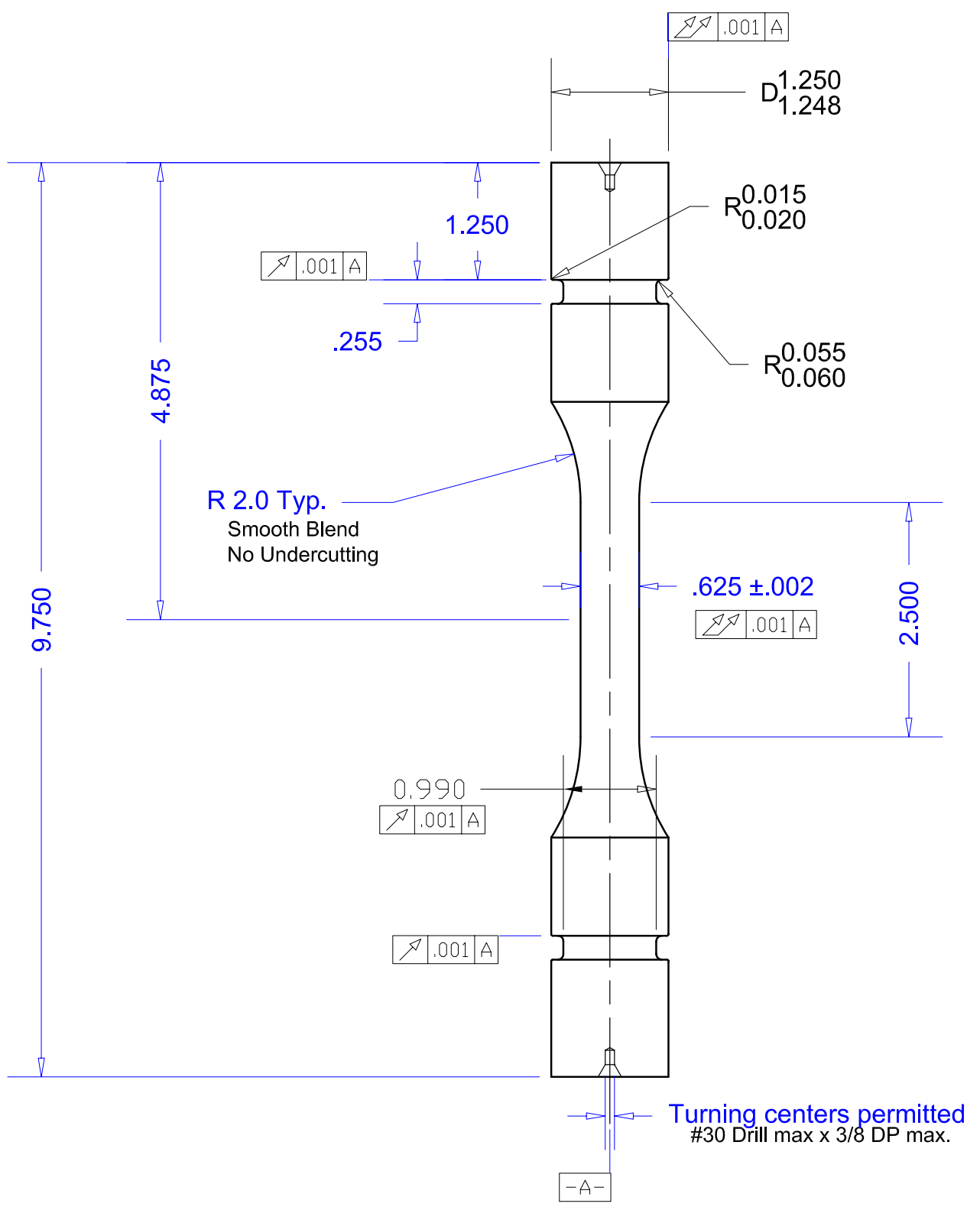

General surface finish 32-microinch or better

\begin{tabular}{|c|c|c|c|c|}
\hline QA & & \multirow{4}{*}{ Oak Ridge National Laboratory } & \multirow{2}{*}{\multicolumn{2}{|c|}{$\begin{array}{l}\text { Title } \\
\text { Graphite Tensile Specimen } \\
0.625 \text { Diam. }\end{array}$}} \\
\hline$\overline{\mathrm{PI}}$ & & & & \\
\hline $\begin{array}{ll}\text { Drawn } & \text { Strizak }\end{array}$ & 08/02/06 & & Drawing Number & Rev \\
\hline Name & Date & & JPS-NGNP-003 & 0 \\
\hline
\end{tabular}


Notes. 1. Grahite grade to be machined shall be specified on the accompanying purchase order.

2. Dimensional inspection shall be performed at ORNL upon receipt.

3. Reference ASTM Standard C 749 - 92 (Reapproved 2002), Fig. 9, Item129.

4. ORNL Deviation form to be completed prior to deviation from the drawing.

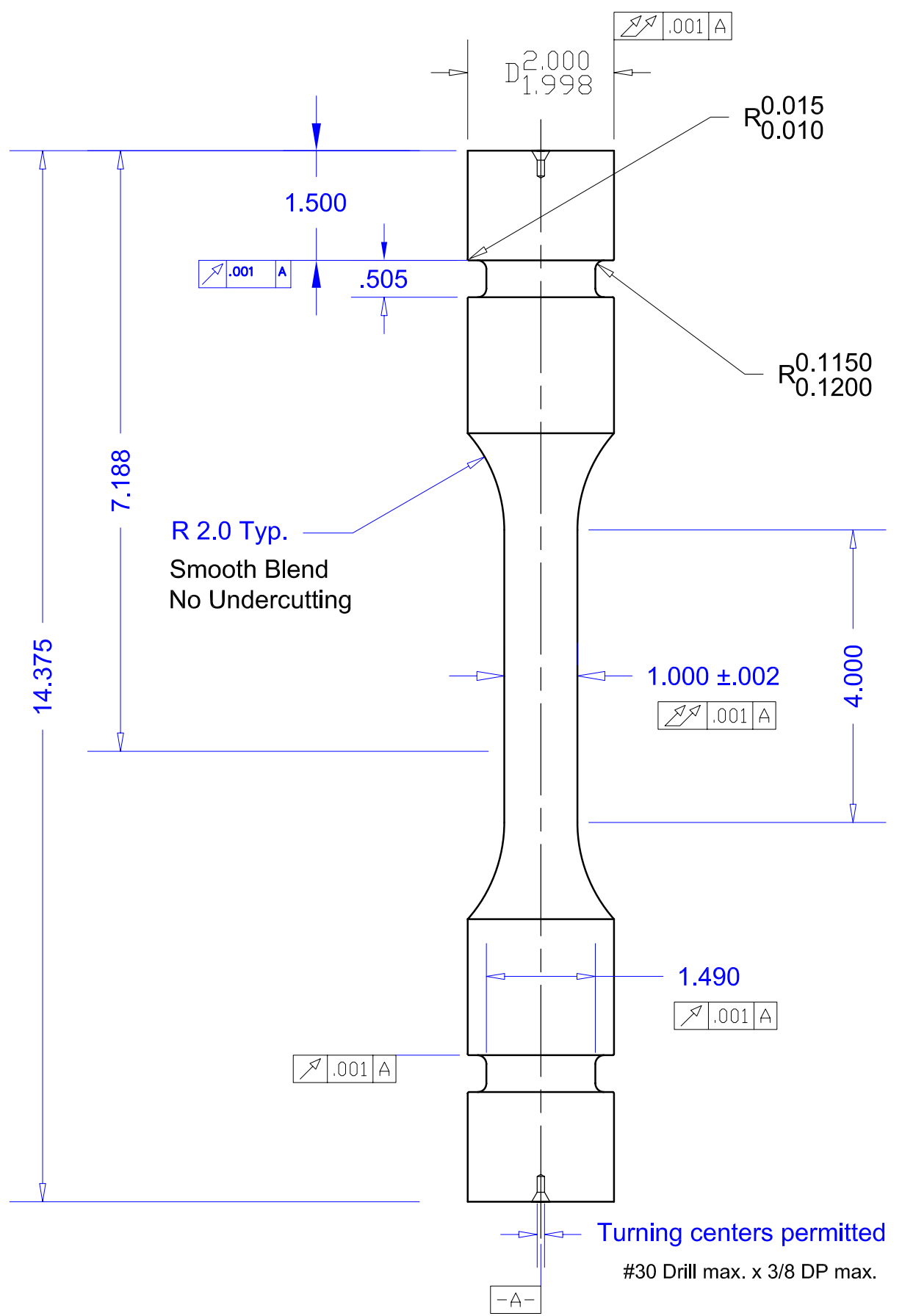

General surface finish 32-microinch or better

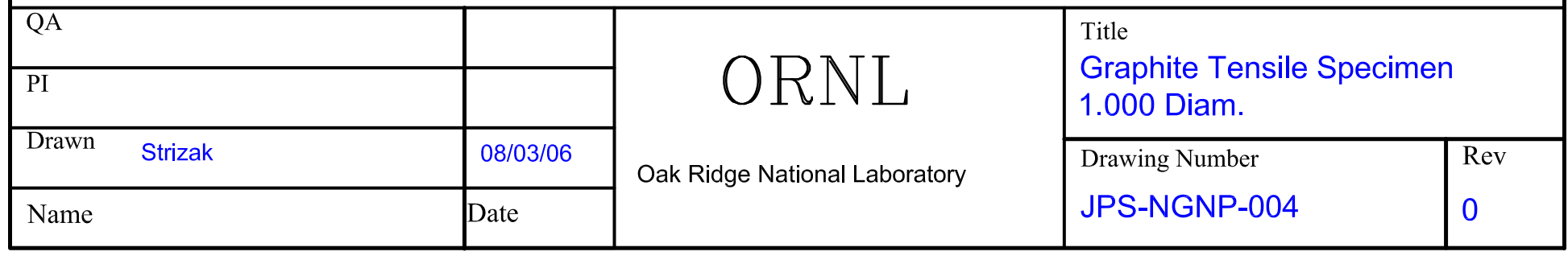


Notes. 1. Grahite grade to be machined shall be specified on the accompanying purchase order.

2. Dimensional inspection shall be performed at ORNL upon receipt.

3. Reference ASTM Standard C 749 - 92 (Reapproved 2002), Fig. 9, Item109.

4. ORNL Deviation form to be completed prior to deviation from the drawing.
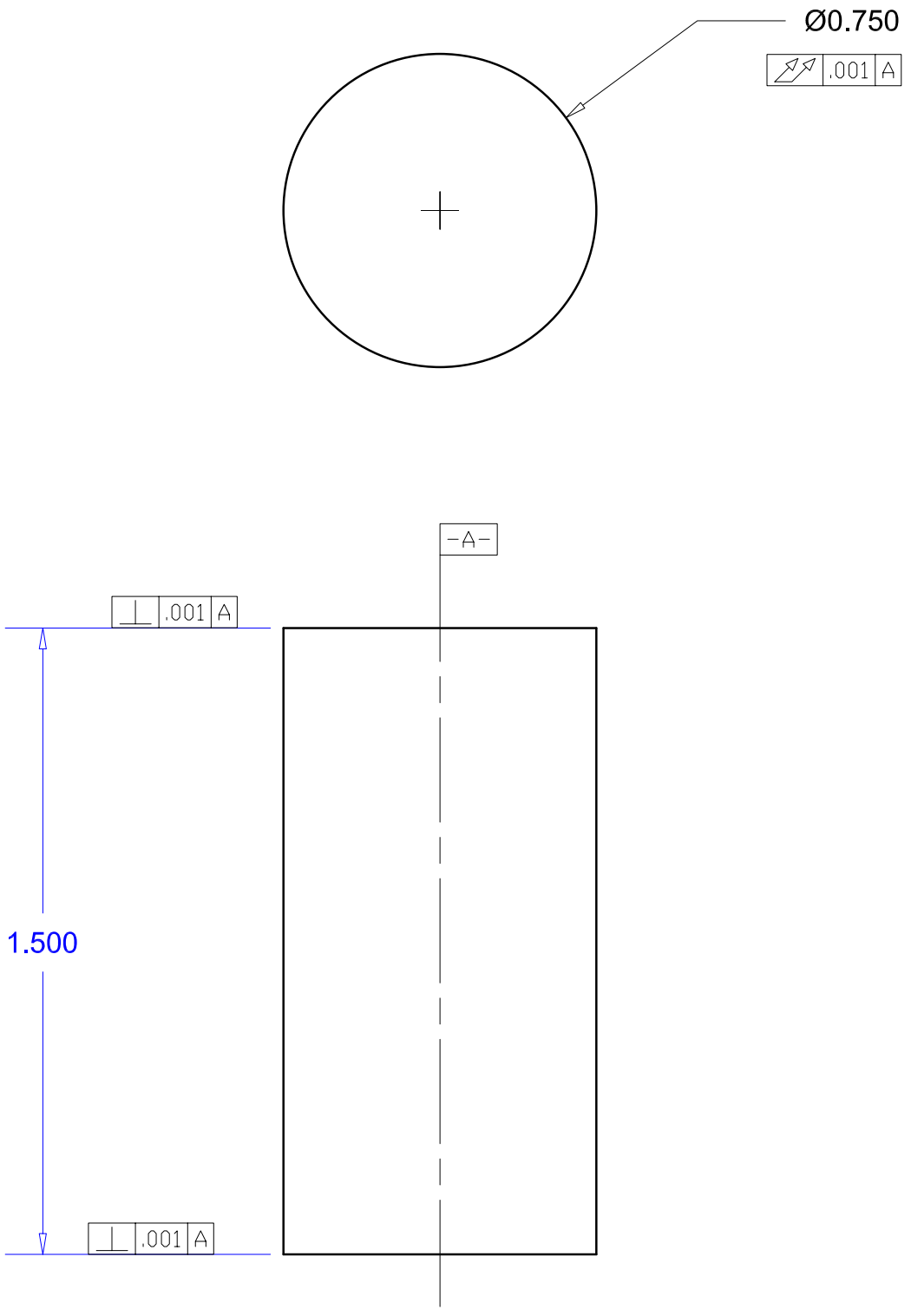

General surface finish 32-microinch or better.

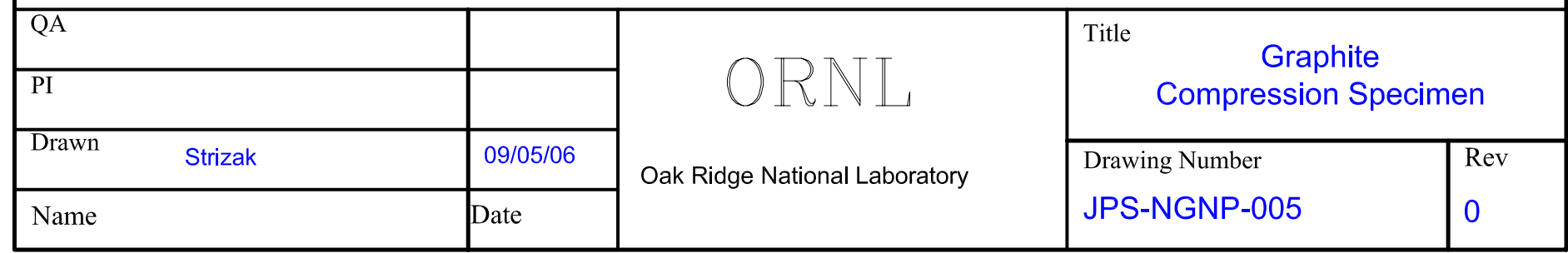




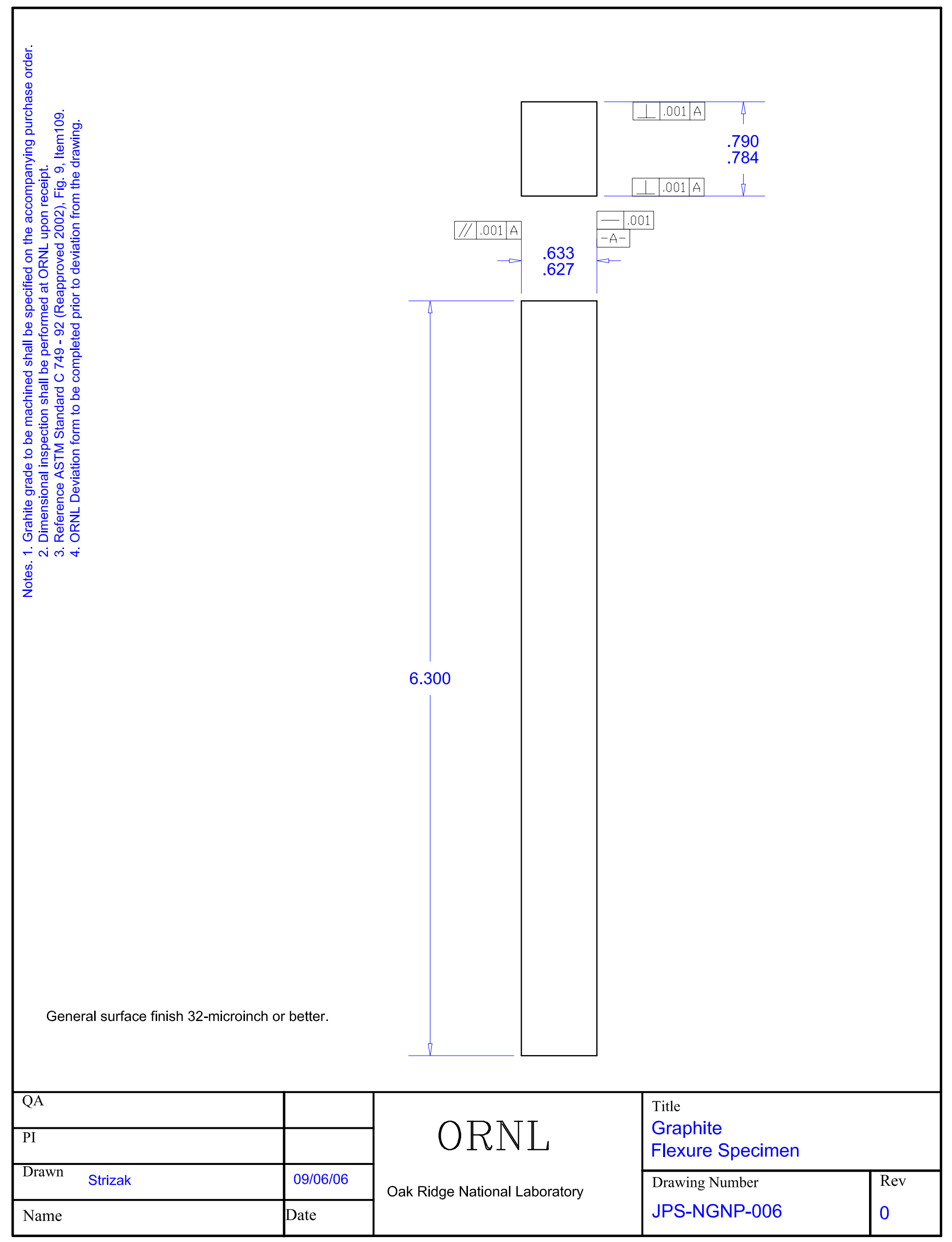




\section{Appendix 5. NBG-17 Billet Cutting Plans}




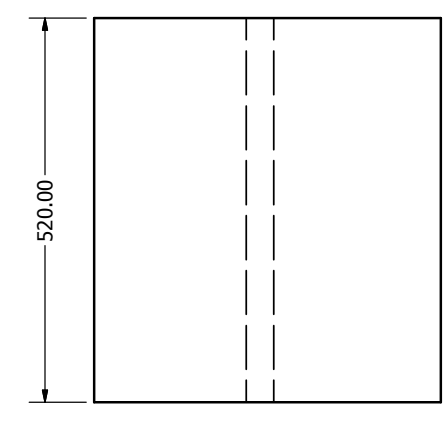

TOP

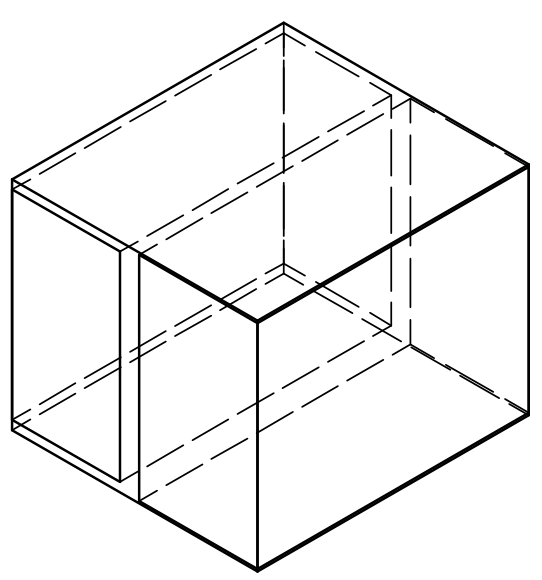

CUT OUT LEFT AND RIGHT SIDES OF BILEF
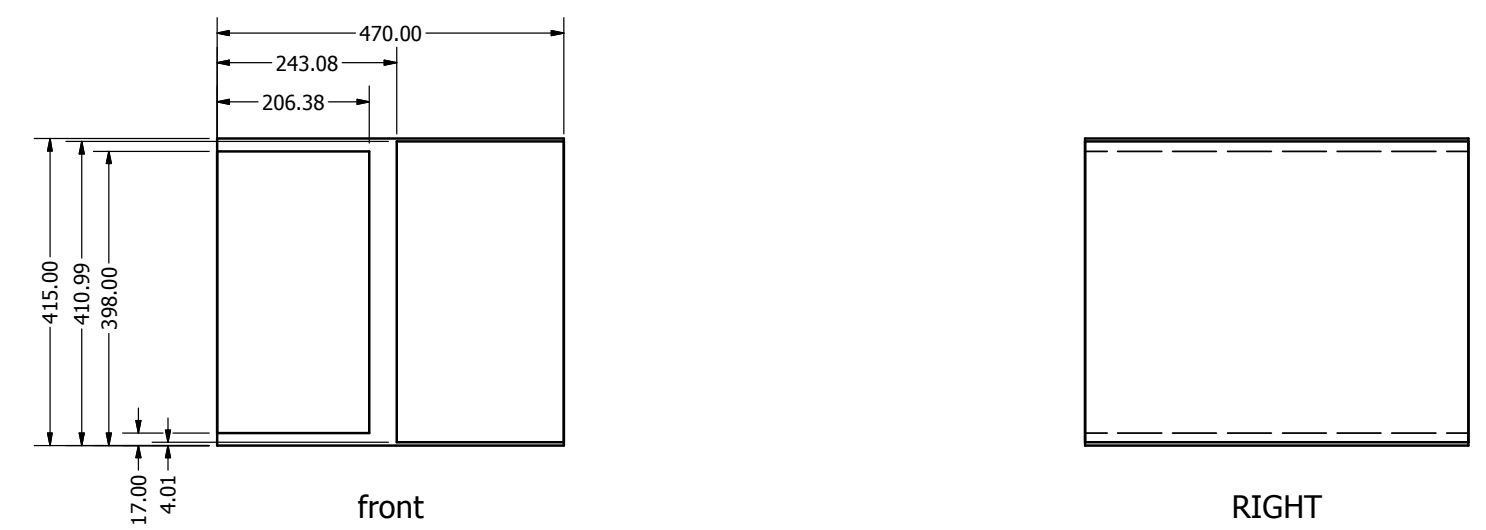

RIGHT

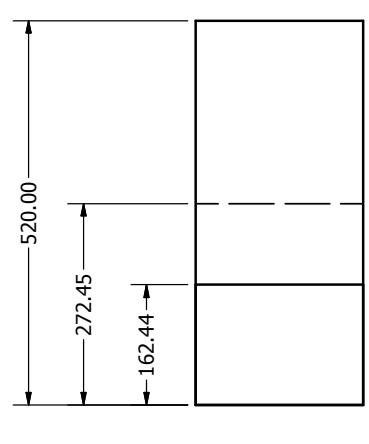

TOP

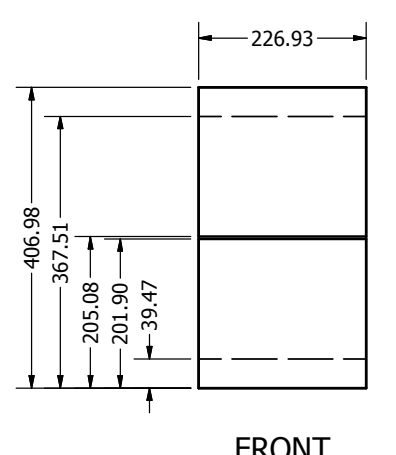

FRONT

CUT SLABS 3, 4, 5, AND 6
FROM RIGHT SIDE OF BILET
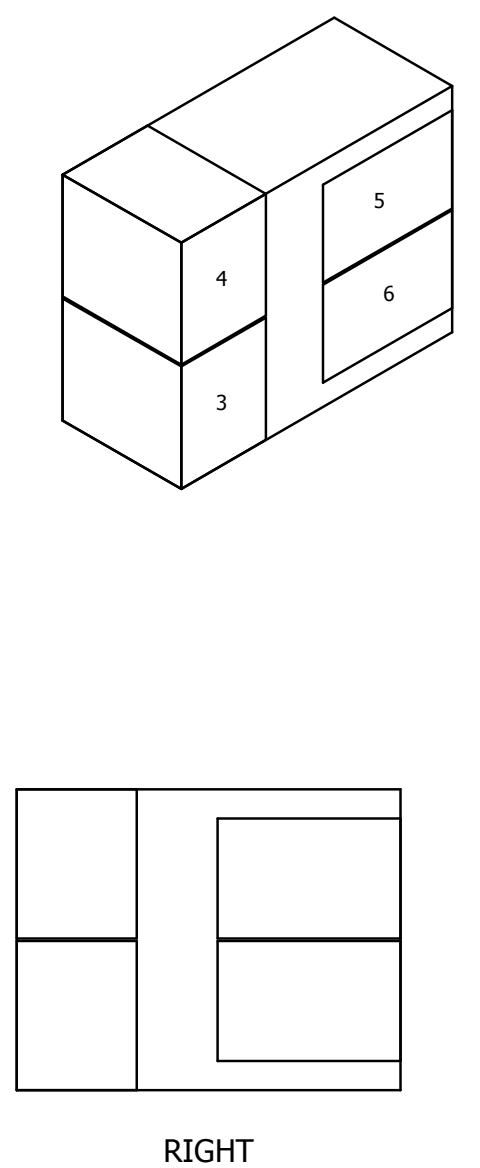

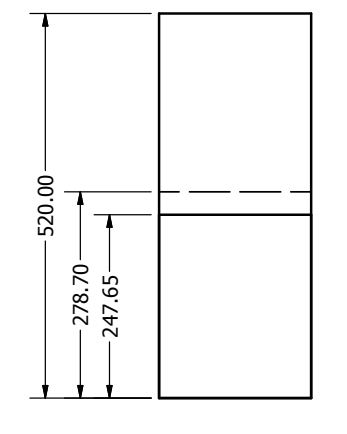

TOP

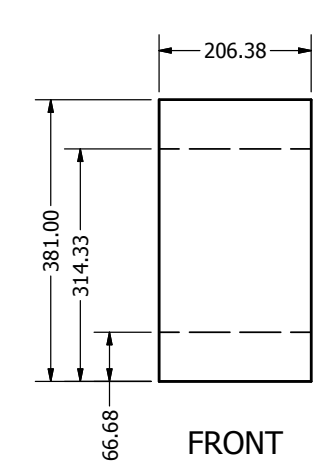

CUT SLABS 1 AND 2 FROM LEFT SIDE OF BILLET
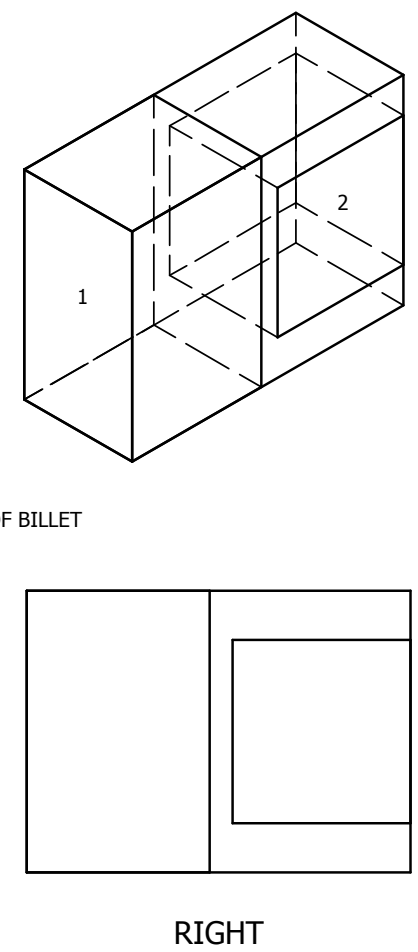

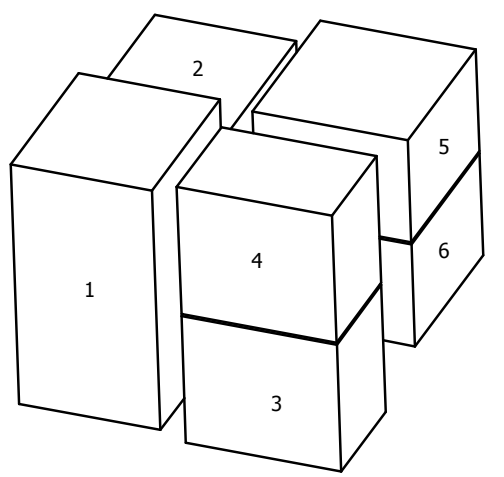

WHOLE BILLET SLABBING DIAGRAM 


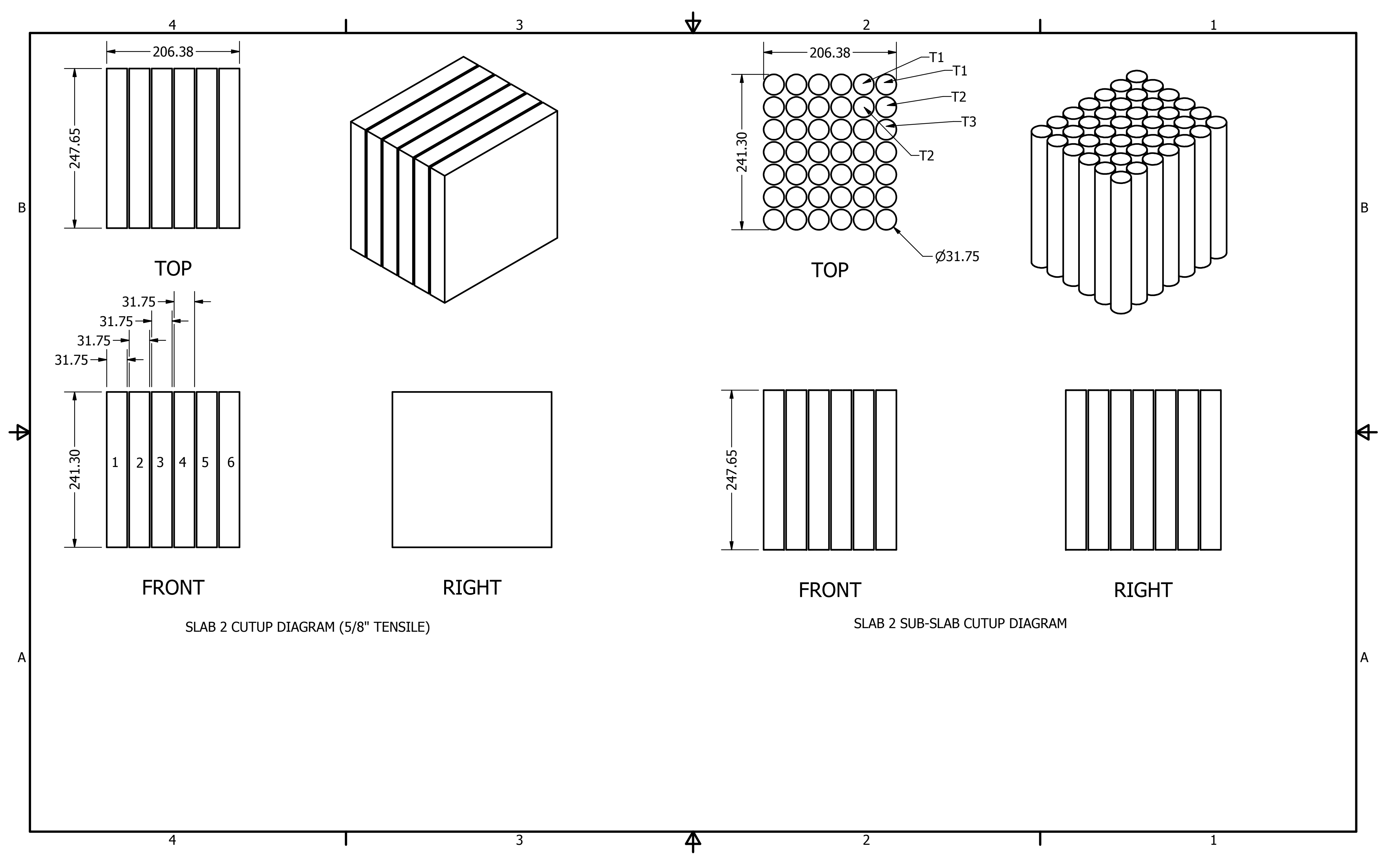




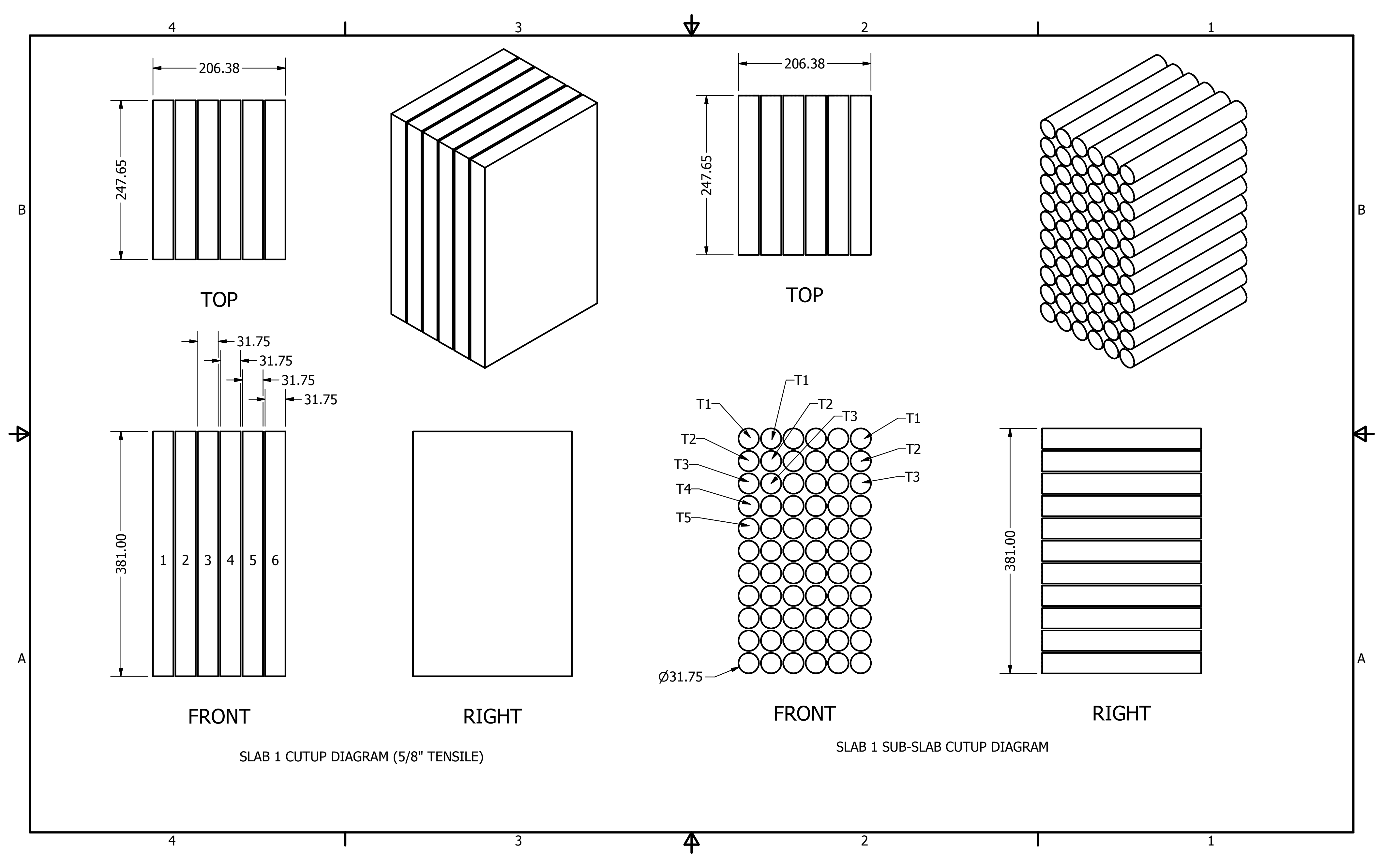




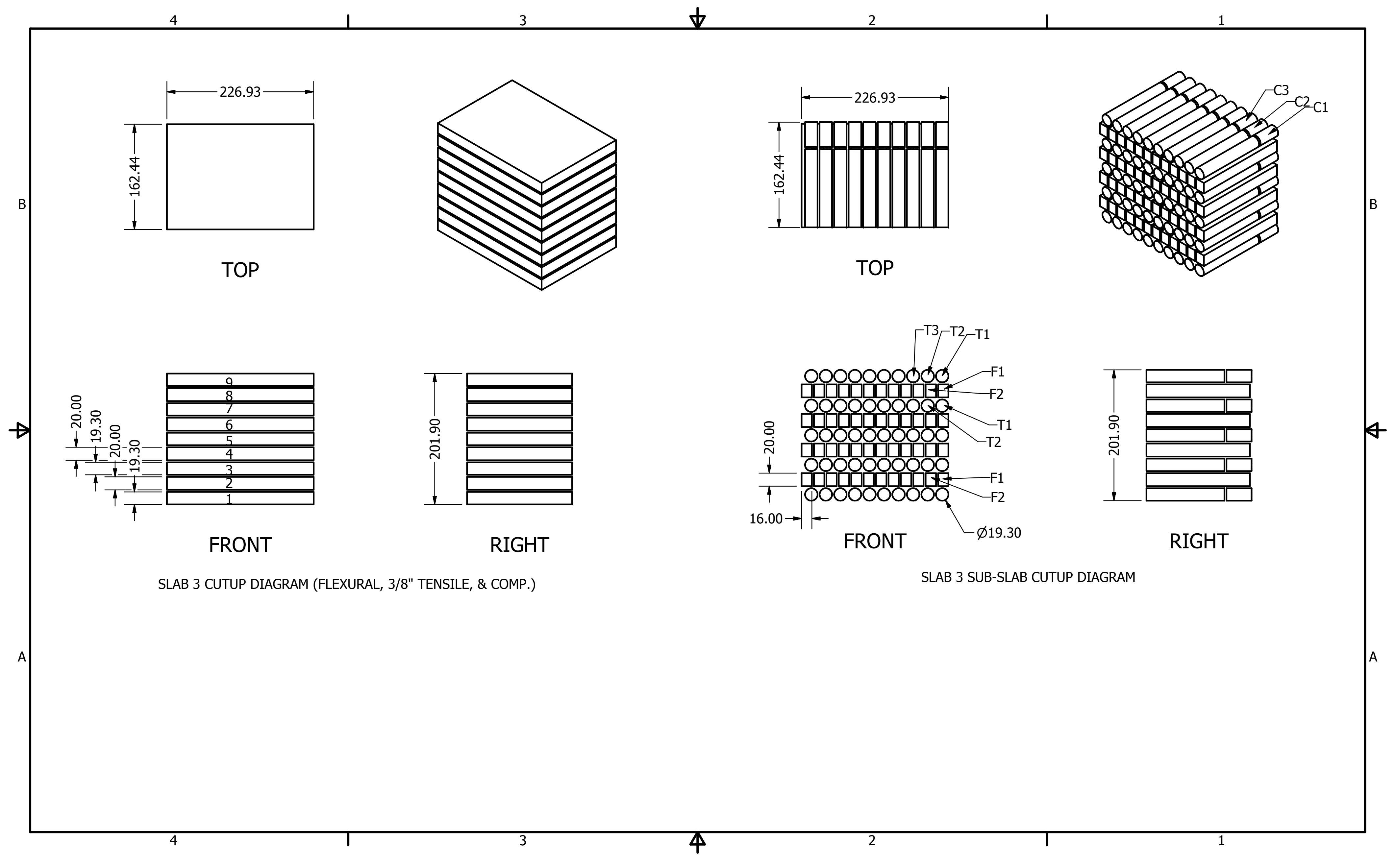




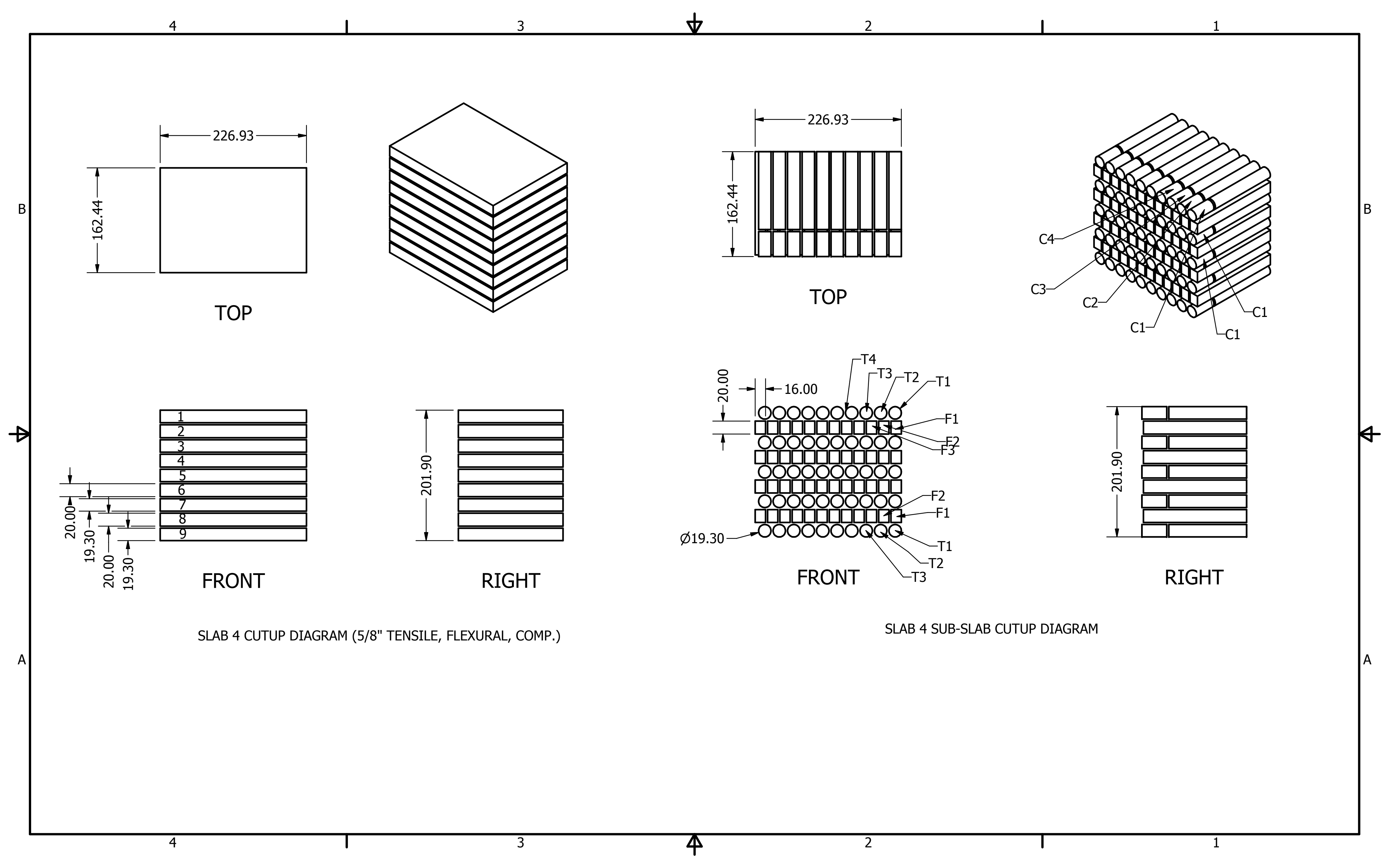




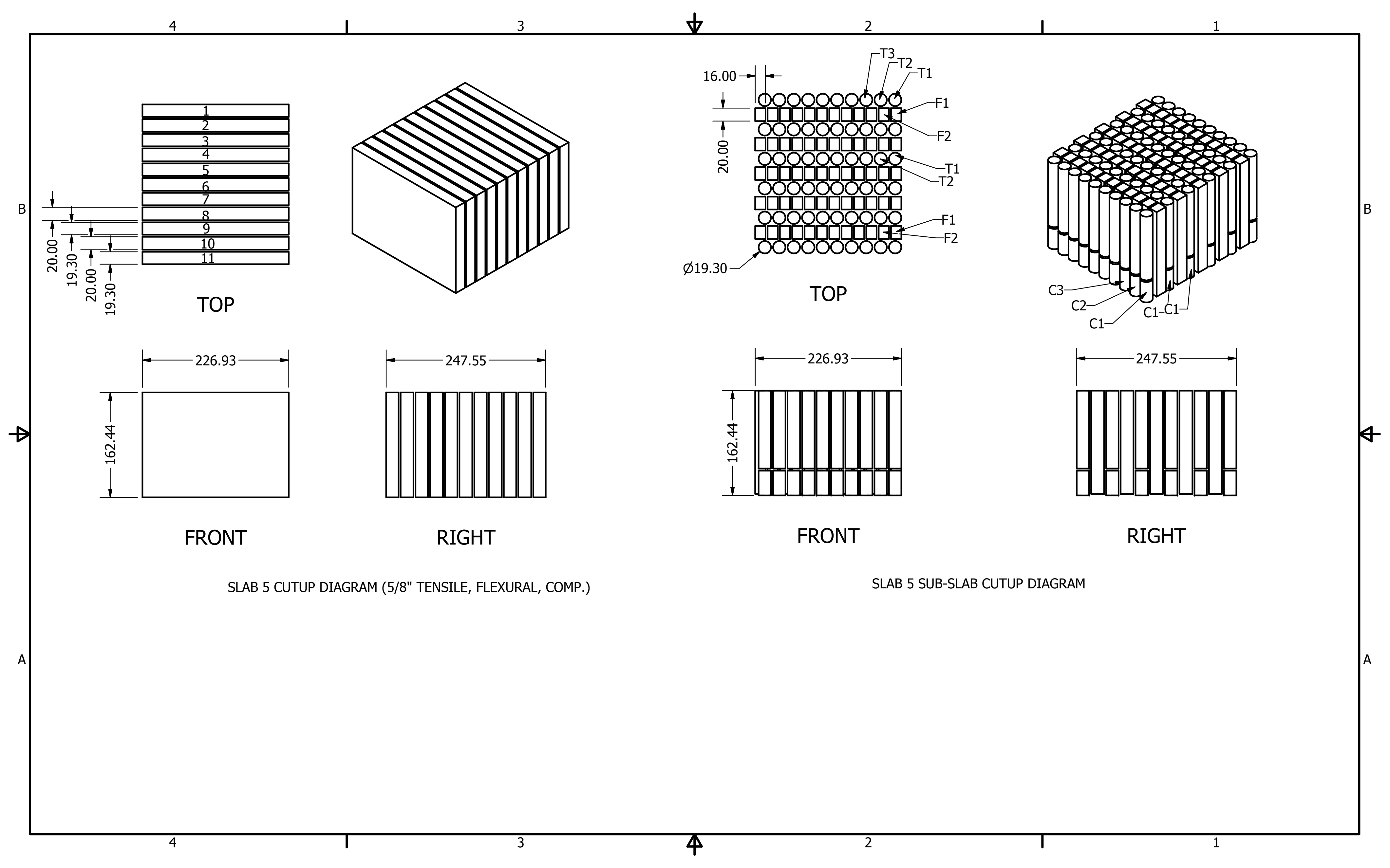




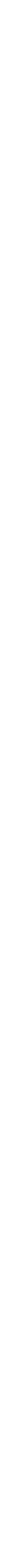


Appendix 6. NBG-18 Billet Cutting Plans 

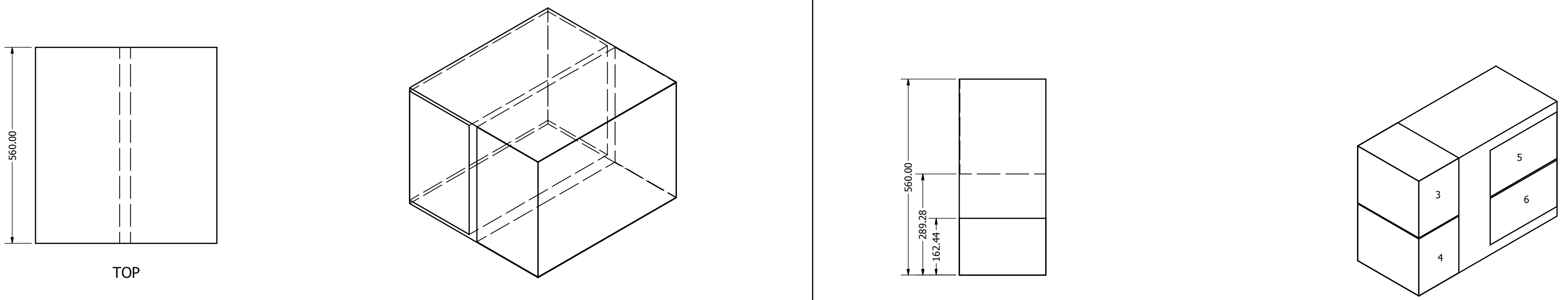

CUT BLLET INTO LEFT AND RIGHT BLOCKS
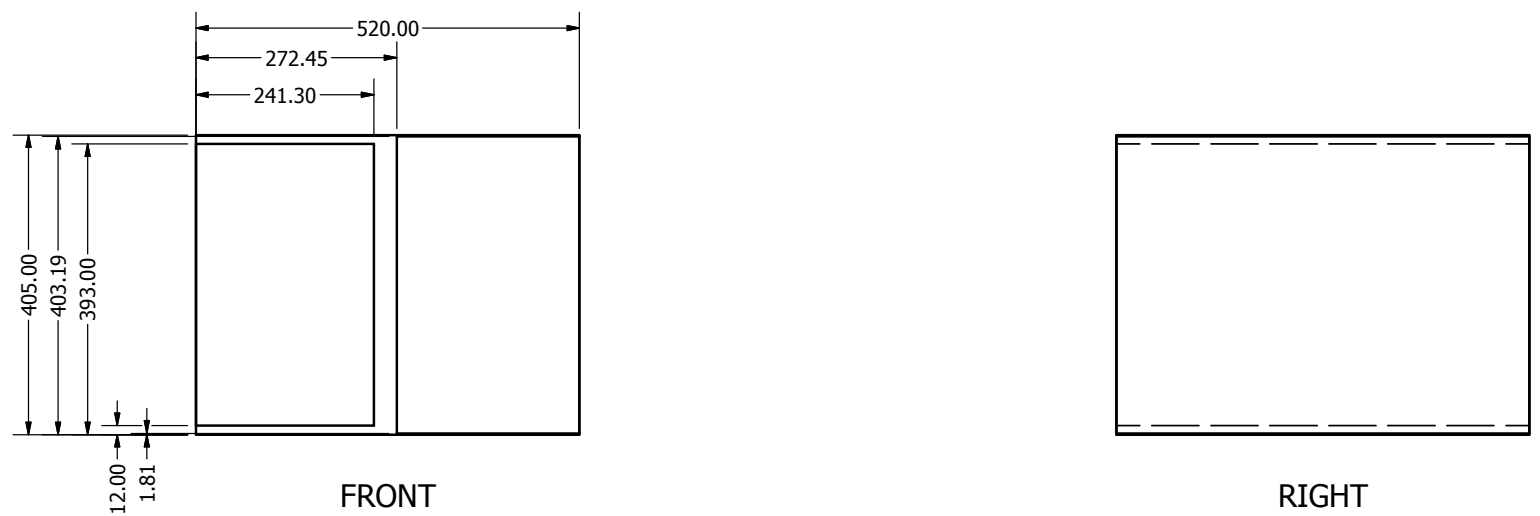

RIGHT

CUU SLABS 3, 4, 5, AND 6 FROM RIGHT

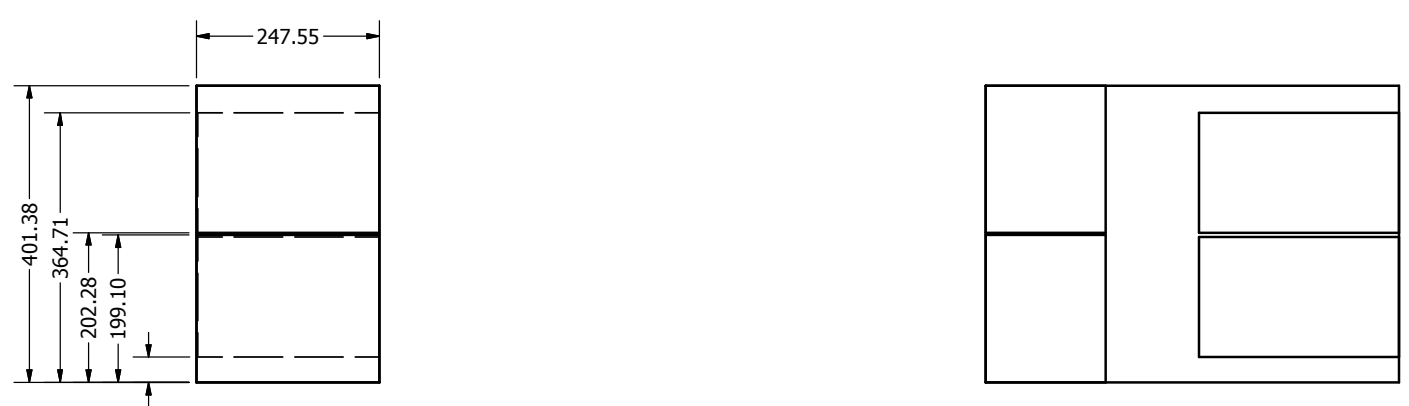

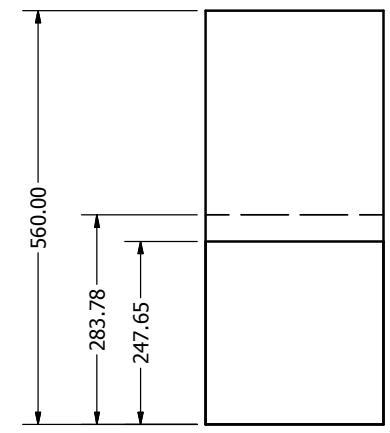

FRONT
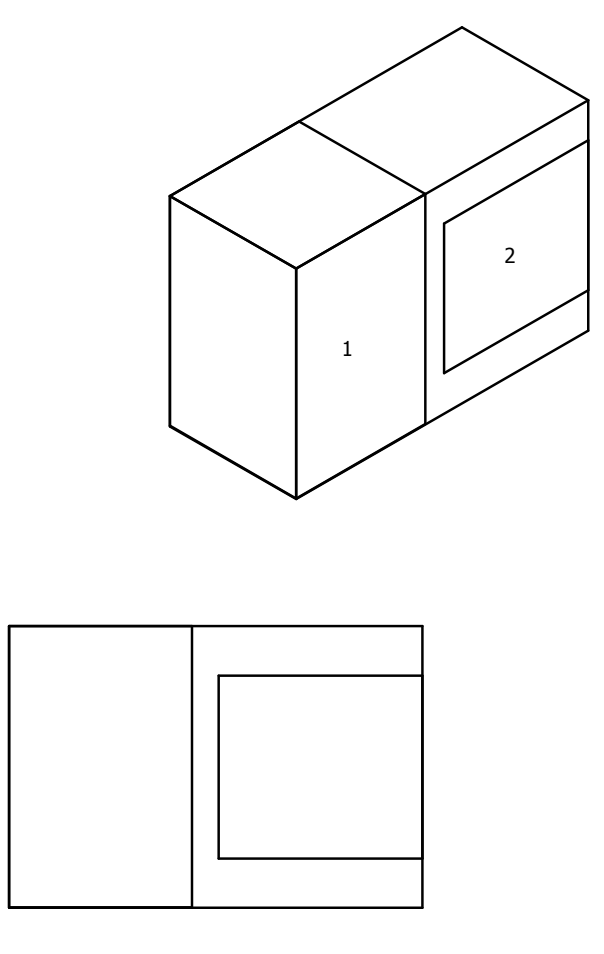

CUT SLABS 1 AND 2 FROM LEFT SIDE OF BILLT

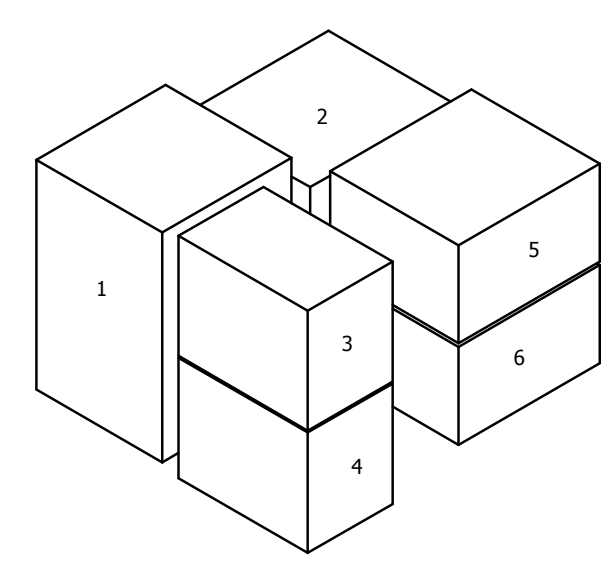

WHOLE BILLET SLABS ISO
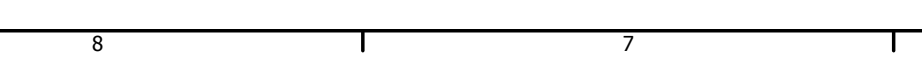


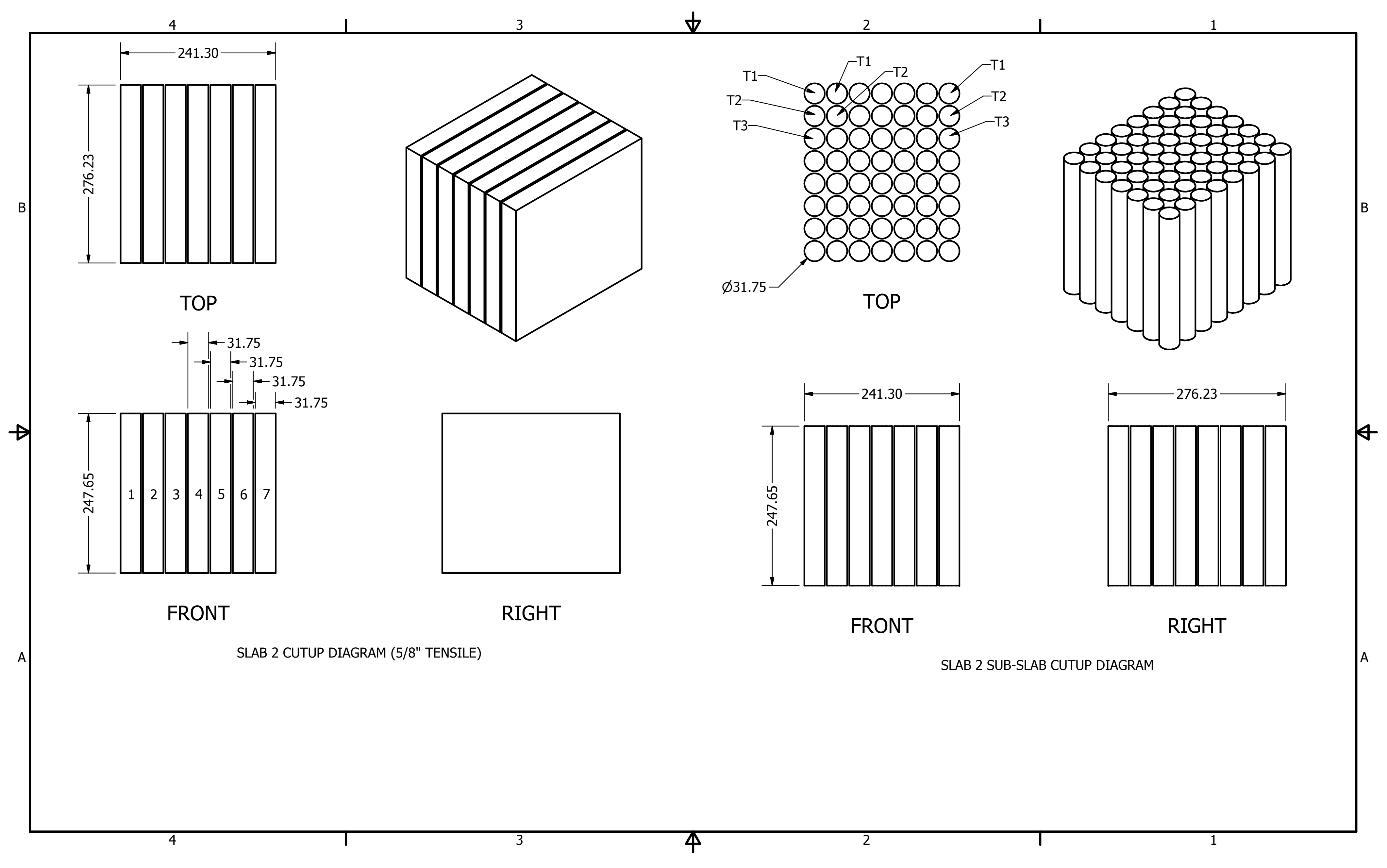




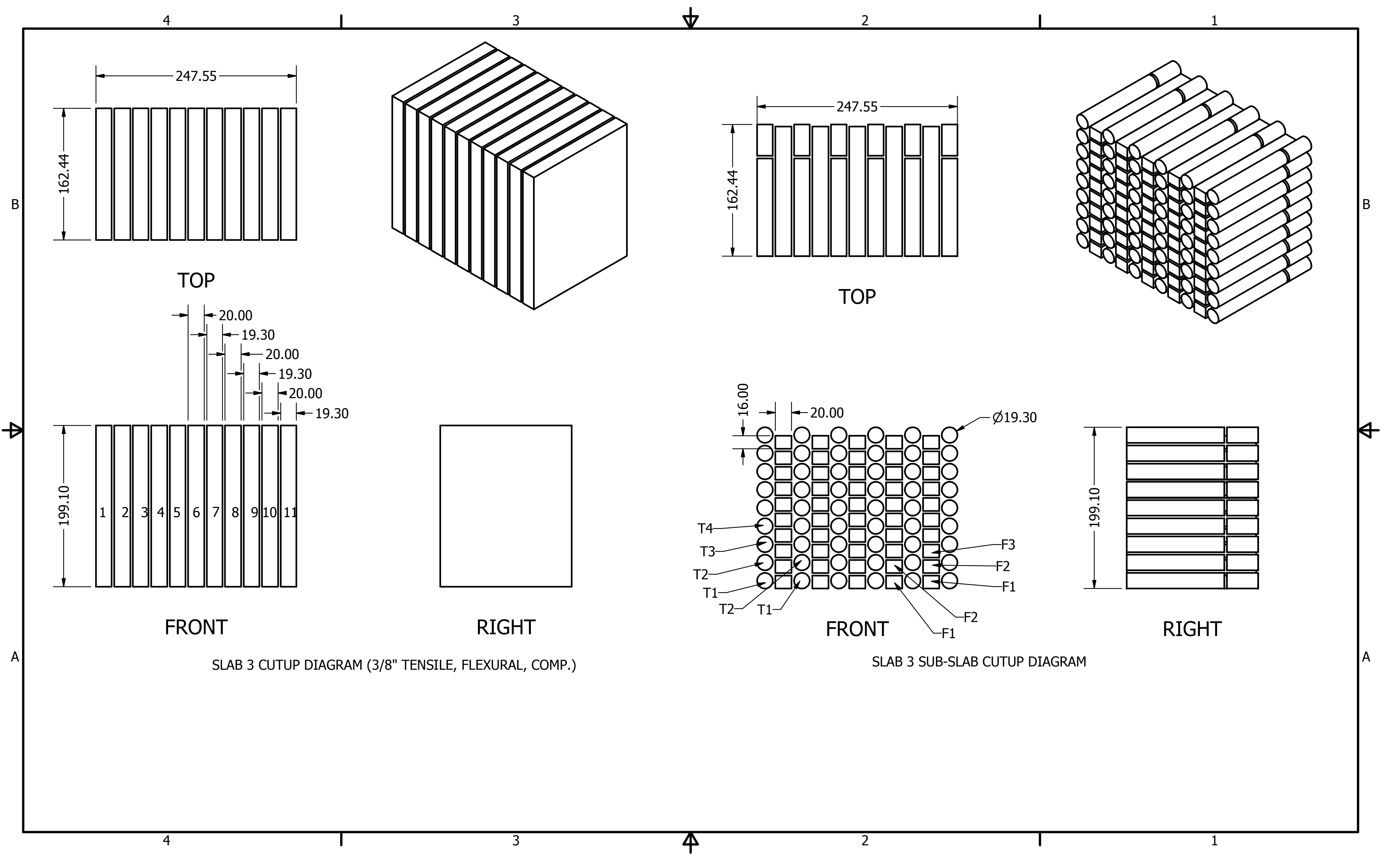




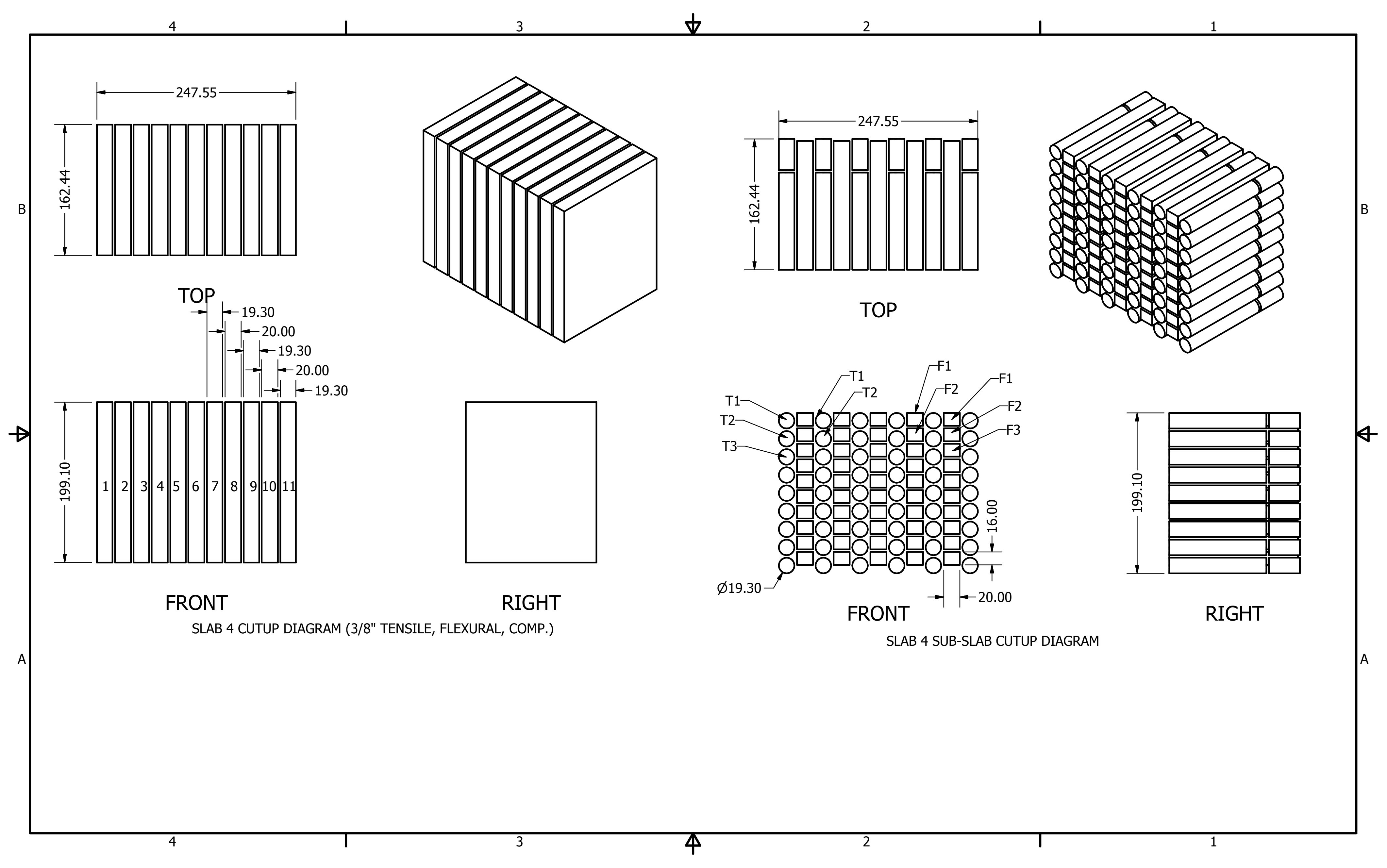




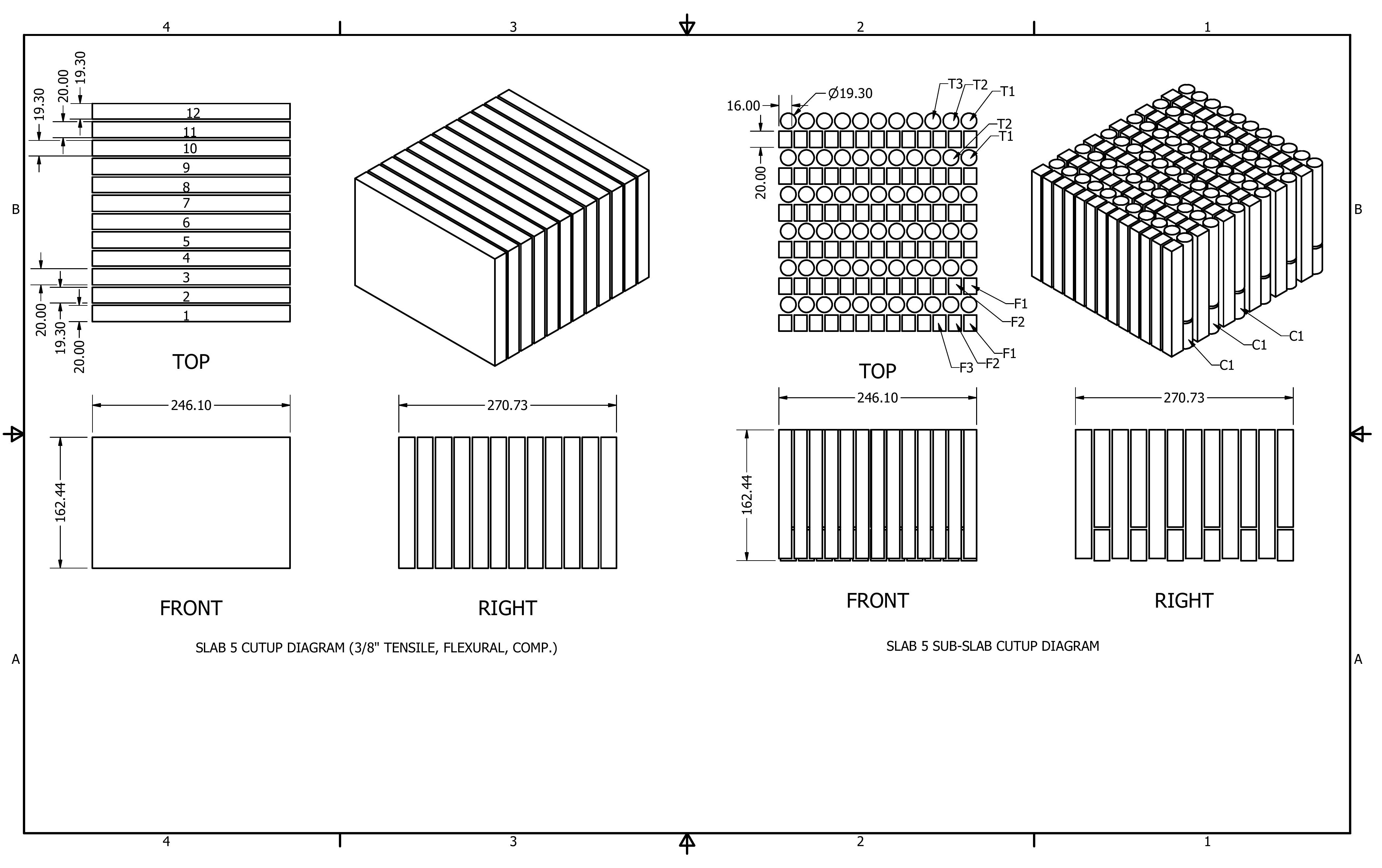




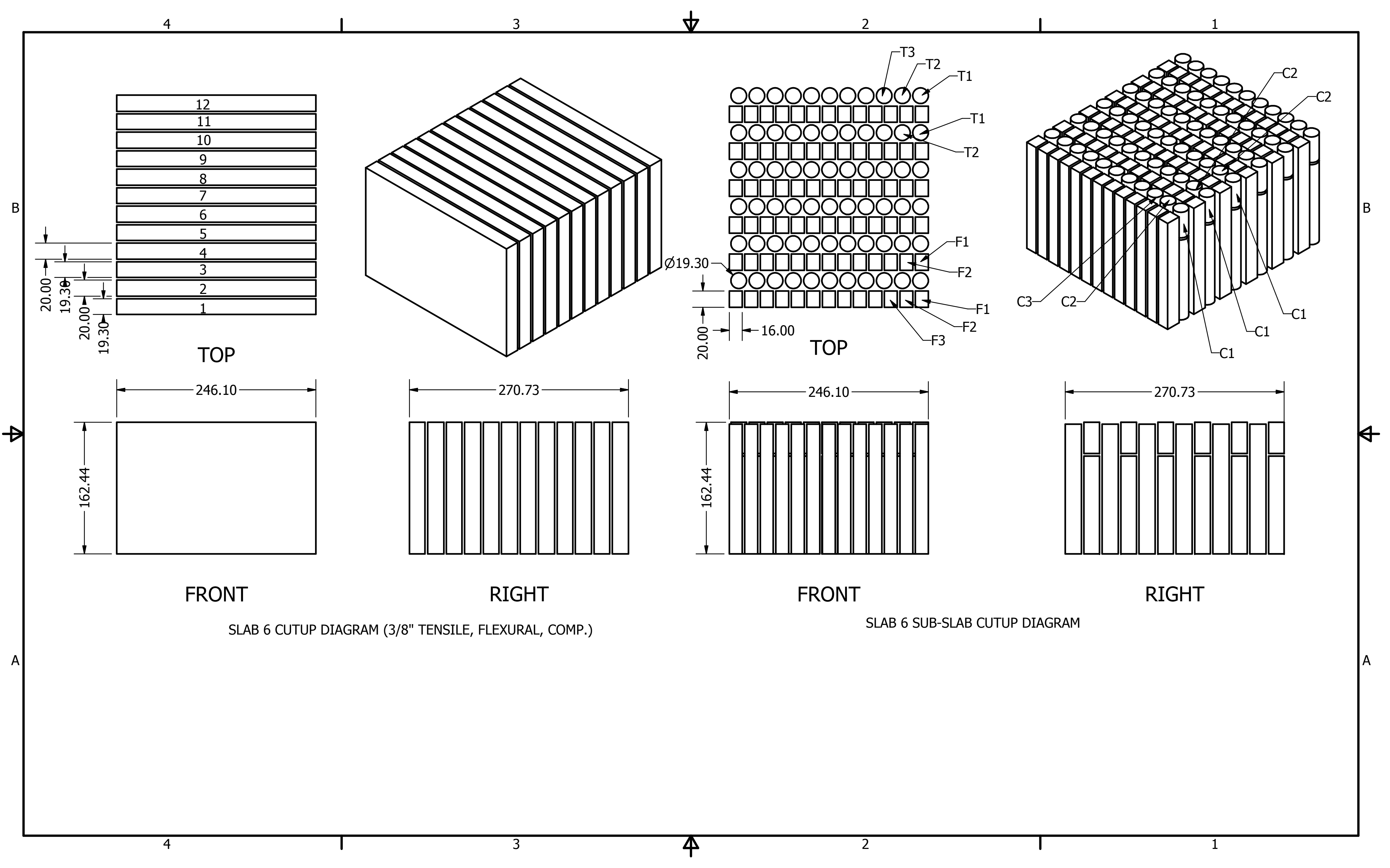


Appendix 7. PCEA Billet Cutting Plans 


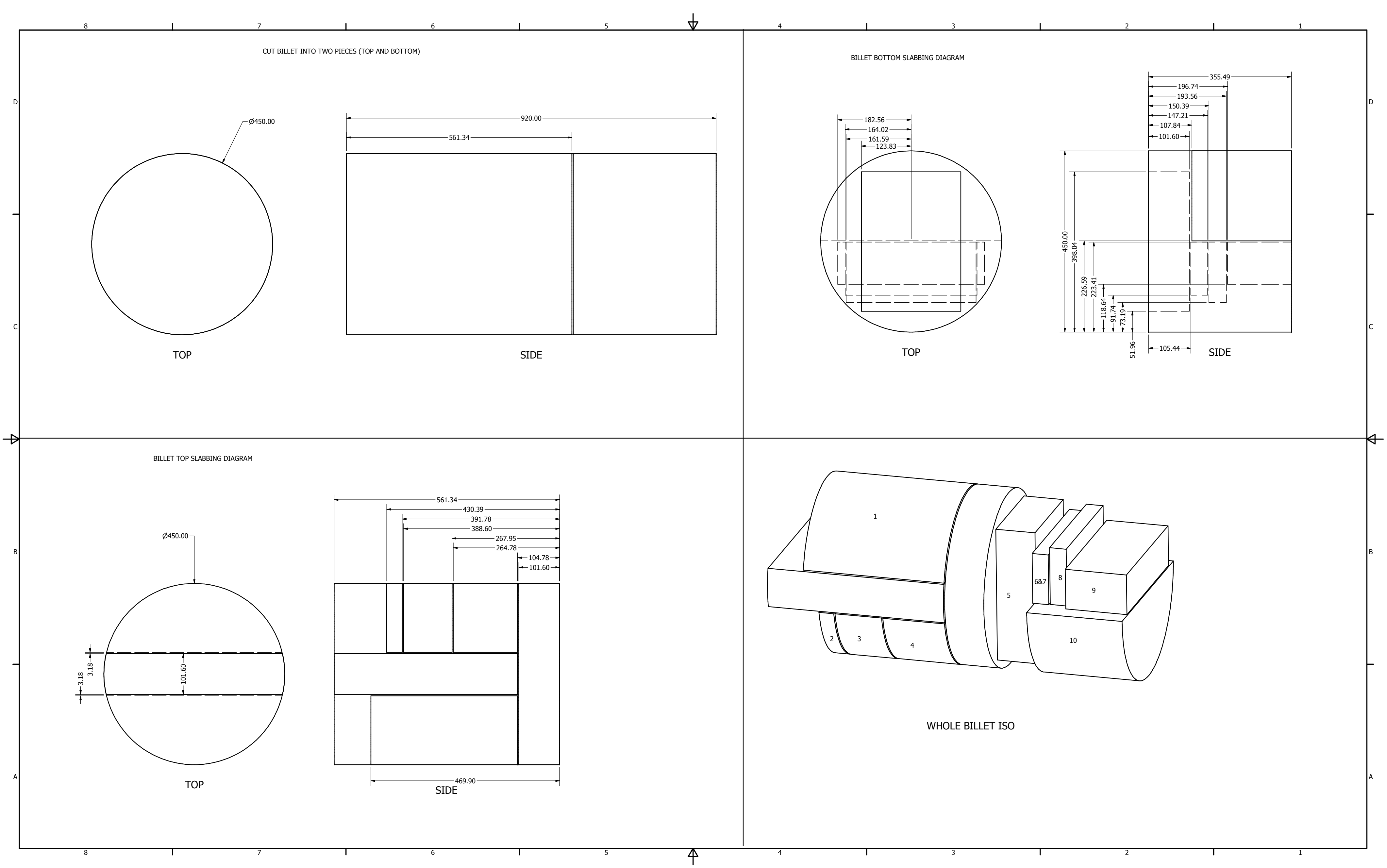




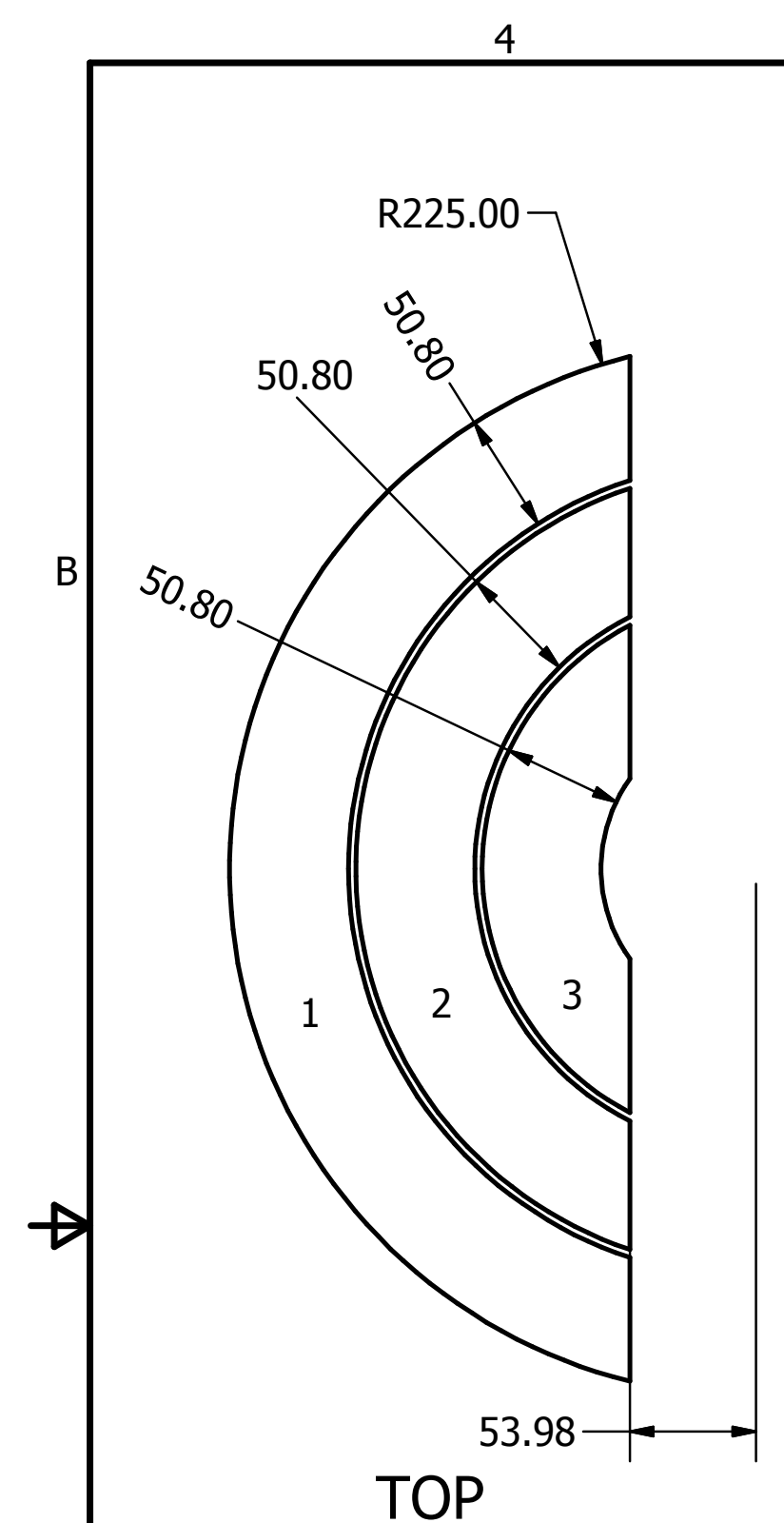

SLAB 1 CUTUP

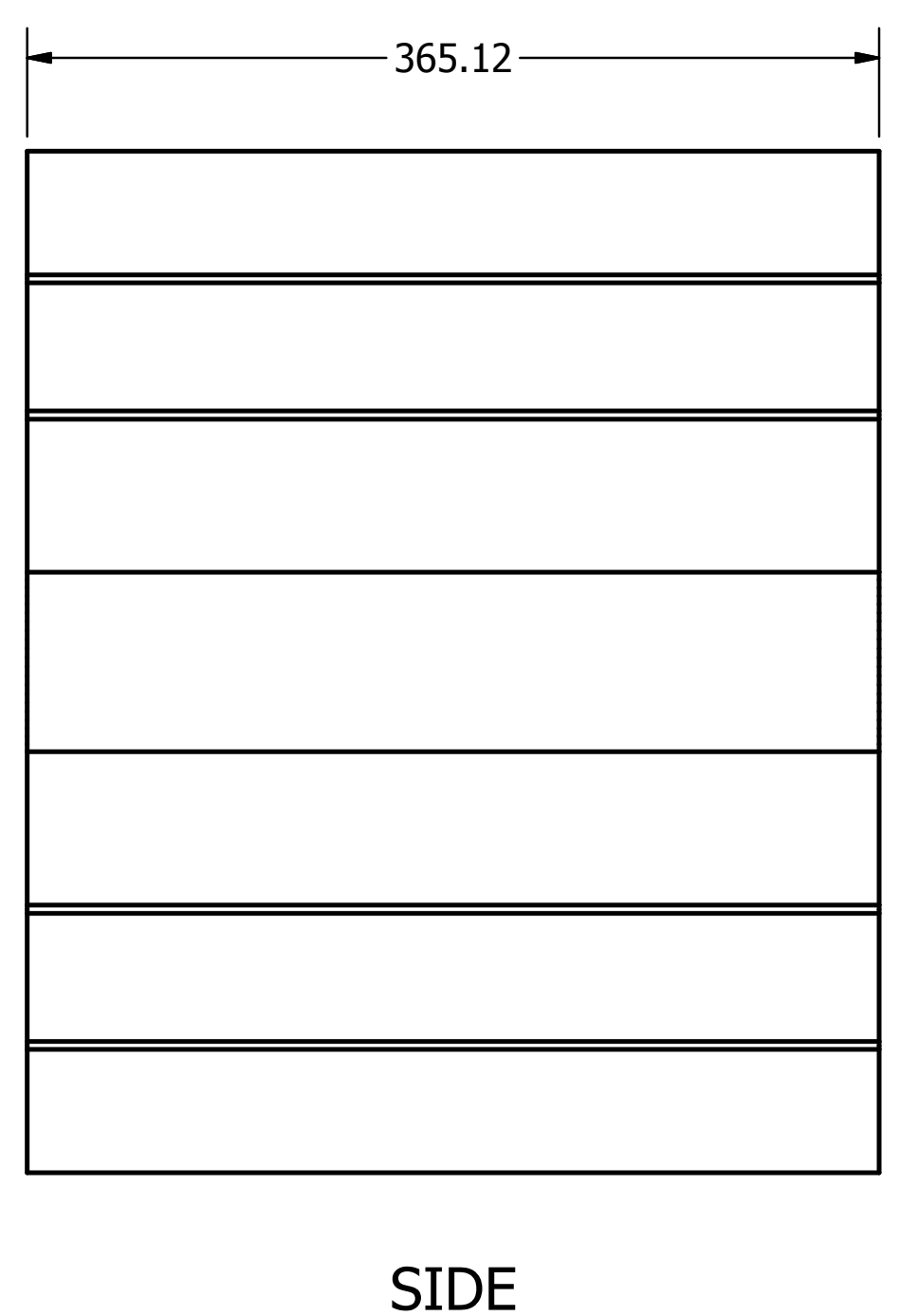

SIDE

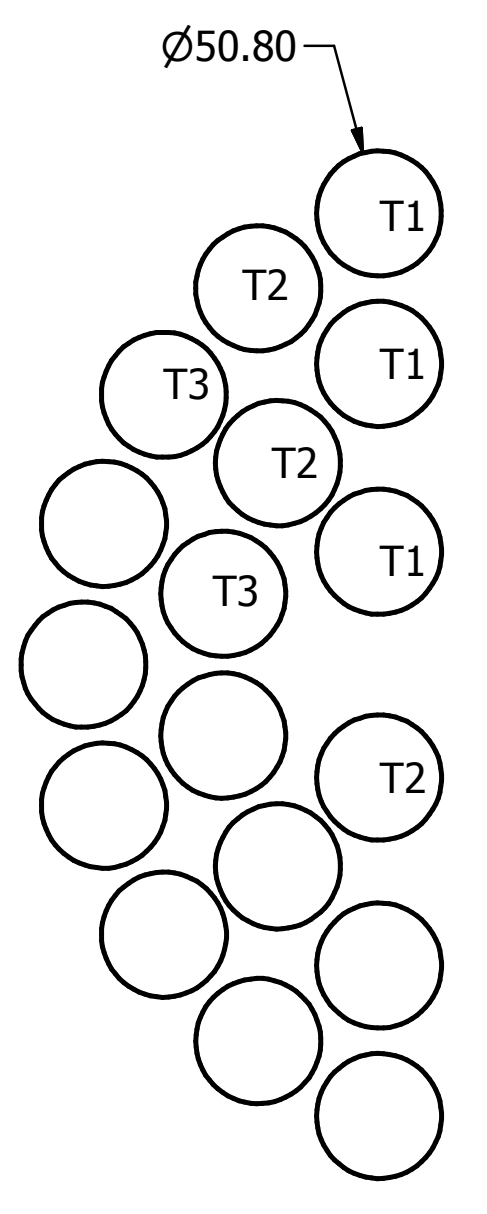

TOP

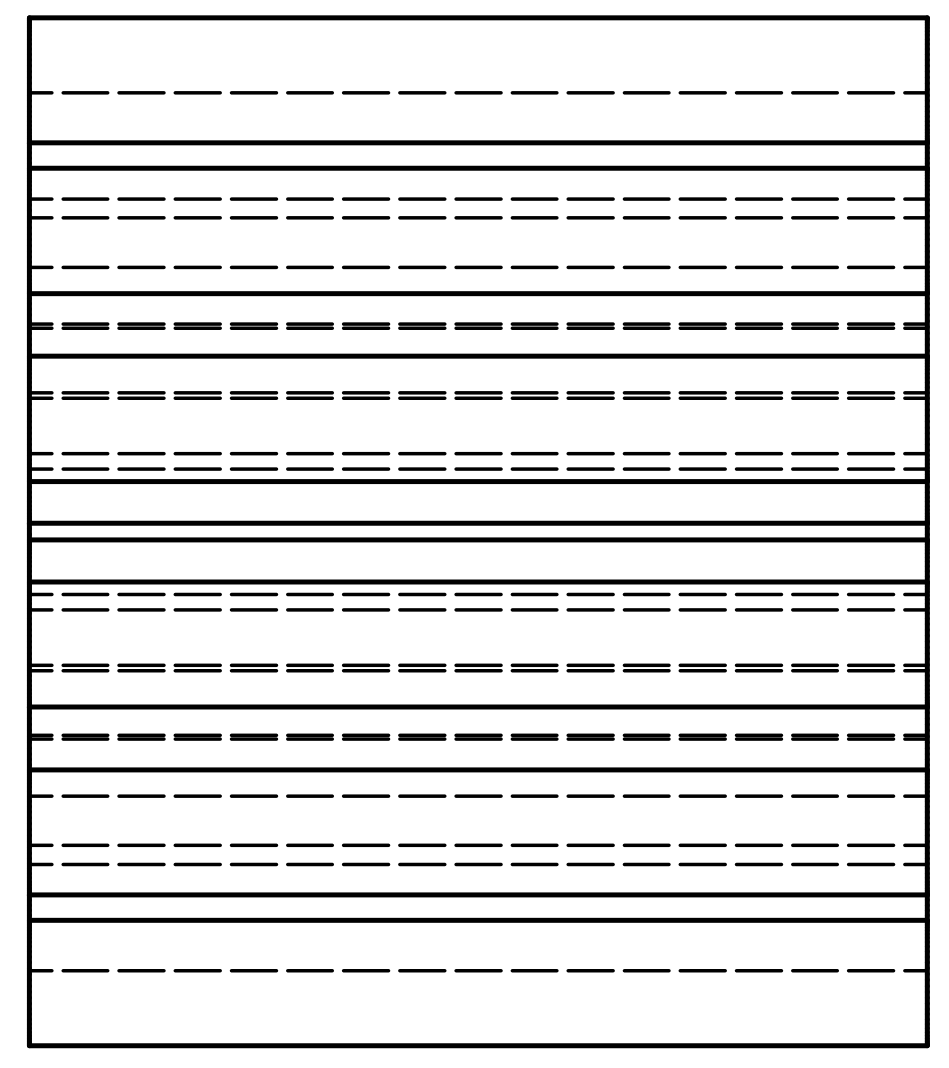

SIDE

SLAB 1 SUB-SLAB CUTUP 


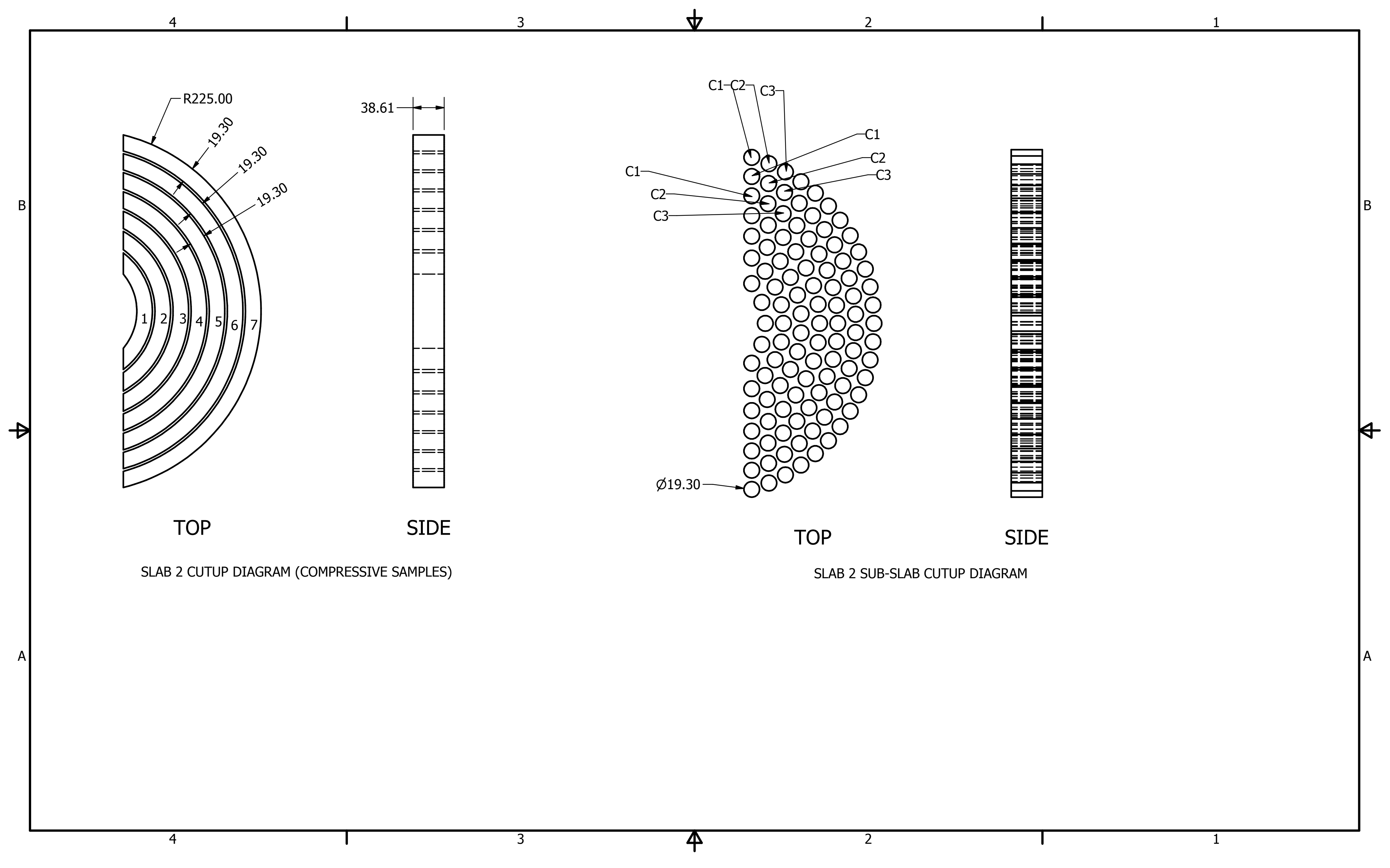




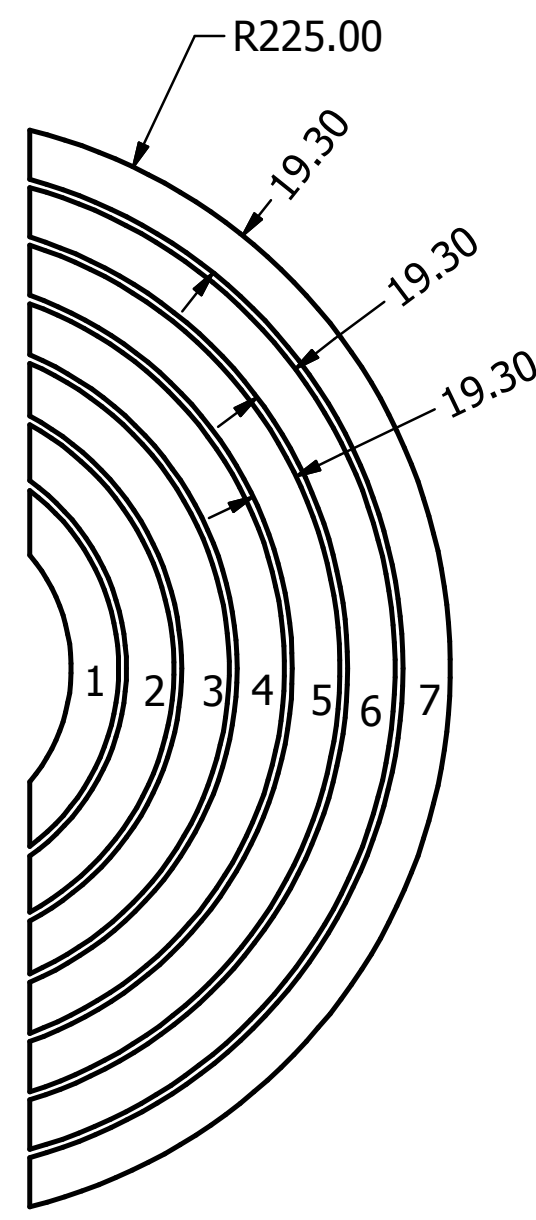

TOP

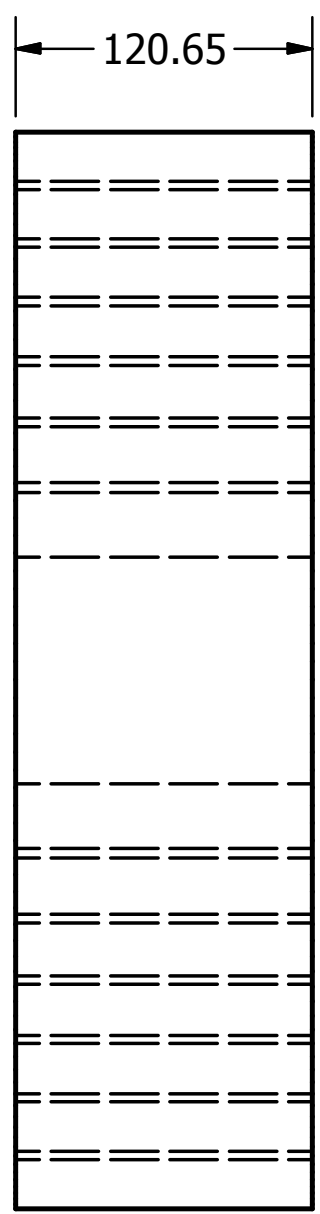

SIDE

SLAB 3 CUTUP DIAGRAM (3/8" TENSILE)

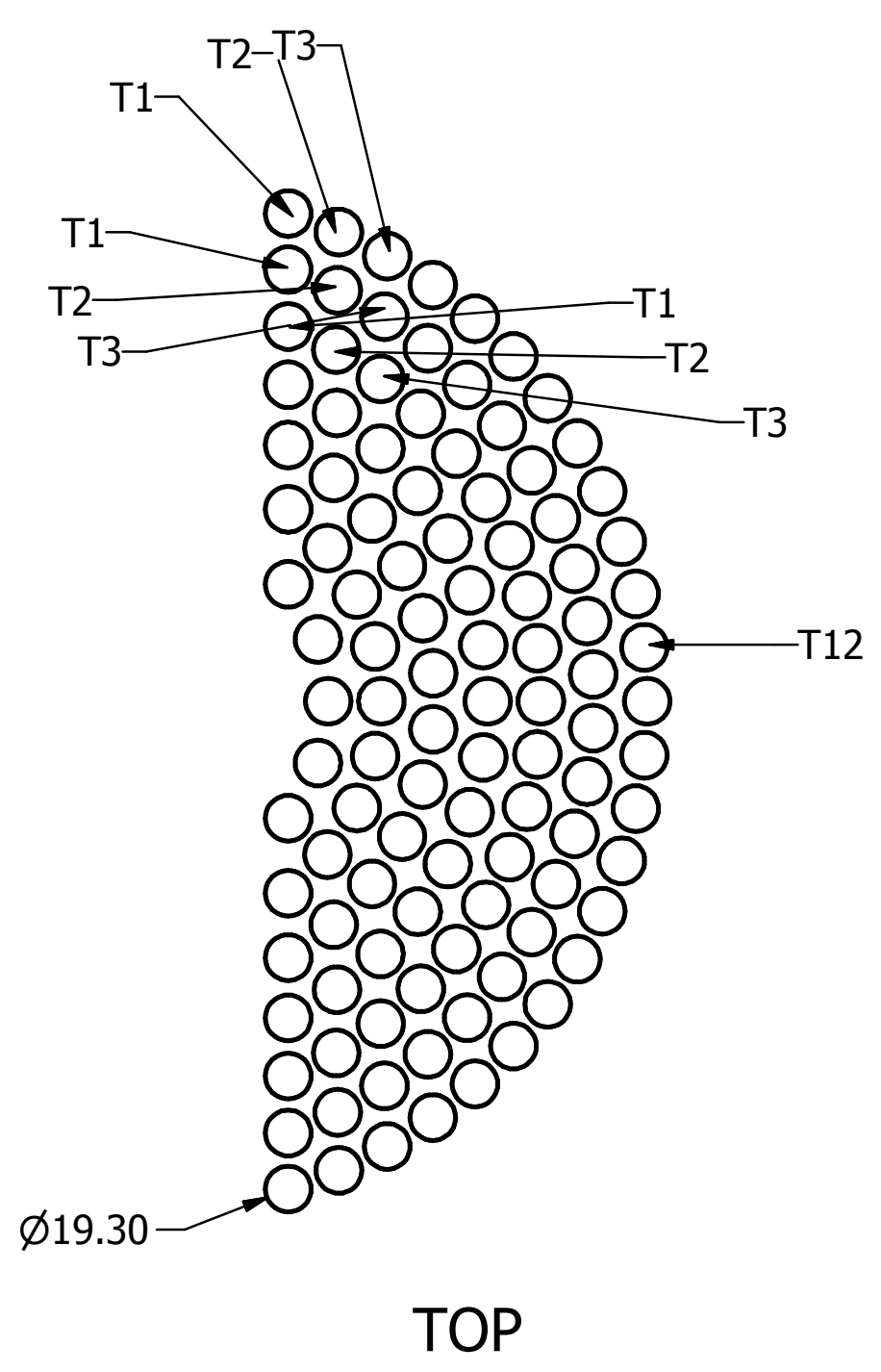

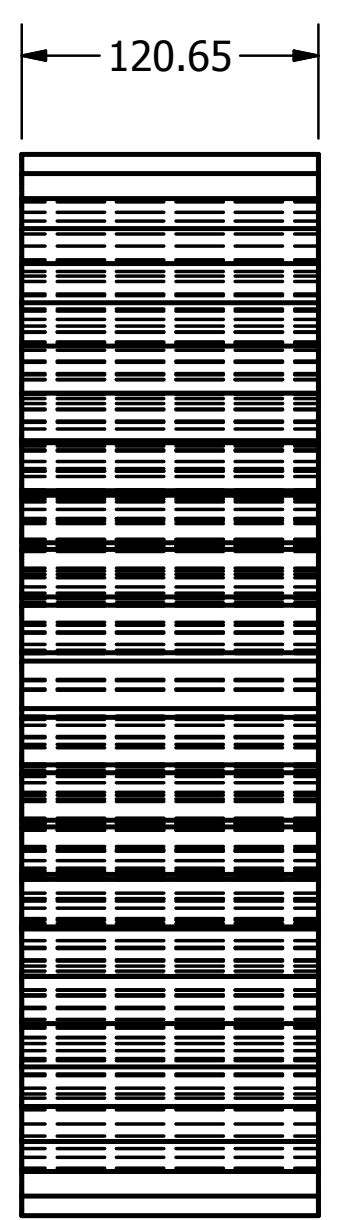

SIDE

SLAB 3 SUB-SLAB CUTUP DIAGRAM 


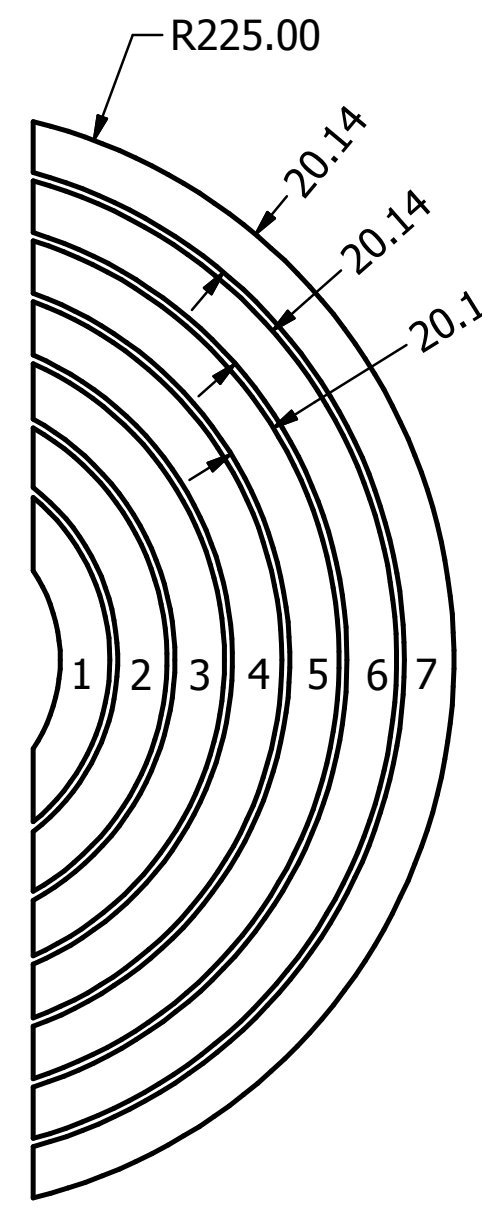

TOP

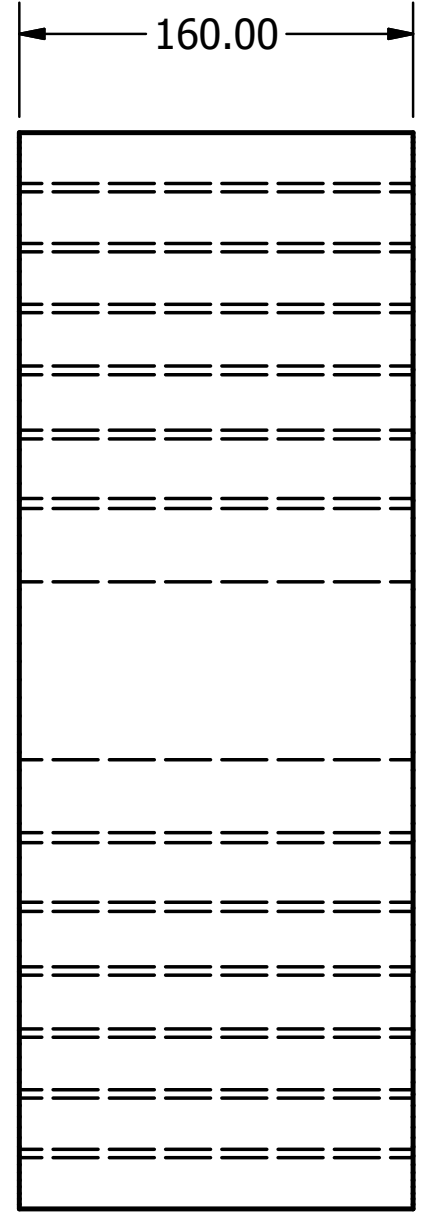

SIDE

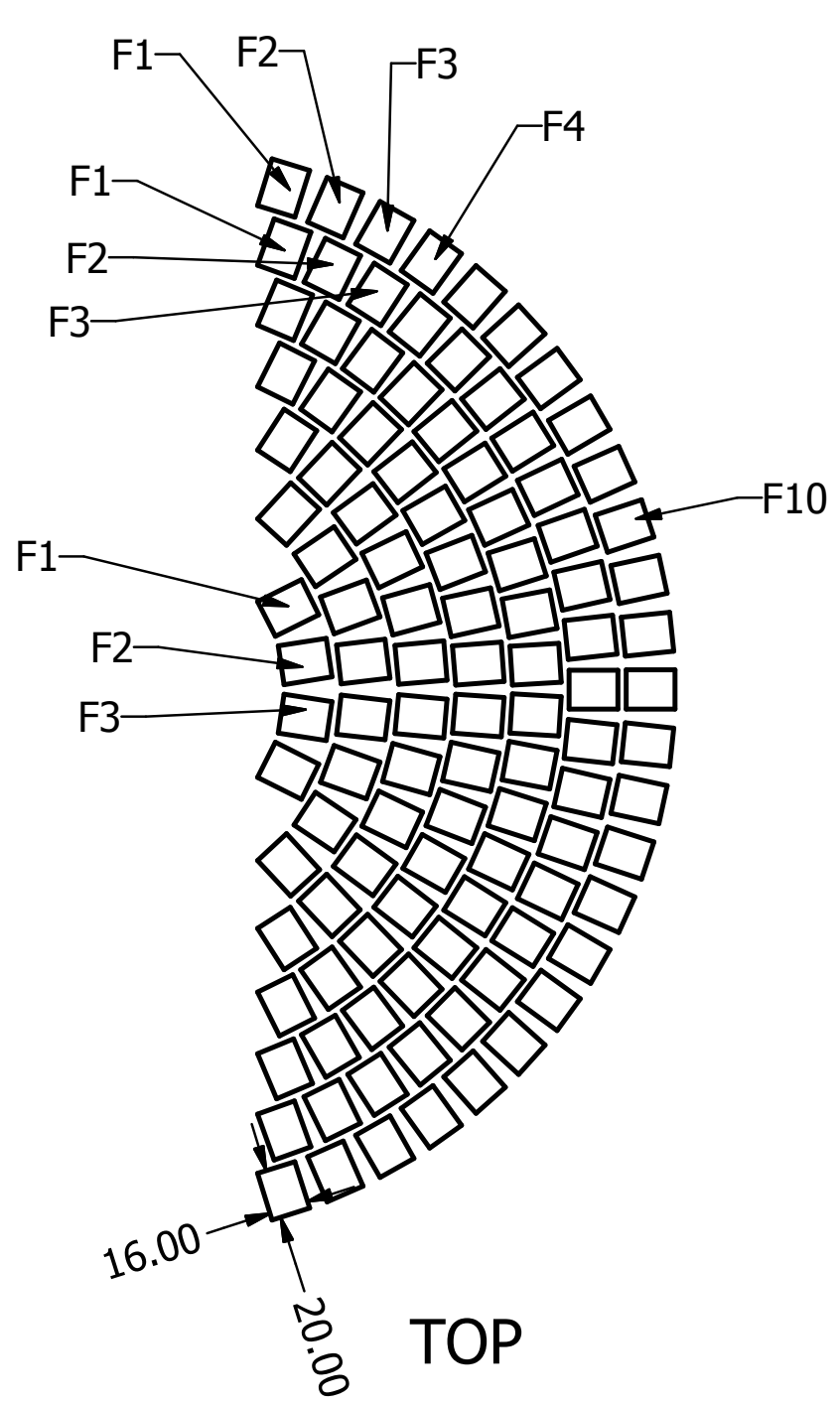

SLAB 4 SUB-SLAB CUTUP

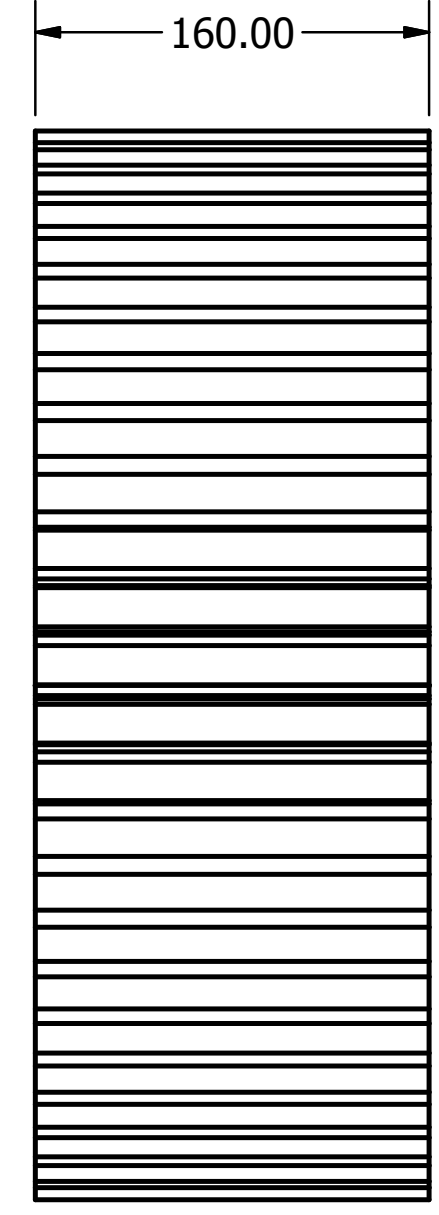

SIDE

SLAB 4 CUTUP DIAGRAM (FLEXURAL) 


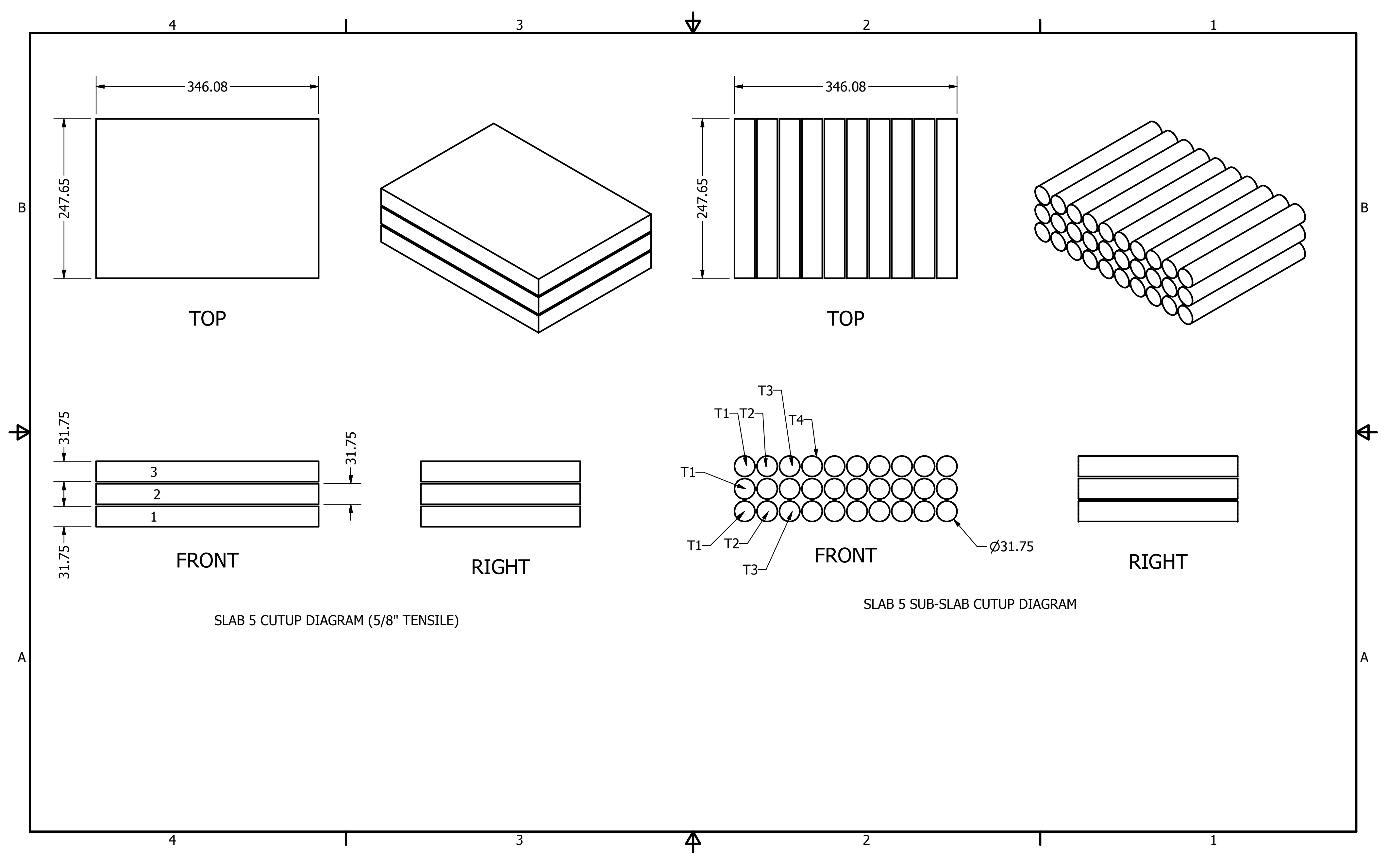




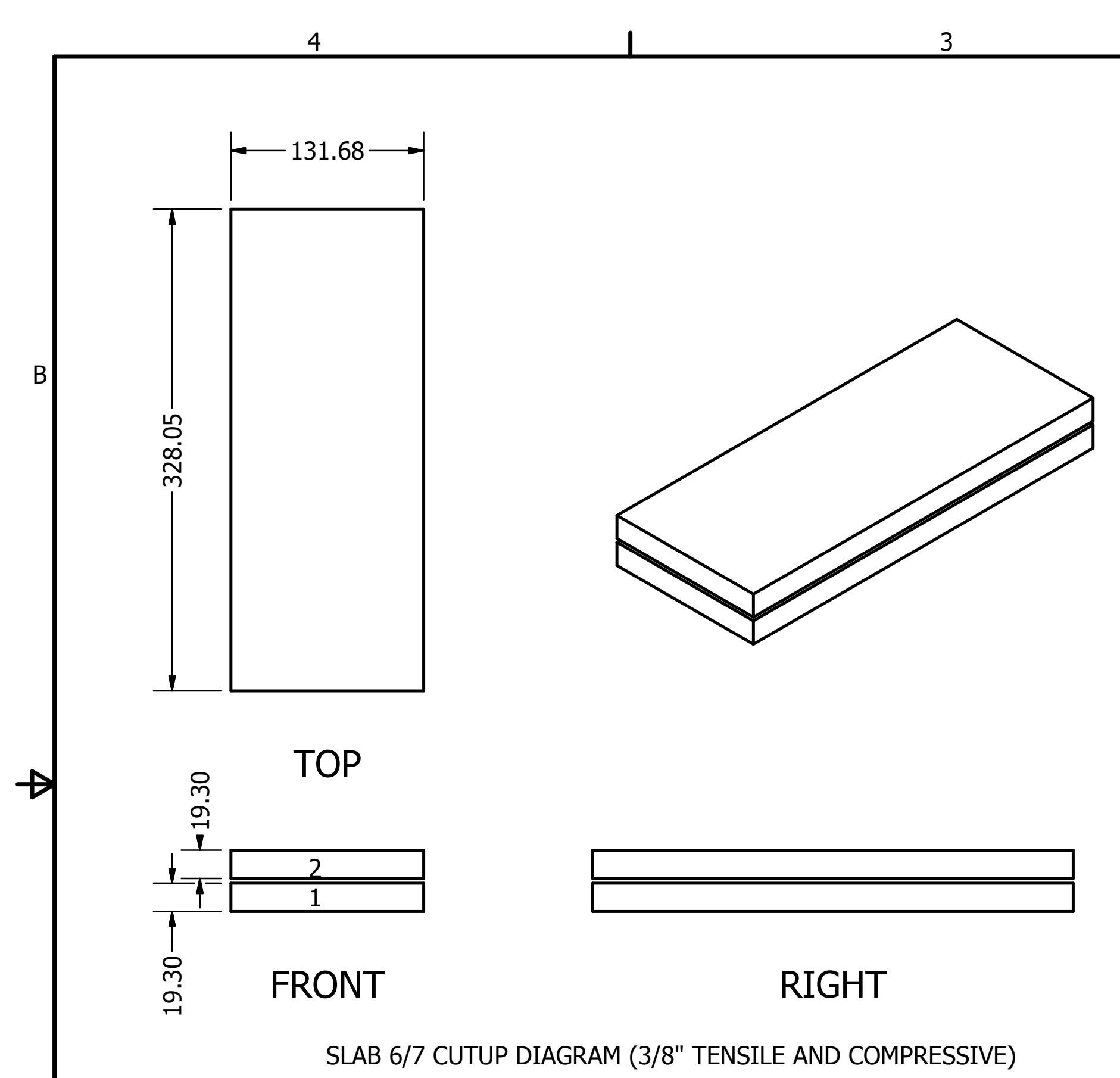

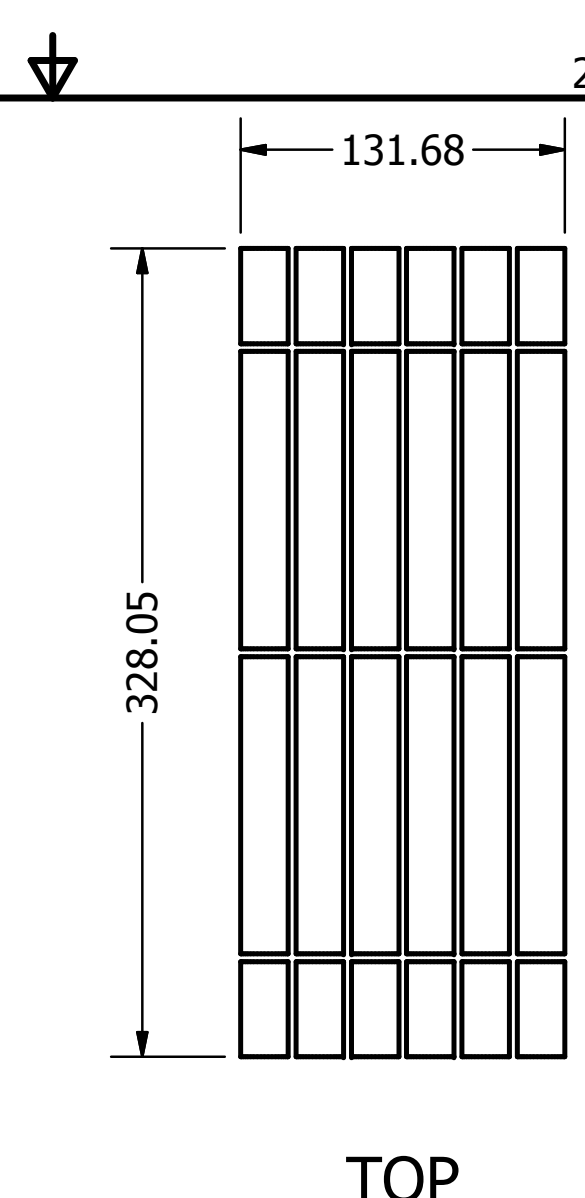

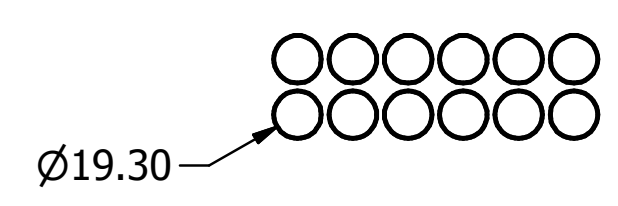

FRONT

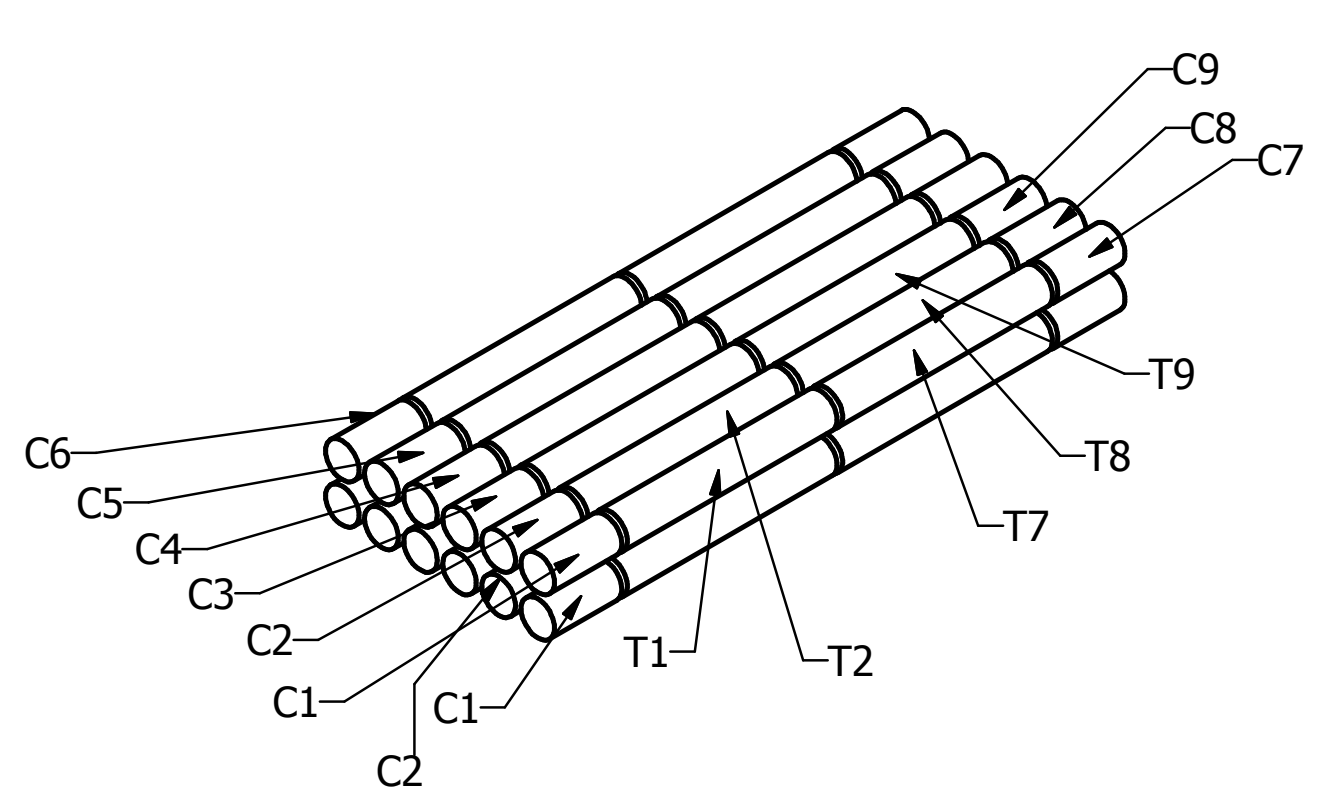

NAMING CONVENTION WRAPS AROUND EACH SUB-SLAB AS SHOWN ABOVE. THE CONVENTION REAPEATS FOR SUBSLAB 1.

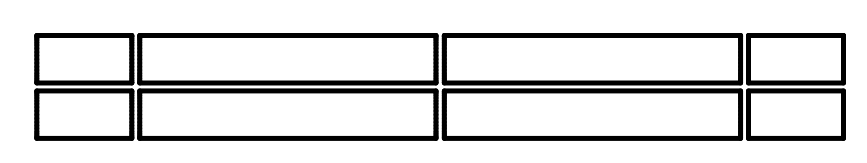

RIGHT

SLAB 6/7 SUB-SLAB DIAGRAM 


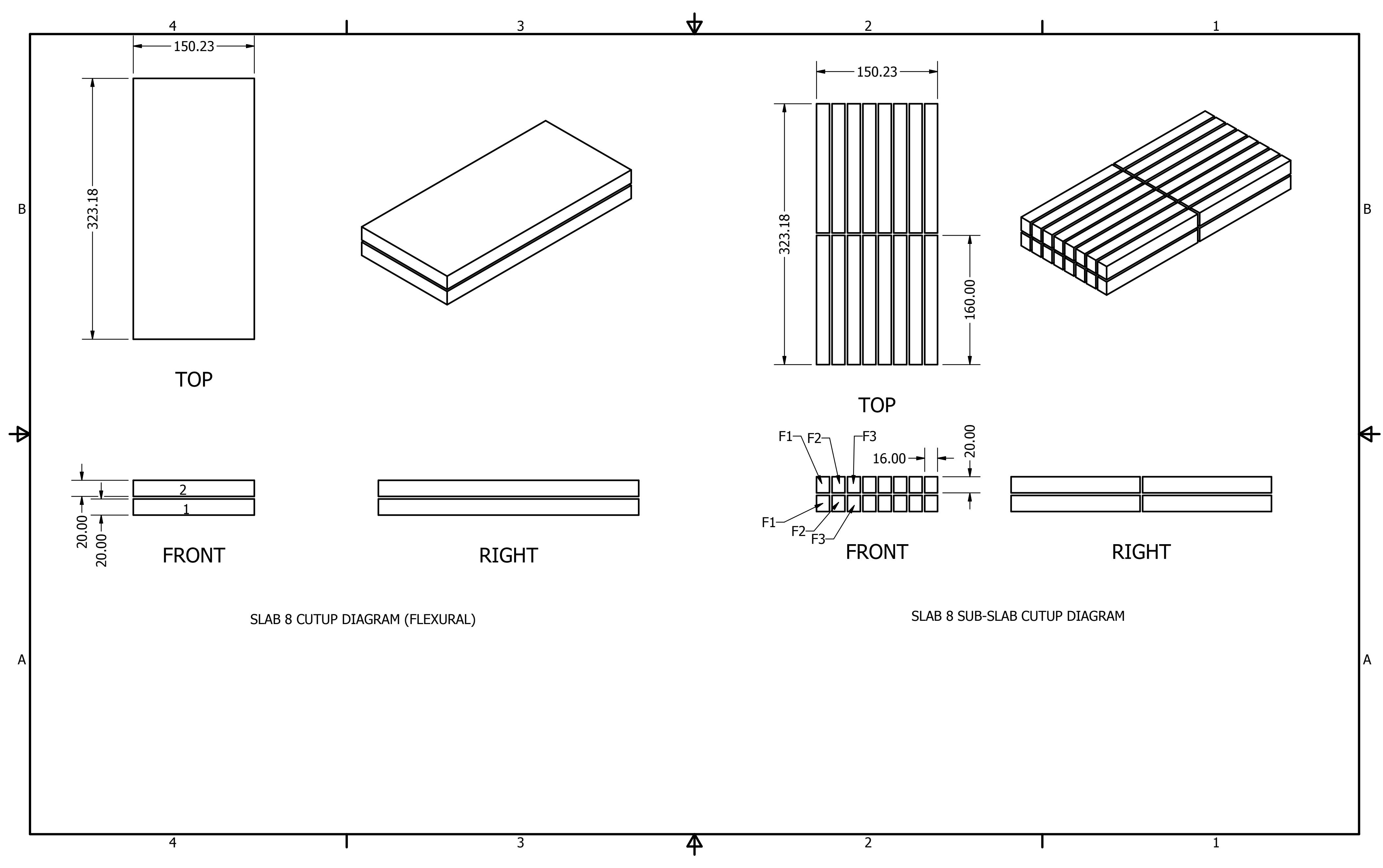




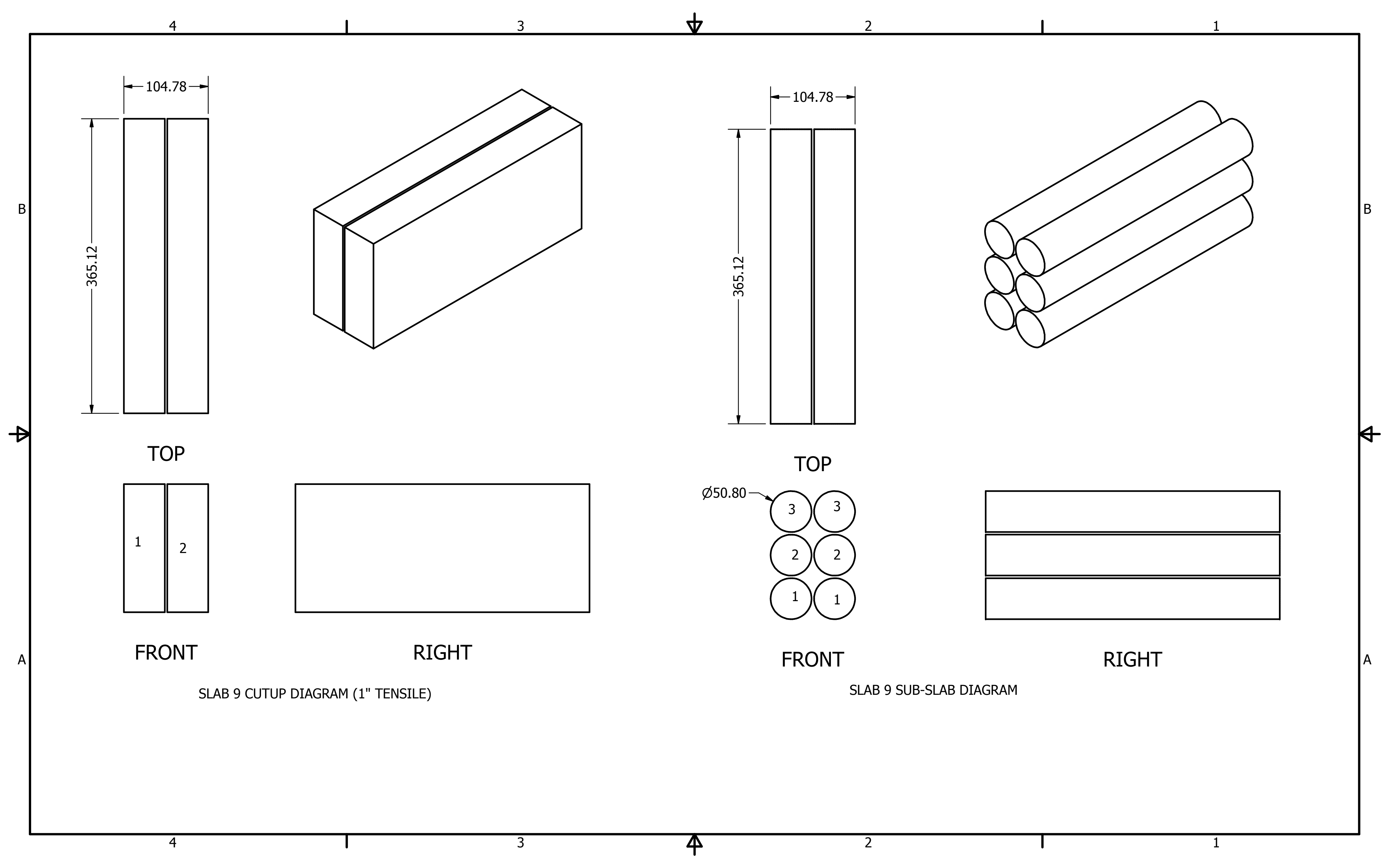




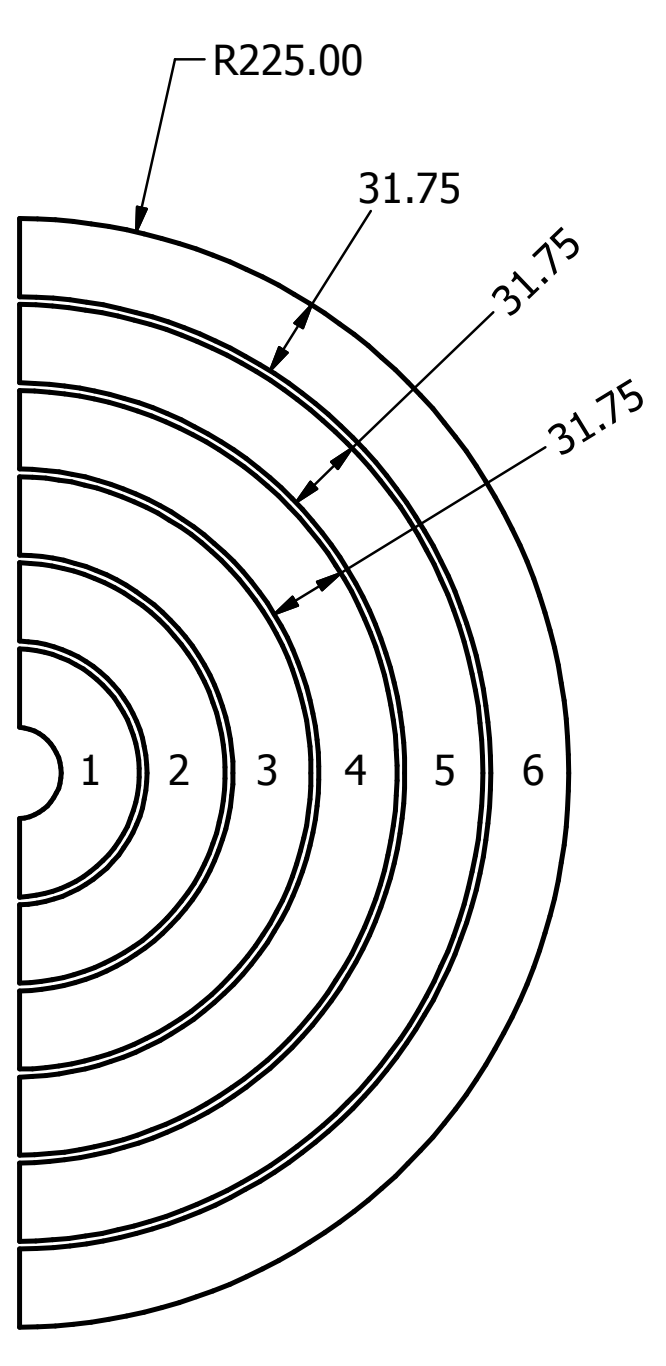

TOP

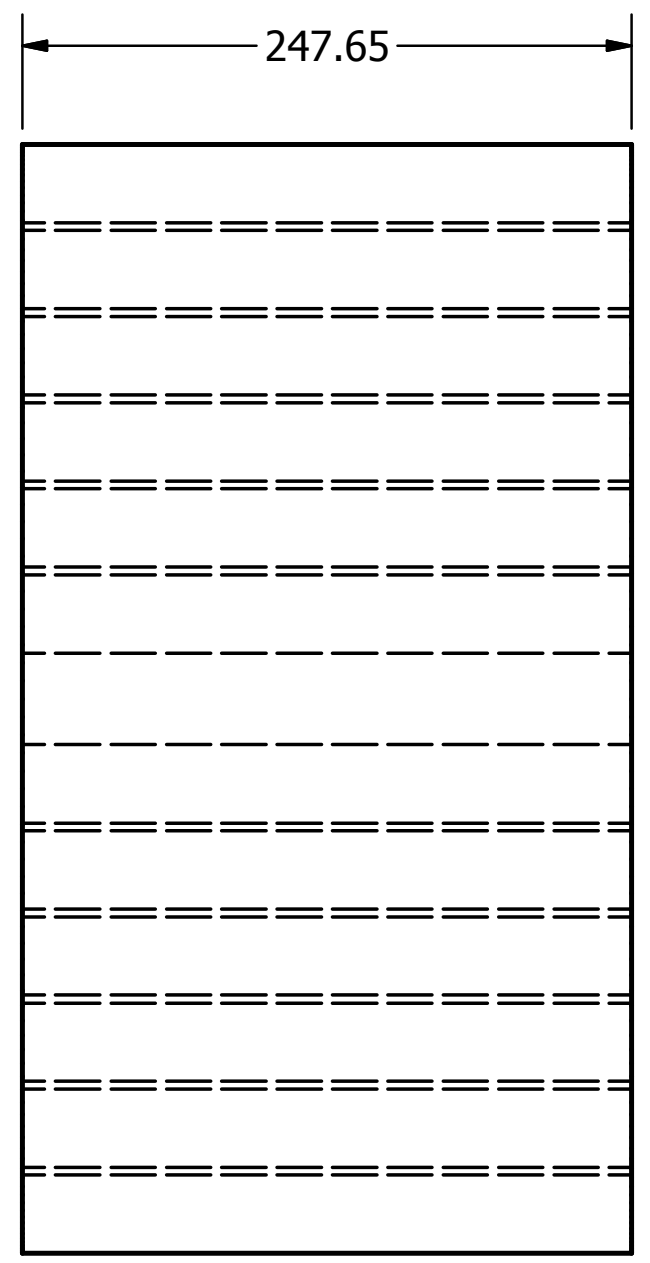

SIDE

SLAB 10 CUTUP DIAGRAM (5/8" TENSILE)

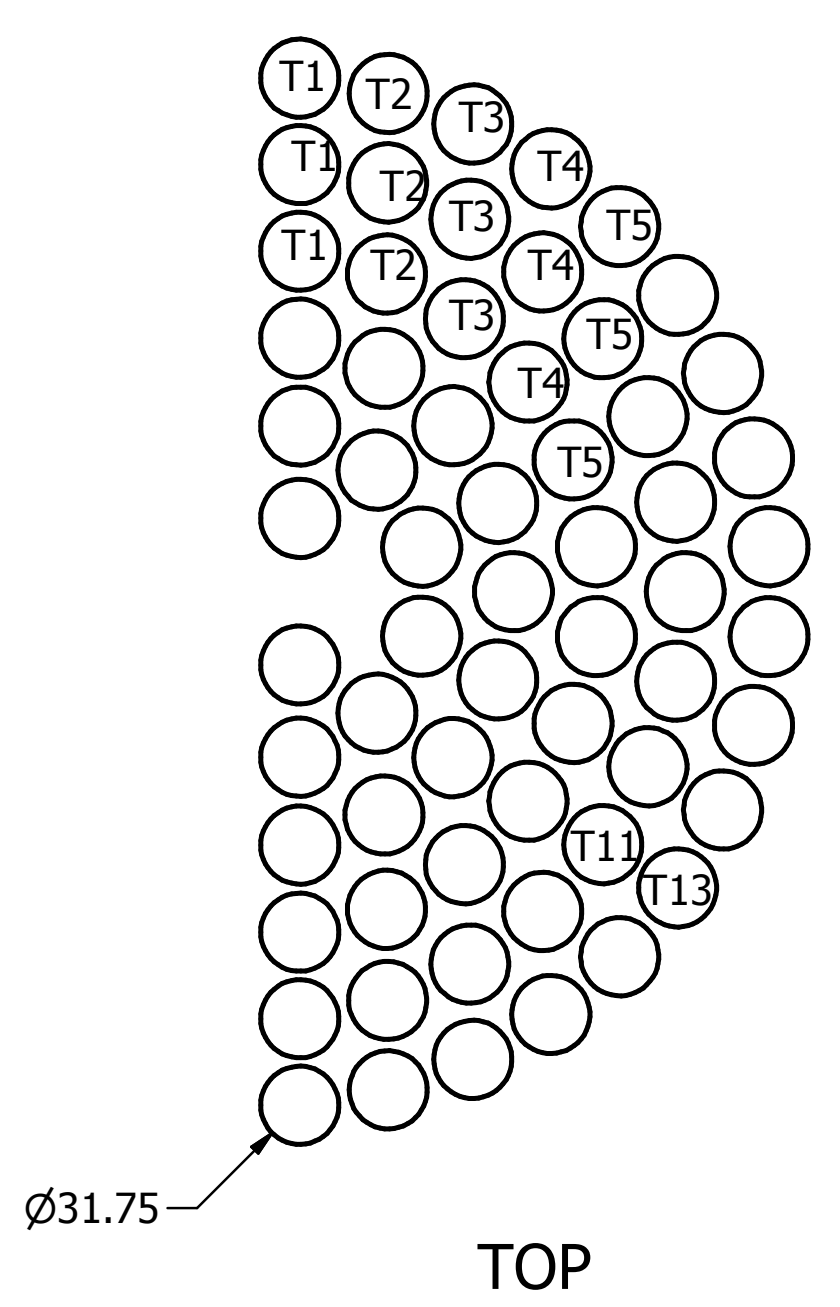

TOP

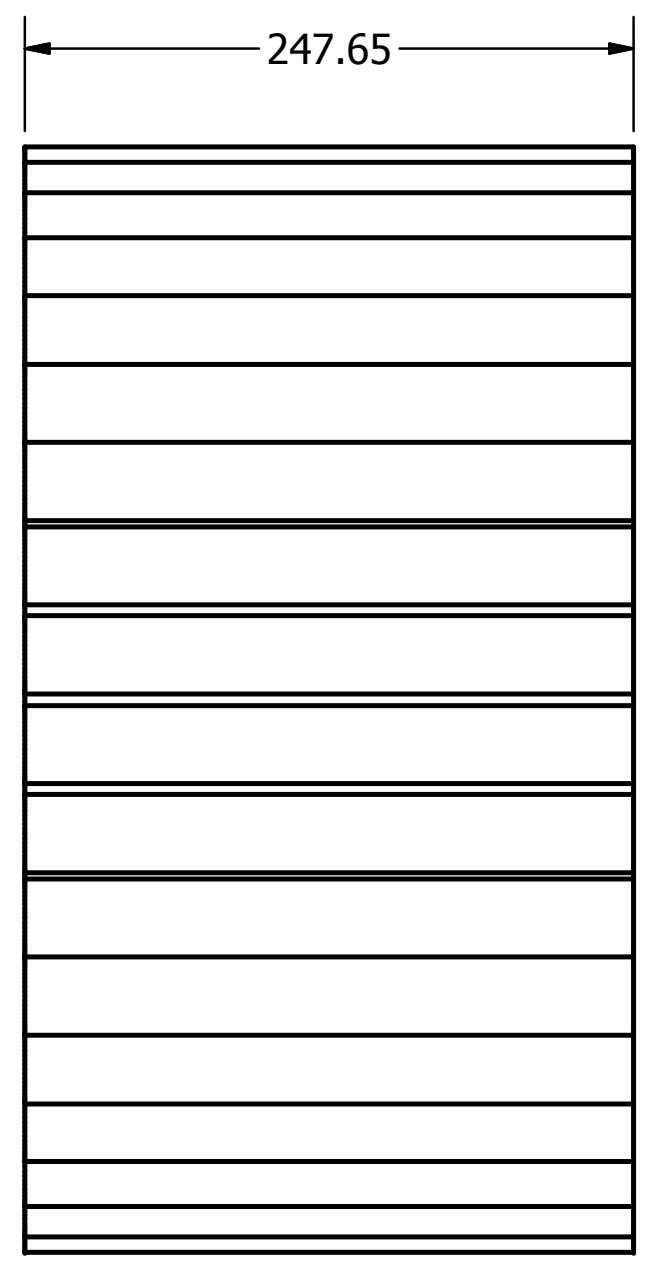

SIDE

SLAB 10 SUB-SLAB CUTUP DIAGRAM 


\section{Appendix 8. IG-43 Billet Cutting Plans}




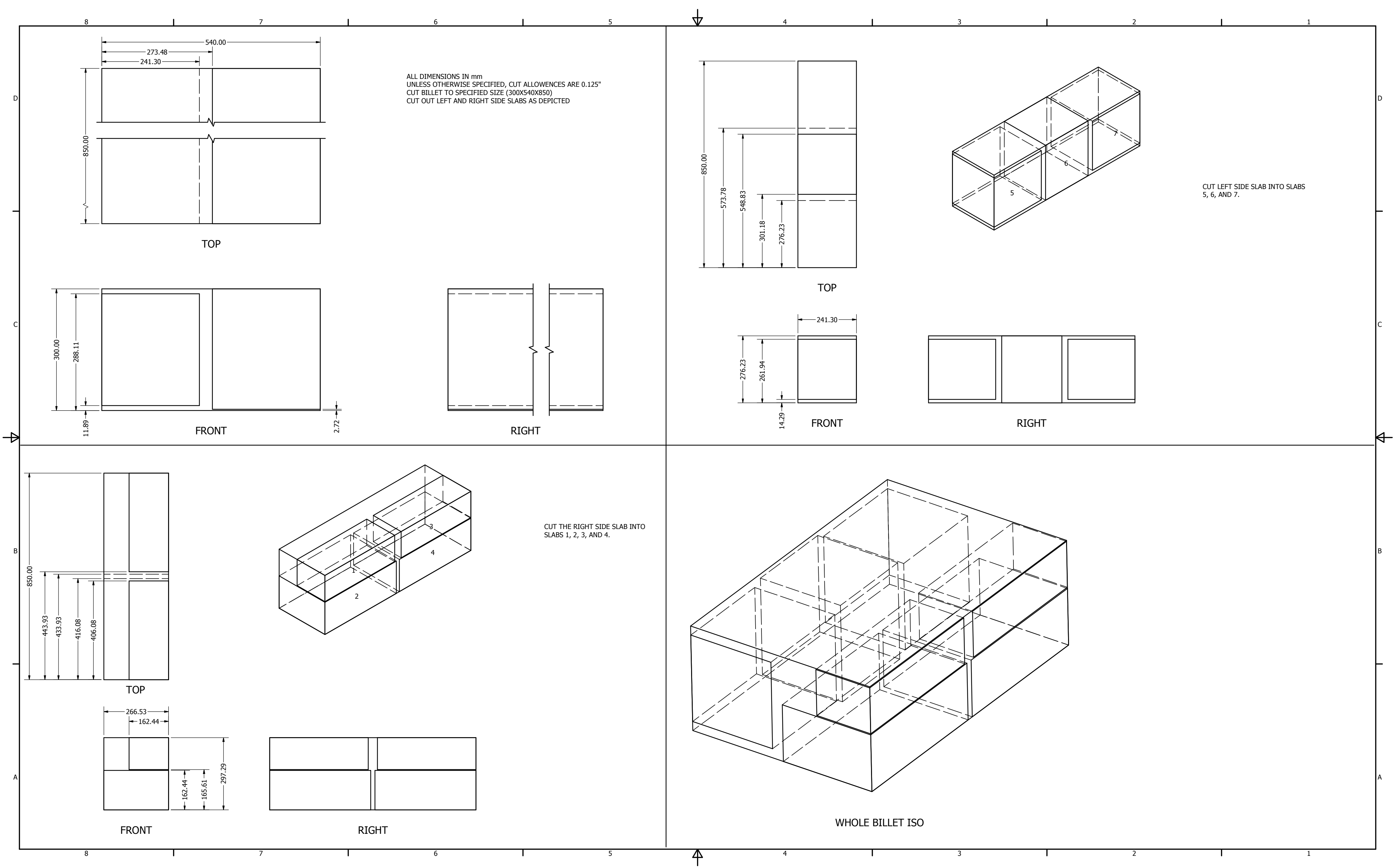




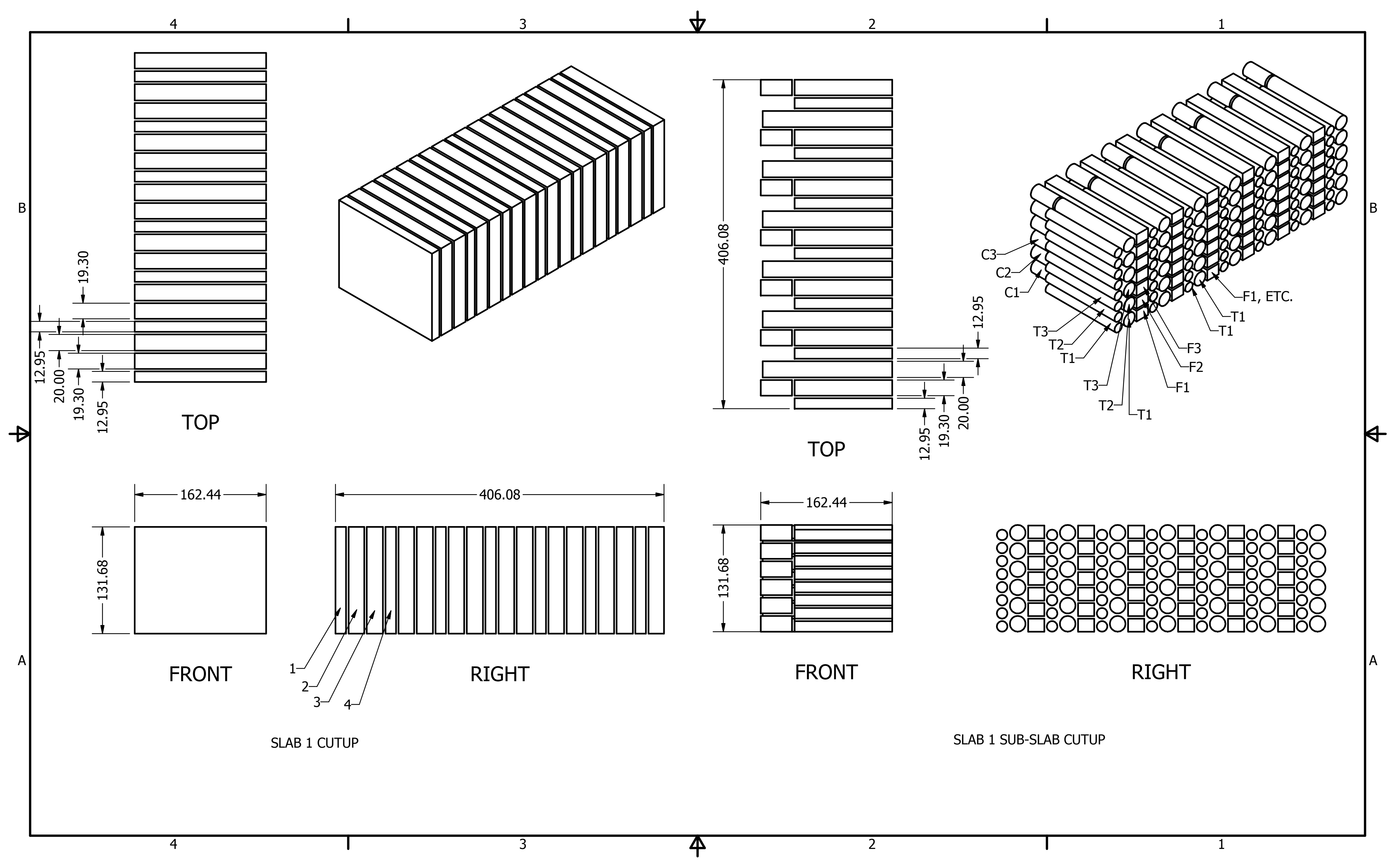




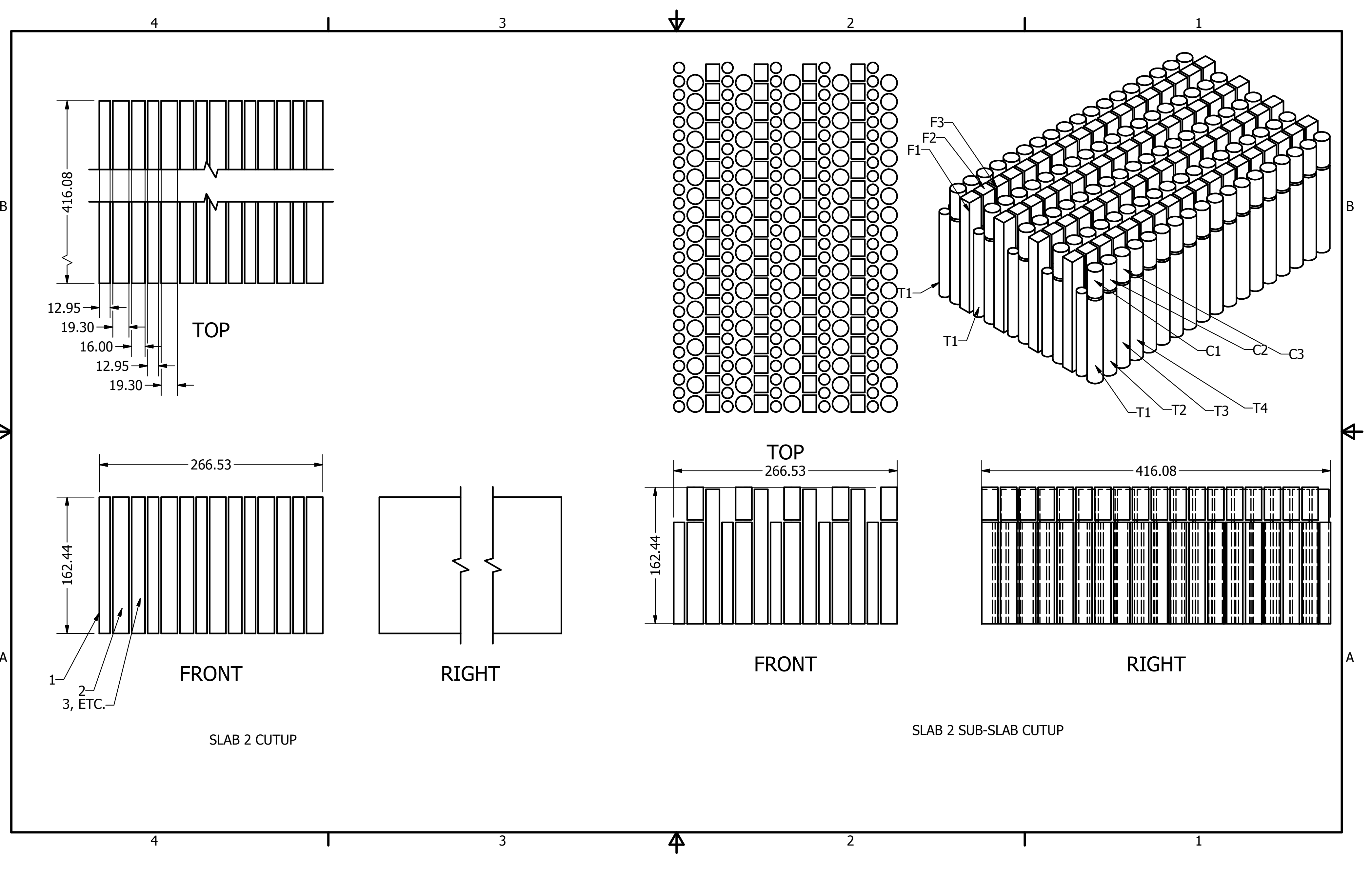




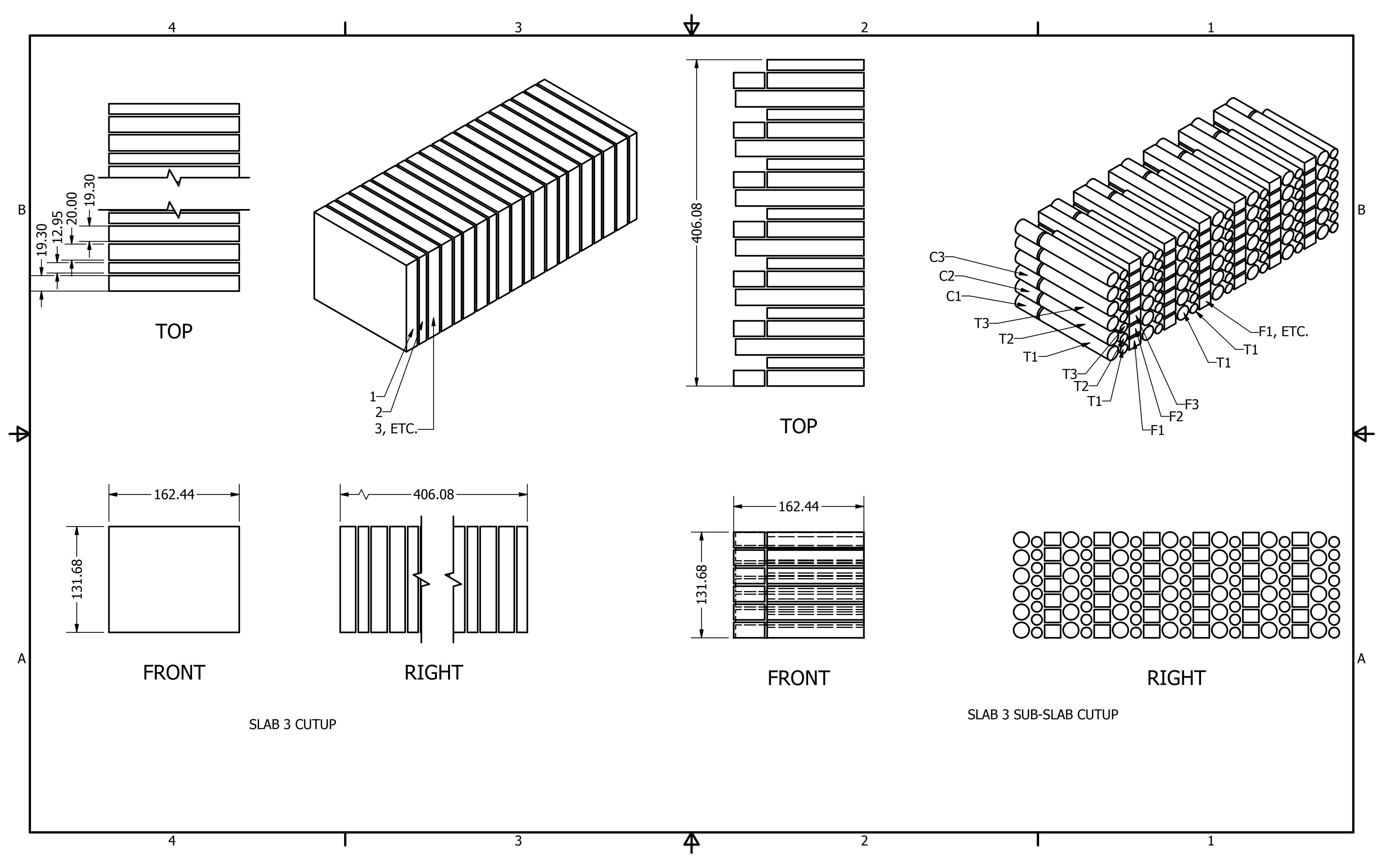




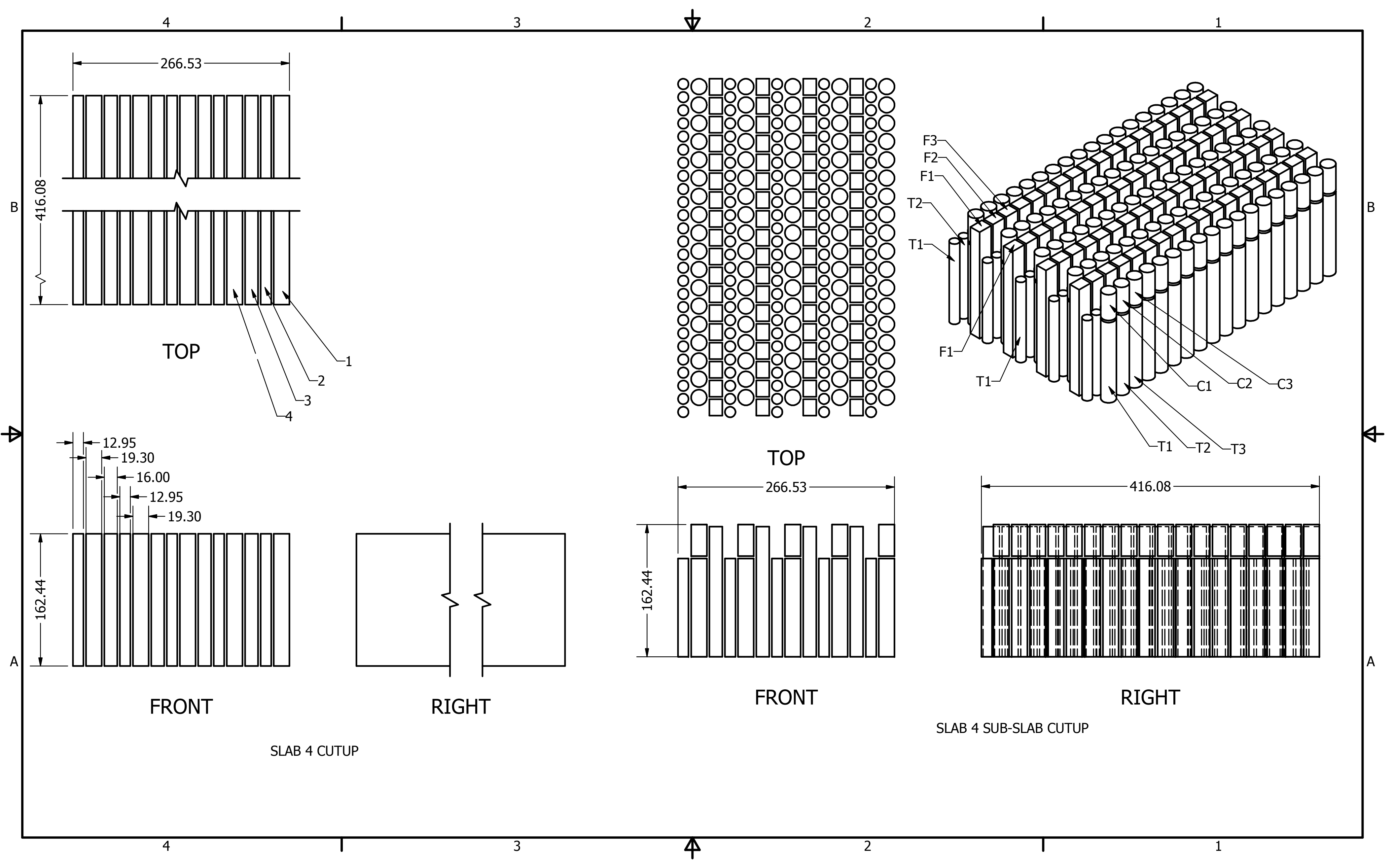




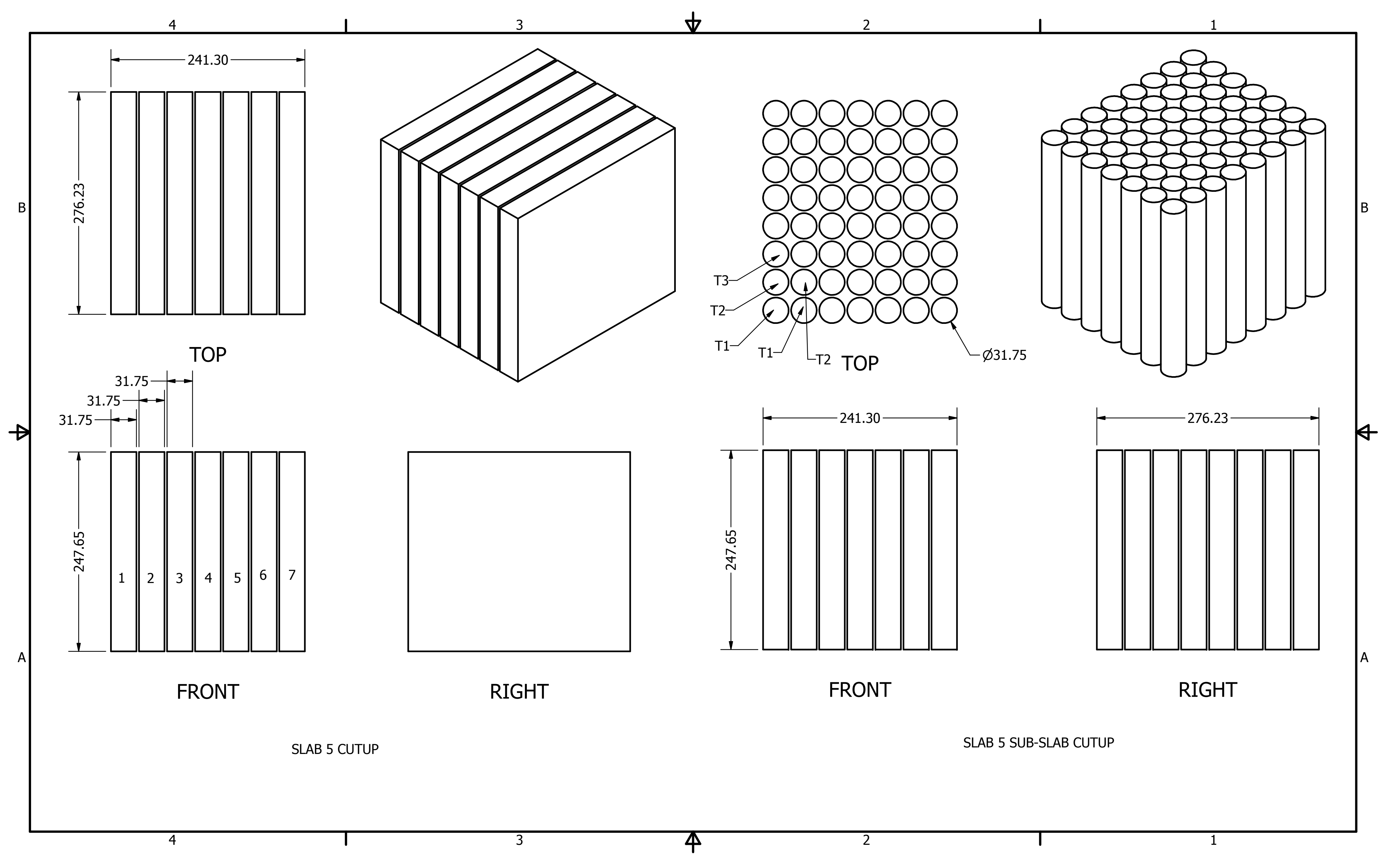




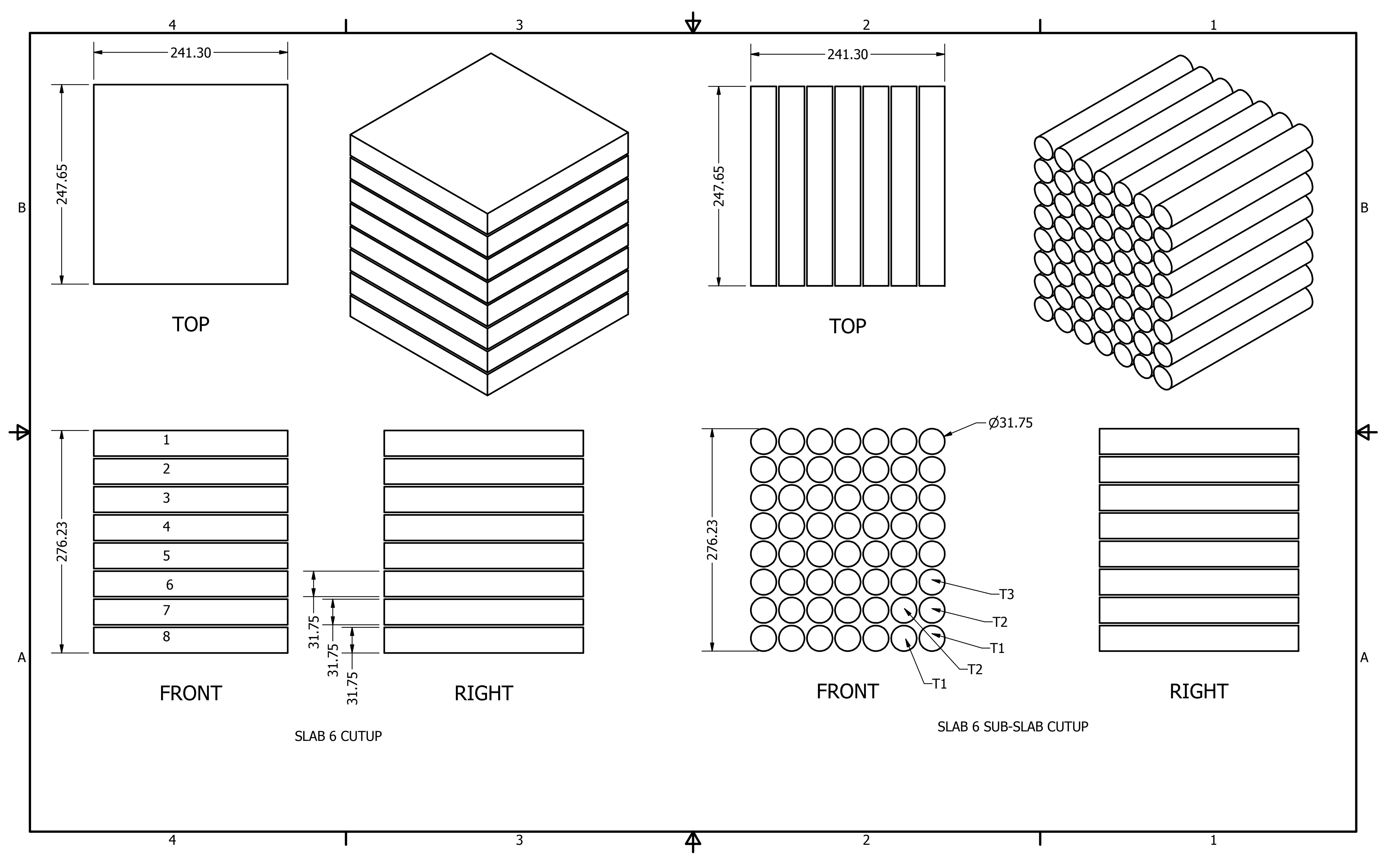




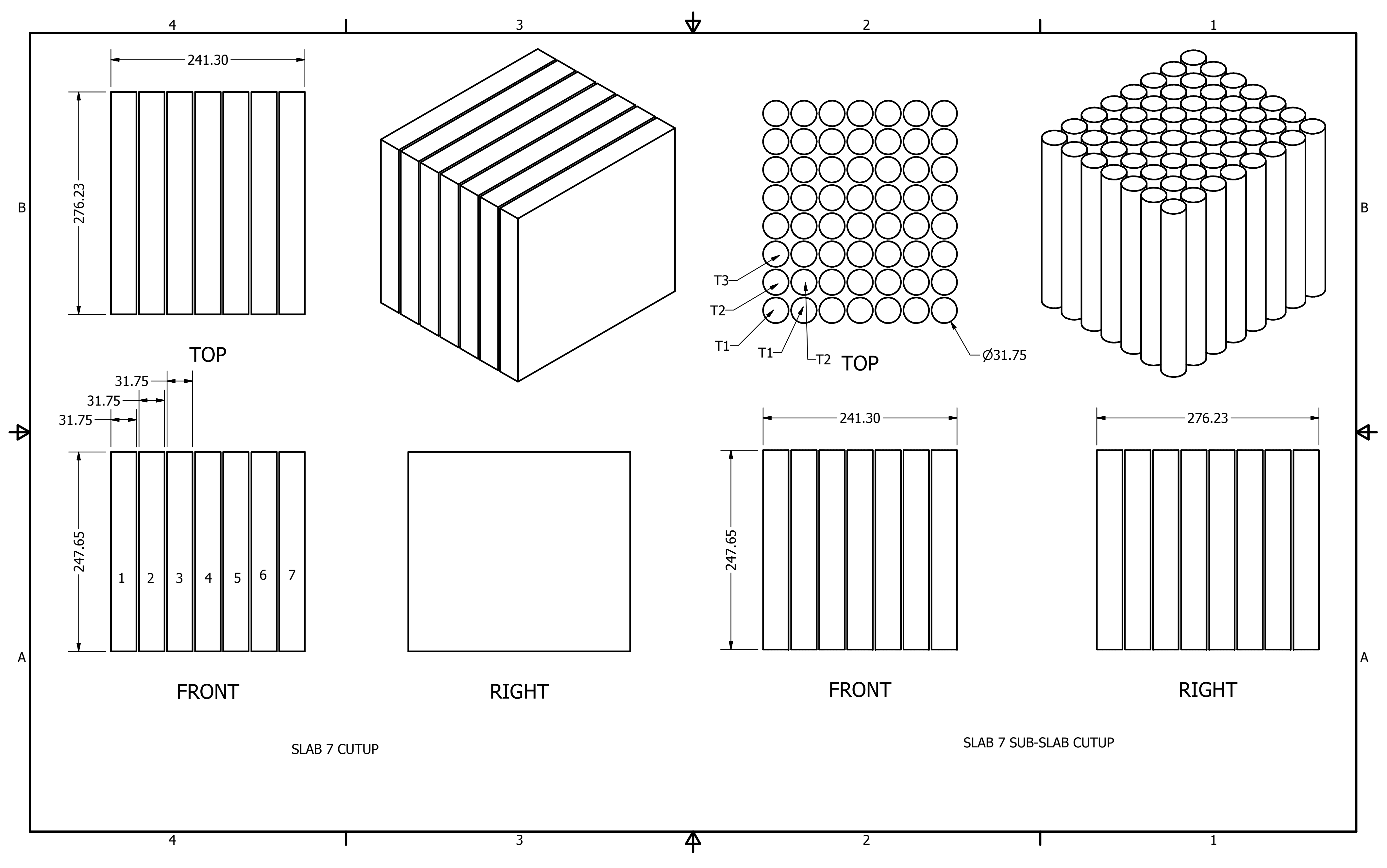




\section{Distribution}

1. T. D. Burchell

2. C. I. Contescu

3. W. R. Corwin

4. S. R. Greene

5. D. T. Ingersoll

6. Y. Katoh

7. J. W. Klett

8. E. Lara-Curzio

9. T. E. McGreevy

10. L. K. Mansur

11. R. K. Nanstad
12. R. A. Raschke

13. W. Ren

14. P. L. Rittenhouse

15. A. F. Rowcliff

16. L. L. Snead

17. R. G. Stoller

18. J. P. Strizak

19. R. W. Swindeman

20. P. F. Tortorelli

21. D. F. Wilson

22. S. J. Zinkle

21. Cathy Barnard, Idaho National Engineering and Environmental Laboratory, P.O. Box 1625, Idaho Falls, Idaho 83415-3750

22. Robert Bratton, Idaho National Engineering and Environmental Laboratory, P.O. Box 1625, Idaho Falls, Idaho 83415-3710

23. Trevor Cook, NE-20/Germantown Building, Office of Advanced Nuclear Research, U.S. Department of Energy, 1000 Independence Avenue, S.W., Washington, DC 20585-1290

24. Susan Lesica, NE-20/Germantown Building, Office of Advanced Nuclear Research, U.S. Department of Energy, 1000 Independence Avenue, S.W., Washington, DC 20585-1290

25. Thomas J. O'Conner, NE-20/Germantown Building, Office of Advanced Nuclear Research, U.S. Department of Energy, 1000 Independence Avenue, S.W., Washington, DC 20585-1290

26. Robert Versluis, NE-20/Germantown Building, Office of Advanced Nuclear Research, U.S. Department of Energy, 1000 Independence Avenue, S.W., Washington, DC 20585-1290

27. Kevan Weaver, Idaho National Engineering and Environmental Laboratory, P.O. Box 1625, Idaho Falls, Idaho 83415-3750

28. William E. Windes, Idaho National Engineering and Environmental Laboratory, P.O. Box 1625, Idaho Falls, Idaho 83415-2218. 